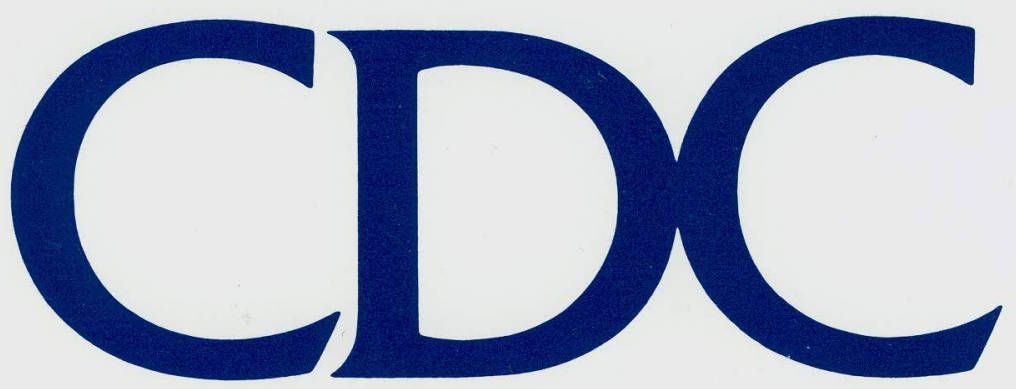

CENTERS FOR DISEASE CONTROL
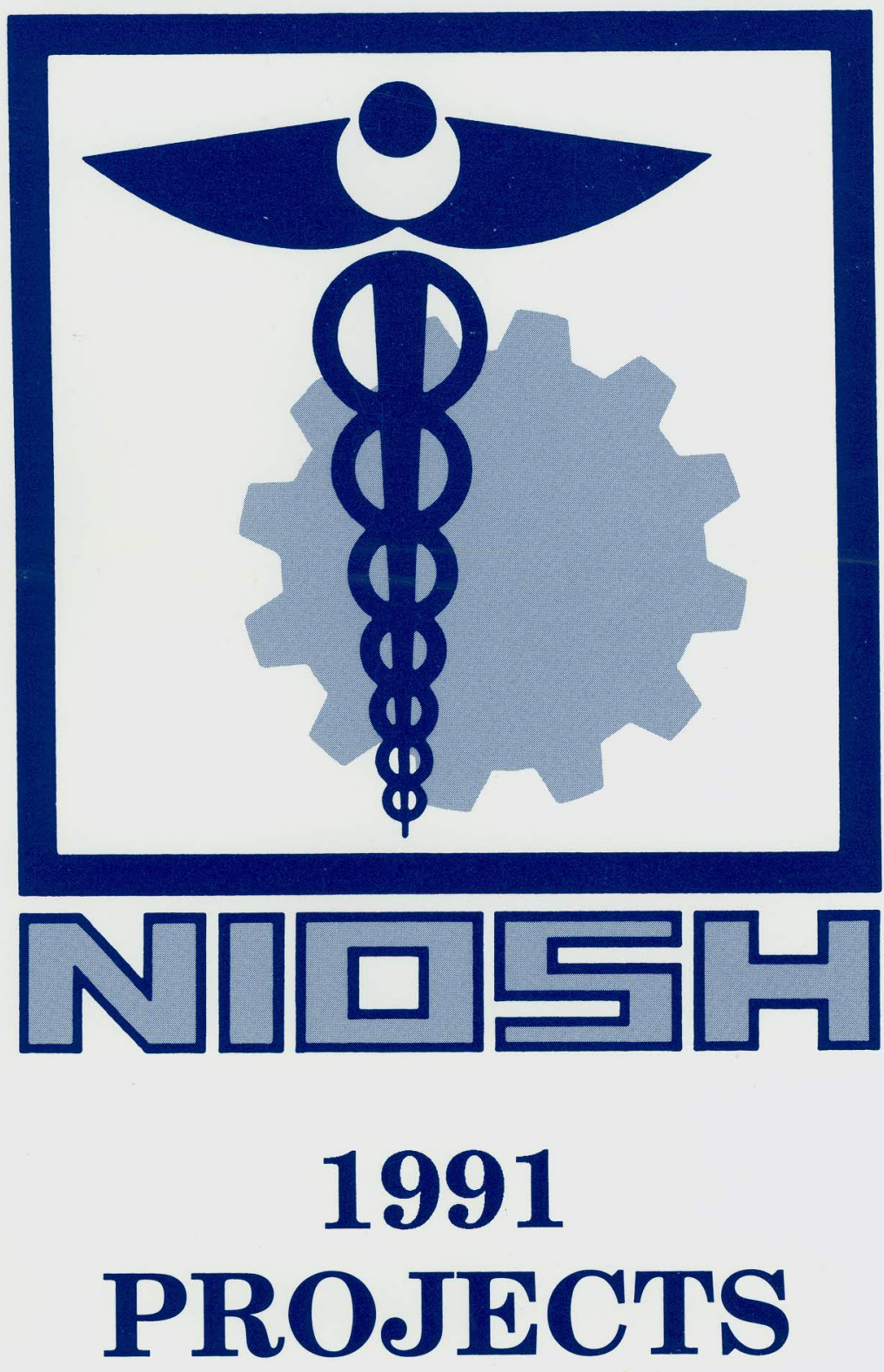

U.S. DEPARTMENT OF HEALTH AND HUMAN SERVICES

Public Health Service

Centers for Disease Control

National Institute for Occupational Safety and Health 


\title{
NATIONAL INSTITUTE FOR OCCUPATIONAL SAFETY AND HEALTH
}

\author{
1991 \\ PROJECTS
}

U.S. DEPARTMENT OF HEALTH AND HUMAN SERVICES Public Health Service Centers for Disease Control

National Institute for Occupational Safety and Health 
DHHS (NIOSH) Publication No. 91-117 


\section{PREFACE}

Happy Birthday, NIOSH. The Institute is 20 years old this year!

As we celebrate the birthday of NIOSH, we celebrate the beginning of a specific life, a life which has had unique meaning for us and for millions of other Americans. That "life," given the name "National Institute for Occupational Safety and Health," was established on April 26, 1971, by the Occupational Safety and Health Act of 1970. Since that time, it is increasingly clear that NIOSH is an essential national resource. We are relevant, and we are needed; also, gratifyingly, in recent years we have become respected and wanted.

Reflecting on the nature of our "life," there are at least six unique attributes of NIOSH:

1. We have a special goal. The opening portions of the Occupational Safety and Health Act of 1970 challenge us "to assure safe and healthful working conditions for every working man and woman in the nation."

2. We have a special role, spelled out in Sections 20, 21, and 22 of the Act. That role includes four functions: (a) conduct research, experiments, and demonstrations related to occupational safety and health; (b) develop and establish recommended occupational safety and health standards; (c) respond to requests for help by evaluating health hazards; and, (d) conduct educational programs to provide an adequate supply of qualified personnel to carry out the purposes of the Act.

3. The Act provides special rights to NIOSH, including the freedom of access to workplaces, and to medical and other records as necessary to perform our investigations. These are precious freedoms which have withstood legal challenge on many occasions.

4. We have a special obligation to be responsive to people who ask for our help, and to adjust to the ever-changing nature of work-related health problems.

5. In the process of exercising our rights and our role, we have acquired a special burden of serving as "the national conscience" for occupational diseases and injuries. This is a most important mission.

Serving as the national conscience is an urgent mission because apathy abounds in our field; there is little sense of outrage regarding occupational diseases, injuries, and traumatic death. Serving as the national conscience is also a stringent mission because such service requires that we have credibility with the Nation. To sustain credibility demands scientific excellence; we can't afford to be wrong. It also requires that we operate with the highest degree of scientific integrity; if ever we veer away from the scientific truth, either to the right or to the left, we risk irreparable damage to our credibility, and loss of our effectiveness.

6. Finally, and most importantly, in NIOSH we have special people, and that includes everybody in the Institute. Everything we do as NIOSH depends on the 850 or so people who are NIOSH. It is our unique group of people who are both the celebrators and the celebrated this year. 
We are proud of the accomplishments we have made during the past twenty years. We are proud of the proposed National Prevention Strategies we developed and are implementing them through the projects described in this document.

By our scientific work we have greatly contributed to the lives and health of workers. However, we can never relax, never rest on what we have accomplished. We must always be equal to the demands on us today. We must have vision--vision of what is changing, vision of what we will be facing, vision of what we must be capable of doing in order to respond effectively. There is much more to be done before we fulfill even the very first words of the Occupational Safety and Health Act, "to assure safe and healthful working conditions for warking men and women...."

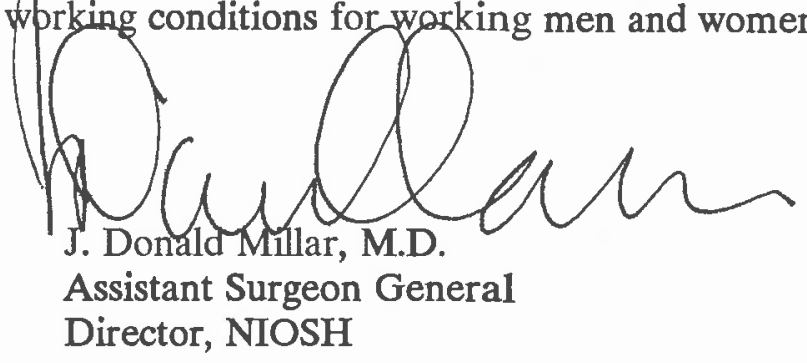




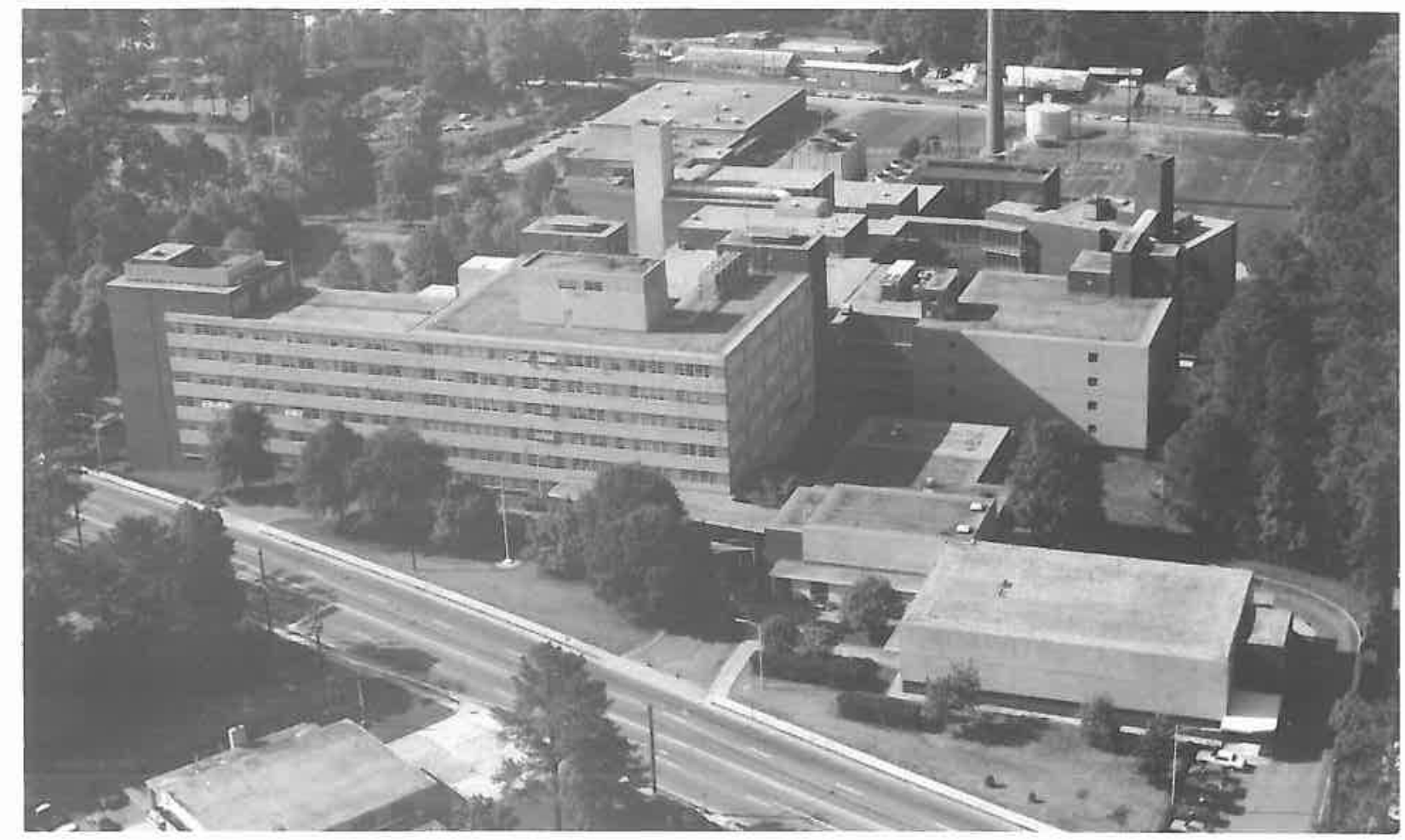

NIOSH Headquarters, Centers for Disease Control

1600 Clifton Road, NE, Atlanta, Georgia 30333

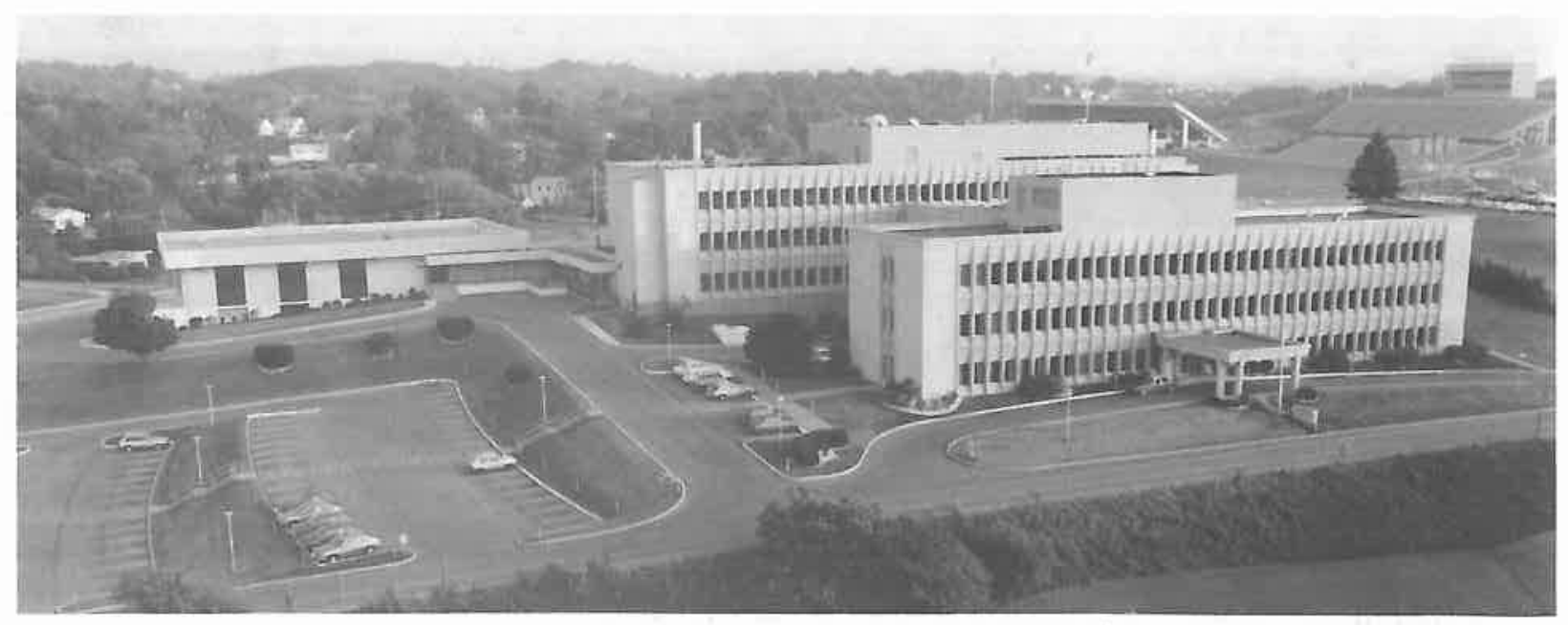

Appalachian Laboratory for Occupational Safety and Health

944 Chestnut Ridge Road, Morgantown, West Virginia 26505 


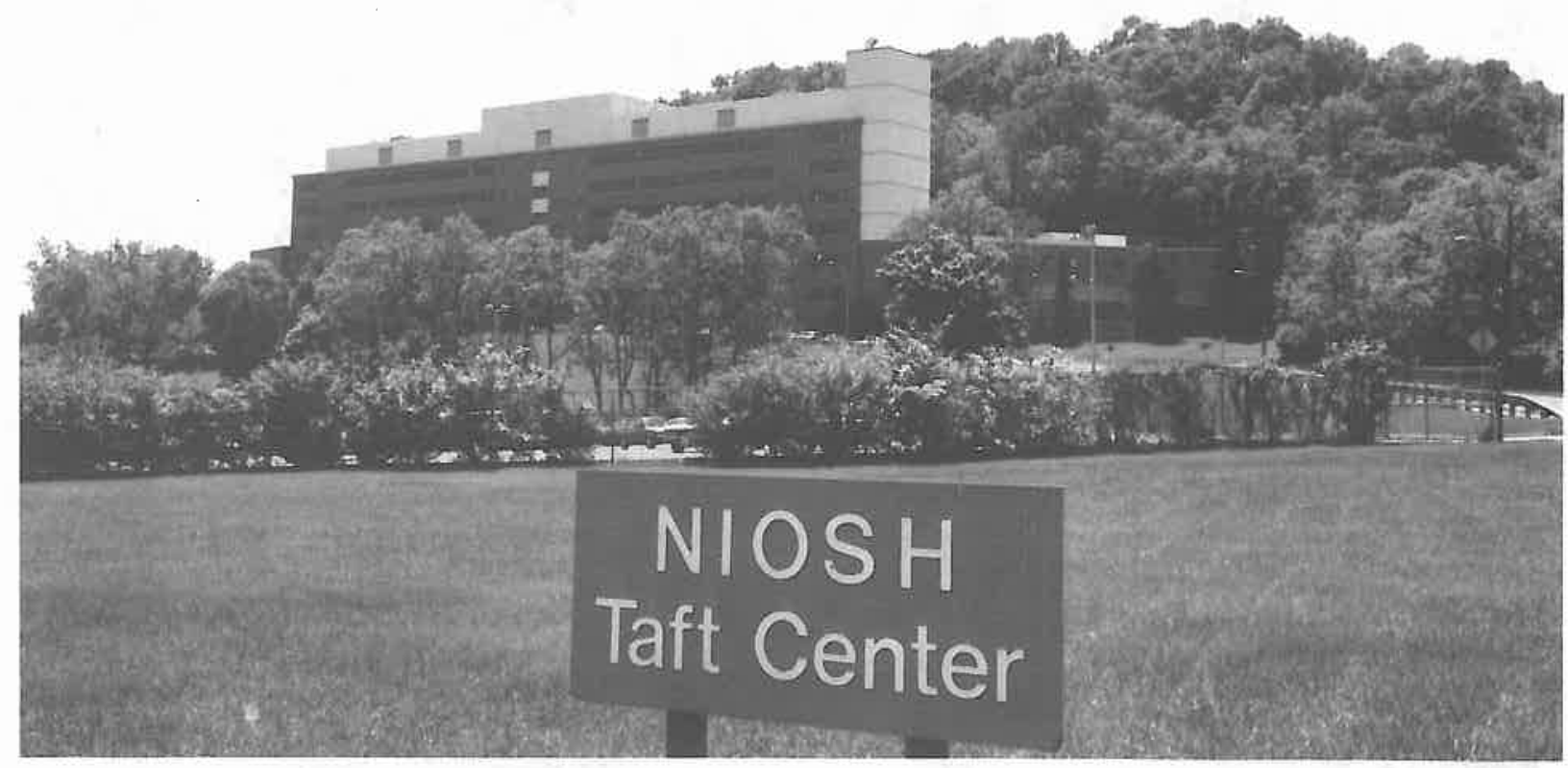

Robert A. Taft Laboratory, 4676 Columbia Parkway, Cincinnati, Ohio 45226

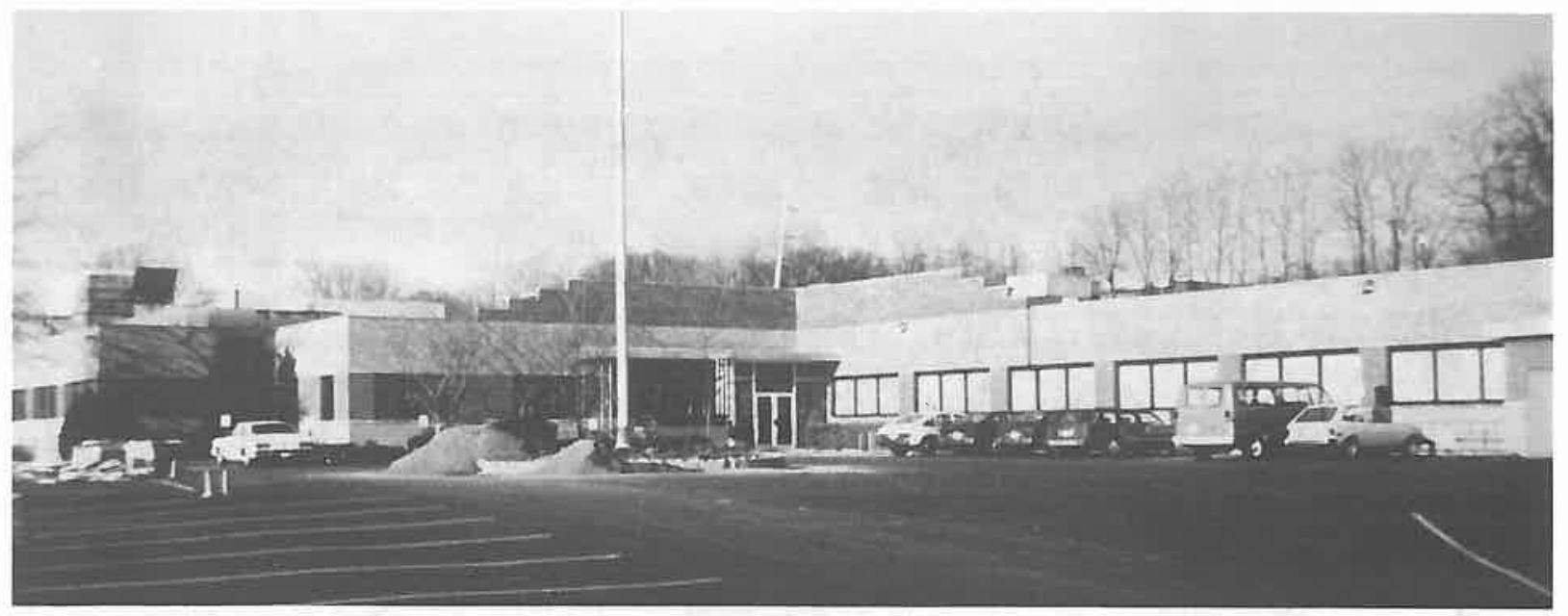

Alice Hamilton Laboratory, 5555 Ridge Avenue, Cincinnati, Ohio 45213 


\section{TABLE OF CONTENTS}

$\underline{\text { PAGE }}$

Preface

iii

NIOSH Facilities - Atlanta, Morgantown v

NIOSH Facilities - Cincinnati vi

$\begin{array}{ll}\text { Introduction } & 1\end{array}$

NIOSH Planning Format $\quad 3$

NIOSH Organization Chart $\quad 4$

NIOSH Divisions' Mission Statements

Summaries of NIOSH Strategies

$\begin{array}{ll}\text { Introduction } & 13\end{array}$

$\begin{array}{ll}\text { Occupational Lung Diseases } & 15\end{array}$

$\begin{array}{ll}\text { Musculoskeletal Injuries } & 18\end{array}$

$\begin{array}{ll}\text { Occupational Cancers } & 22\end{array}$

Severe Occupational Traumatic Injuries 25

$\begin{array}{ll}\text { Occupational Cardiovascular Diseases } & 30\end{array}$

Disorders of Reproduction 33

Neurotoxic Disorders $\quad 38$

Noise-Induced Hearing Loss $\quad 42$

Dermatological Conditions $\quad 45$

$\begin{array}{ll}\text { Psychological Disorders } & 48\end{array}$ 
NIOSH Projects by Program Areas

Occupational Lung Diseases $\quad 54$

$\begin{array}{ll}\text { Musculoskeletal Injuries } & 76\end{array}$

$\begin{array}{ll}\text { Occupational Cancers } & 80\end{array}$

Severe Occupational Traumatic Injuries $\quad 92$

$\begin{array}{lr}\text { Occupational Cardiovascular Diseases } & 98\end{array}$

Disorders of Reproduction $\quad 99$

$\begin{array}{ll}\text { Neurotoxic Disorders } & 101\end{array}$

$\begin{array}{ll}\text { Noise-Induced Hearing Loss } & 104\end{array}$

$\begin{array}{ll}\text { Dermatological Conditions } & 106\end{array}$

$\begin{array}{ll}\text { Psychological Disorders } & 107\end{array}$

$\begin{array}{ll}\text { Agriculture-Related Projects } & 109\end{array}$

$\begin{array}{ll}\text { Construction-Related Projects } & 117\end{array}$

$\begin{array}{ll}\text { Assistance Requests } & 124\end{array}$

$\begin{array}{ll}\text { Administration } & 127\end{array}$

$\begin{array}{ll}\text { Other } & 130\end{array}$

NIOSH Projects by Division

$\begin{array}{ll}\text { Division of Biomedical and Behavioral Science } & 137\end{array}$

Division of Physical Sciences and Engineering 142

Division of Respiratory Disease Studies $\quad 147$

Division of Surveillance, Hazard Evaluations, and Field Studies

153

Division of Safety Research $\quad 161$ 
$\underline{\text { PAGE }}$

Division of Standards Development and Technology Transfer

Division of Training and Manpower Development

170

Office of the Director

172 



\section{INTRODUCTION}

NIOSH management is presently faced with both a challenge and a unique opportunity through the need to revitalize its current planning system. That planning system includes both the computerized system, by which data are entered, stored, retrieved, and communicated, and of at least equal importance, the system by which a priority-ordered determination of the Institute's work is made. The present mainframe-based computer system has served the Institute well for a number of years, providing an opportunity for the uniform display of often disparate programs. This system has allowed divisions located apart from each other, and from the operational headquarters of the Institute, to enter research and service project data in a standardized format, to have immediate access to these data, to periodically edit project information as needed, and provide progress reviews on accomplishments.

In the last ten years, however, both hardware and software technologies have progressed to allow more optimum utilization of the project system. With modifications in the planning system, greater savings in time, and improvement in accuracy and availability of data, can be made. To that end, the Office of Program Planning and Evaluation, together with the Management Systems Branch, enlisted the services of a contractor to study the current and potential needs of the Institute. The contractor provided expert support to managers' opinions, gained through experience, as follows: whatever type of computerized system is ultimately decided upon, significant changes need to be made in order to appropriately manage current and potential requirements. The Office of Program Planning and Evaluation is leading an effort to determine from all divisions, offices, and other relevant groups within the Institute all of their planning needs. Those needs will serve as the basis for addressing the computerized element of the planning system.

The need for attention to the system for planning, apart from its hardware and software components, is acute. The influences which impact upon the decision to actually perform work on certain projects must be the result of consideration of a multitude of influences. Those influences can occur as a result of planned or unplanned events throughout the year. For example, the federal budget cycle, with its vagaries, constitutes a problematic concern in the targeting of each year's set of projects. Project decisions are scheduled to be made shortly before the change in fiscal years; however, it may be several months beyond that point when the actual budget is determined. Additionally, with that budget may come requirements not previously anticipated which will necessitate work in certain areas. Programmatically, Institute management has encouraged input to its planning system from a variety of sources. Planning once conducted exclusively by division-level management, is now influenced by the creation of a number of working groups such as the Indoor Air Quality Working Group and the Musculoskeletal Injuries Working Group. These groups have responsibility for developing Institute-level planning for which the divisions develop responsive projects. Furthermore, the Institute's management has stimulated an active role in its advisory committees of the Mine Health Research Advisory Committee (MHRAC), and the Board of Scientific Counselors (BSC), to provide active input through review and recommendation to the planning system. Unquestionably, these processes provide the Institute with the highest quality of extant scientific opinion to influence project planning. The challenge is to provide a mechanism and a cycle for the inclusion of this guidance. 
Outside of the Institute's own stimulus, planning influences continue to grow, each of which must be attended to officially and as part of the scheduled event. The document, Healthy People 2000 Objectives, devotes an entire chapter to occupational safety and health. The Institute is recognized as the leader in achievement of those objectives through the stimulation of action by other agencies and through management of our own programs. Furthermore, the Public Health Service has adopted "A Plan To Strengthen Public Health In The United States," which is a comprehensive effort to strengthen the Public Health Service in this nation. NIOSH has an important role in that strengthening, and has important objectives in each of the sections.

While less specific, the Institute must also include in its planning processes attendance to the objectives of other entities with which we share common objectives. There is a plan for the Office of Minority Health and the Office of International Health to which we are committed. There is a shared planning responsibility between our program and that of the Association of Schools of Public Health and teachers of preventive medicine. The CDC grants program and the planning of our own extramural programs have vital importance to ourselves and our constituents.

Finally, there is a need to plan for the unforeseen. New agendas and emergencies arise with growing frequency. In any planning system, there must be, apart from its need for standardization, flexibility to the extent that it allows modification as needs change. It is with these issues in mind that we approach the coming year with full realization that there will be appreciable work needed before a system can be identified and implemented. It is also with anticipation that we look toward creation of a system that will help us respond to the absolute need for a planned program. 


\section{NIOSH PLANNING FORMAT \\ FY 1991}

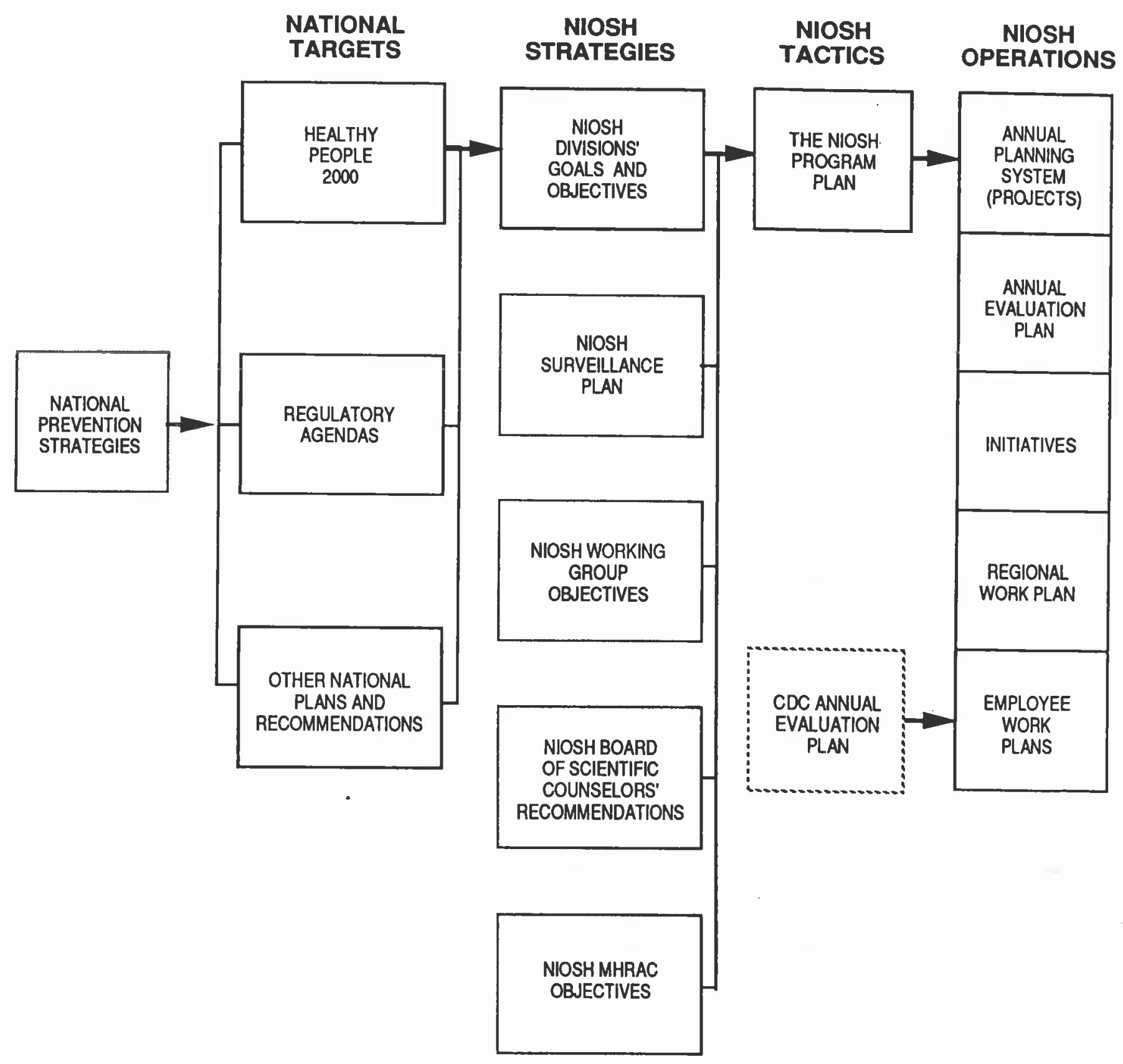


THE NATIONAL INSTITUTE FOR OCCUPATIONAL SAFETY AND HEALTH

1600 clifton Road

Atlanta, GA 30333
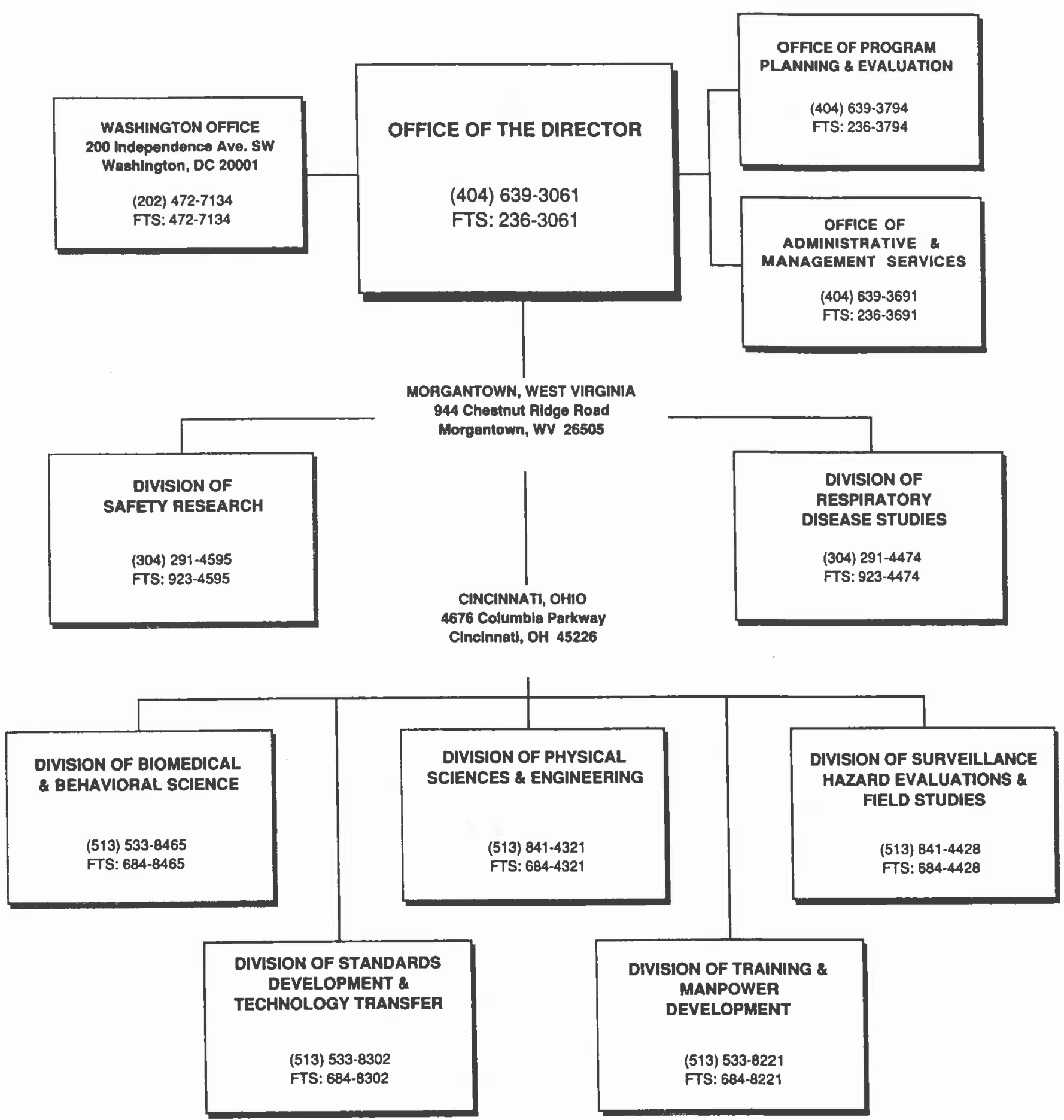

JULY 1991 


\section{DIVISION OF BIOMEDICAL AND BEHAVIORAL SCIENCE}

The Division of Biomedical and Behavioral Science (DBBS) plans and conducts laboratory research and work site studies in the disciplines of toxicology, behavioral science, ergonomics, and physical agents to determine safety and health consequences of occupational exposures. DBBS investigates health and safety problems resulting from new industrial technologies, and develops biological monitoring and diagnostic procedures to improve the health, safety performance, functional capacity, and life expectancy of workers. Consultation and research data necessary to develop criteria for workplace exposure standards are furnished as part of these activities.

DBBS investigates the psychological (e.g., stress), neurobehavioral, biomechanical, and physiological effects of hazardous working conditions, resulting from exposure to chemical and physical agents as well as psychological and biomechanical stressors, found in the work environment. The division research assesses physical and biomechanical work capacity, neurobehavioral status, and psychological tolerance to stressful occupational conditions, as influenced by demographic, experiential, health, and environmental factors. Interventions and control procedures are developed and evaluated for their efficacy in addressing job stress and strain, safety performance, and health outcomes (e.g., musculoskeletal disorders).

DBBS conducts research on the effects of exposure to physical agents such as noise and nonionizing radiation in the workplace. Studies seek to delineate mechanisms of injury and exposure factors that are of consequence to the health and well-being of the work force. Investigations, including instrumentation and methods development, for characterizing and relating exposure factors to biological and performance changes in animal and human populations are undertaken.

The DBBS toxicology research addresses issues of occupational concern such as dose-response relationships, mechanisms of toxicity, and development of methods to evaluate the effects of exposure to toxic agents, psychological, and biomechanical stressors. Approaches include applications of cellular biology, biochemistry, immunochemistry and pharmacokinetics. In vivo experimental animal and in vitro human and animal tissue culture systems are utilized to answer fundamental toxicology questions which relate to dose-response effects and mechanisms of toxic agent actions. The ultimate product of such studies is the development of biomarkers which can be utilized in workplace studies to indicate extent of exposure to occupational hazards effects of such exposure and as early indicators of the potential for developing the disease/toxicity associated with exposure.

DBBS is located at the Robert A. Taft Laboratory, 4676 Columbia Parkway, Cincinnati, Ohio 45226. The Division Director is Janet C. Haartz, Ph.D., telephone (513) 533-8465, FTS 684-8465. 


\section{DIVISION OF PHYSICAL SCIENCES AND ENGINEERING}

The Division of Physical Sciences and Engineering (DPSE) conducts work site and laboratory research to develop procedures and equipment for the control and measurement of occupational safety and health hazards. DPSE also provides assistance to the industrial hygiene community in operating a quality control reference program for industrial hygiene laboratories.

DPSE conducts a control technology assessment and research program to prevent occupational disease and injury before they occur by assisting employers, including smaller businesses, in better design and operation of the workplace. This work involves identification and evaluation of effective engineering controls and work practices used in a variety of processes and industries. The division promotes the transfer and widespread application of these preventive engineering control measures. It also provides engineering expertise in formulating effective workplace standards.

DPSE conducts research to establish performance requirements for direct reading, area, and personal instrumentation used in the evaluation and prevention of exposures to hazardous levels of chemical and physical agents. The division also provides consultation for the development of criteria and standards on monitoring strategies, instrumentation, and controls.

DPSE conducts research to develop and improve methods for analysis of toxic substances found in the workplace. Also, DPSE provides analytical chemistry support to the Institute's laboratory research and field investigation programs, including routine measurement of samples by established methods, special measurement of complex samples, and short-term development of methods. This analytical research and support involves the use of state-of-the-art analytical instrumentation such as high resolution gas chromatography, gas chromatography-mass spectrometry, high performance liquid and ion chromatography, and Fourier Transform Infrared Spectroscopy (FTIR). In addition, DPSE provides consultation in analytical chemistry to all elements of NIOSH, and to other government agencies, recommending appropriate sampling and analytical methods.

Quality of the nation's workplace environment analytical data is assessed through the Proficiency Analytical Testing (PAT) Program. DPSE (working with the American Industrial Hygiene Association) determines the analytical competence of participating laboratories, and assists the laboratories in improving analytical performance. The division also encourages and supports development and promulgation of national guidelines for accreditation of industrial hygiene laboratory facilities; selects and develops standard reference materials for use in the measurement of industrial hygiene hazards, and provides for quality assurance in the analysis of the Institute's laboratory and field programs and contract laboratories.

DPSE is located at the Alice Hamilton Laboratory, 5555 Ridge Avenue, Cincinnati, Ohio 45213. The Division Director is Philip J. Bierbaum, telephone (513) 841-4321, FTS 684-4321. 


\section{DIVISION OF RESPIRATORY DISEASE STUDIES}

The Division of Respiratory Disease Studies (DRDS) is the focal point for clinical, epidemiological, environmental, and laboratory research, as well as service programs related to prevention of occupational respiratory diseases.

To identify and quantify the effects of occupational exposures, elucidate differential host susceptibilities, and develop methods for the early detection and prevention of occupational respiratory diseases, DRDS conducts basic and applied research in the areas of biochemistry, physiology, immunology, pathology, microbiology, pharmacology, industrial hygiene, and aerosol physics. Surveillance is conducted to determine trends in prevalence and to evaluate progress in prevention of occupational lung diseases. Clinical studies of workers are performed to evaluate respiratory effects of occupational environments, to clarify the mechanisms of human responses, and to develop and refine techniques for occupational respiratory disease investigations. Occupational exposures to hazardous substances are quantified through comprehensive industrial hygiene investigations. Epidemiological studies of worker populations are conducted to assess risk of disease associated with a variety of exposures at mines, mills, and other industrial, construction, and agricultural workplaces where occupational respiratory diseases occur. Industrial hygiene, medical, laboratory, and epidemiological techniques are also employed by industrial hygienists, physicians, nurses, medical technicians, and epidemiologists who, through the division's Respiratory Disease Hazard Evaluation Program, evaluate reported problems occurring at specific work sites.

DRDS administers the National Coal Workers' X-ray Surveillance Program and the National Coal Workers' Autopsy Study under the provisions of the Federal Mine Safety and Health Act of 1969, as amended in 1977. Mandated programmatic activities include X-ray Facility Certification, Mine Plan Approvals, B Reader Examinations, and the coordination of the processing, storage, and retrieval of files and records related to medical examinations.

Training and experience in epidemiological, clinical, and laboratory-based research related to occupational respiratory diseases is provided through DRDS-sponsored positions in the Centers for Disease Control Epidemic Intelligence Service, the NIOSH Pulmonary Medicine Fellowship Program, and the National Research Council's Resident Research Associateships program, as well as through DRDS elective experiences for occupational medicine residents and West Virginia University graduate students.

DRDS is located at 944 Chestnut Ridge Road, Morgantown, West Virginia 26505-2888. The Division Director is Gregory R. Wagner, M.D., telephone (304) 291-4474, FTS 923-4474. 


\section{DIVISION OF SAFETY RESEARCH}

The Division of Safety Research (DSR) serves as the focal point for the Institute's occupational injury research and prevention program. The division also operates the federal respirator and coal mine dust personal sampler unit (CMDPSU) testing and certification programs, and conducts research to provide criteria for improving respirators and other personal protective equipment and devices.

Occupational Injury Research. DSR collects, analyzes, interprets, and summarizes occupational injury and fatality data to identify worker populations at high risk of occupational injury, and monitor occupational injury trends. DSR investigates selected traumatic injuries and fatalities to identify potential causal factors and prevention strategies. Laboratory and field investigations are conducted to identify and evaluate existing prevention techniques and technology, and develop and evaluate new prevention techniques. As worker protection strategies are formulated, DSR conducts applied field intervention trials and demonstration projects to determine their technical efficacy and practical applicability. DSR develops technical criteria to support recommendations for occupational safety standards, and develops, implements, and evaluates the impact of risk communication efforts. DSR also provides technical assistance in solving safety problems which require expertise in industrial and system safety engineering, ergonomics, industrial hygiene, and related disciplines.

Respirator and CMDPSU Certification and Research. DSR evaluates, certifies, and maintains official records on respirators and CMDPSU as required by the Federal Mine Safety and Health Amendments Act of 1977, and the Occupational Safety and Health Act of 1970. DSR continually reviews performance requirements, standards, and guidelines for certification. The division also develops new performance requirements and standards for respirators. To ensure that respirators continue to meet regulatory requirements, DSR conducts performance audits of certified respirators, and quality assurance audits of respirator manufacturing plants.

Additionally, DSR investigates field problems associated with NIOSH-certified equipment; provides technical assistance to users on the selection, use, maintenance, and operation of certified equipment; conducts research to characterize respirator performance in the laboratory under simulated work site conditions, and at work site settings; conducts research to evaluate human physiological response to respirator and protective ensemble (i.e., protective clothing) wear under various conditions; and identifies and recommends needed research to the occupational safety and health community.

DSR is located at the Appalachian Laboratories for Occupational Safety and Health (ALOSH), 944 Chestnut Ridge Road, Morgantown, West Virginia 26505-2888. The Division Director is Thomas R. Bender, M.D., M.P.H., telephone (304) 291-4595, FTS 923-4595. 


\section{DIVISION OF STANDARDS DEVELOPMENT AND TECHNOLOGY TRANSFER}

The Division of Standards Development and Technology Transfer (DSDTT) develops, from existing scientific and technical information, documents containing (a) criteria for recommended occupational safety and health standards, and (b) technical and scientific information relevant to a variety of occupational safety and health issues. In cooperation with the U.S. Department of Labor, DSDTT coordinates NIOSH testimony at the Department of Labor hearings on proposed standards to support scientific and technical considerations, and prepares and annually revises the legislatively mandated toxic substances list. DSDTT manages a clearinghouse for receiving, storing, retrieving, and disseminating technical information on occupational safety and health.

DSDTT compiles and analyzes the results of research and investigations pertaining to selected occupational safety and health hazards for the purpose of preparing recommended standards. These recommendations include environmental limits, requirements for medical examinations for workers, labeling, personal protective equipment and clothing, employee notification of hazards, safe work practices, sanitation, monitoring, and record keeping. The division prepares special occupational hazard reviews and risk assessments of potential workplace hazards when new evidence of a particular hazard is received, and prepares recommended emergency temporary standards as appropriate.

DSDTT identifies information on worker exposure, chemical hazard severity, and other data through profile development. The division establishes liaison with government and non-governmental sources to obtain technical data, and develops and maintains the NIOSH computer-based technical information system and other computer-oriented information resources.

The division identifies, in priority order, those substances, industries, and occupations that pose an unacceptable safety and health hazard, and prepares priority lists of substances, processes, industries, etc., for which document development and Institute research should be developed or revised. DSDTT also analyzes information on the exposure of workers to safety and health hazards, and assesses the adequacy of studies, research, and data collection activities to provide the basic information needed for decisions on quantitative risk estimation, document development, priorities establishment, and other actions coming from essential information.

DSDTT is located at the Robert A. Taft Laboratories, 4676 Columbia Parkway, Cincinnati, Ohio 45226. The Division Director is Richard W. Niemeier, Ph.D., telephone (513) 533-8302, FTS 684-8302. 


\section{DIVISION OF SURVEILLANCE, HAZARD EVALUATIONS, AND FIELD STUDIES}

The Division of Surveillance, Hazard Evaluations, and Field Studies (DSHEFS) conducts surveillance of the nation's work force and workplaces to assess the magnitude and extent of jobrelated illnesses, exposures, and hazardous agents. DSHEFS conducts legislatively mandated health hazard evaluations at the request of unions, employers, or employees. The division also conducts mandated industry-wide epidemiologic and industrial hygiene research programs including longitudinal record studies, clinical/environmental field studies, and industrial hygiene surveys. DSHEFS provides technical assistance on occupational safety and health problems to federal, state, and local agencies, and other technical groups.

Surveillance systems are used for the early detection and continuous assessment of the type and frequency of occupational disease, disability, and deaths. Surveillance systems are also used for determining potential exposures to hazardous agents and for evaluating the effectiveness of intervention efforts. Existing data sources from federal, state, and local agencies, labor, industry, physicians, and medical centers are adapted for use as components of a surveillance system. Special emphasis has been given recently to agriculture and construction. DSHEFS assists in the facilitation and coordination of occupational health and safety surveillance, within and outside the Institute, as well as development of a program for state-based surveillance, intervention, and prevention procedures.

The industry-wide studies program (1) identifies the occupational causes of disease in the working population and their offspring and determines the incidence and prevalence of acute and chronic effects of work-related exposures; (2) conducts intervention studies to reduce occupational disease in working populations and their offspring; (3) provides information on the extent of exposure to agents of interest in the workplace; and (4) develops, disseminates, and evaluates risk communications for subjects of epidemiologic studies.

The health hazard evaluations and technical assistance (HETA) program responds to requests from employers, employees, employee representatives, and federal, state, and local agencies. This program is mandated by Section 20(a)(6) of the Occupational Safety and Health Act and implemented by regulations at 42 CFR 85 . The typical HETA response to a request for assistance results in an evaluation of whether chemical, physical, biological, or other agents are hazardous as used or found in the workplace. Recommendations are then made for control procedures, improved work practices, and medical programs to reduce exposure levels and prevent adverse health effects. The results of individual evaluations may trigger wider studies of similar exposures in other settings or may stimulate recommendations for implementation or modification of health standards.

DSHEFS is located at the Alice Hamilton Laboratory, 5555 Ridge Avenue, Cincinnati, Ohio 45213. The Division Director is Lawrence J. Fine, M.D., telephone (513) 841-4428, FTS 684-4428. 


\section{DIVISION OF TRAINING AND MANPOWER DEVELOPMENT}

The Division of Training and Manpower Development (DTMD) implements Section 21 of the Occupational Safety and Health Act of 1970 which mandates the training and education functions. The educational resource development program assesses manpower needs for OSH practitioners and researchers on a nationwide basis. DTMD develops programs to increase the numbers and competence of the OSH professional and paraprofessional work force. To help meet the demand, DTMD administers a major training grant program to foster the development of academically based training programs for occupational physicians, occupational health nurses, industrial hygienists, toxicologists, epidemiologists, and safety professionals. DTMD also develops specific criteria for the selection of qualified organizations to conduct research training, graduate degree and continuing education, and outreach programs to expand the network of knowledgeable professionals in occupational safety and health.

The curriculum development program designs and produces course packages and other training materials for Institute-sponsored training programs, including those presented by in-house faculty as well as those conducted by universities and other outside training organizations. The continuing education program provides short-term technical training courses, including seminars, independent study packages, and specialized workshops to train-the-trainer to federal, state and local government, private industry, labor unions, and other organizations in the OSH field.

DTMD special emphasis projects have targeted primary care physicians (Project EPOCH), engineers (Project SHAPE), managers (Project Minerva), vocational education/and science teachers to include occupational safety and health knowledge in their formal program of study. The division establishes a collaborating relationship with the many professional societies and accrediting bodies to formalize the process of long-term commitment through professional networking.

DTMD is located at the Robert A. Taft Laboratories, 4676 Columbia Parkway, Cincinnati, Ohio 45226. The Division Director is Thomas C. Purcell, Ph.D., telephone (513) 533-8221, FTS 684-8221. 



\title{
SUMMARIES
}

\section{OF}

\section{NATIONAL PREVENTION STRATEGIES}

\author{
Occupational Lung Diseases \\ Musculoskeletal Injuries \\ Occupational Cancers \\ Severe Occupational Traumatic Injuries \\ Occupational Cardiovascular Diseases \\ Disorders of Reproduction \\ Neurotoxic Disorders \\ Noise-Induced Hearing Loss \\ Dermatological Conditions \\ Psychological Disorders
}





\section{SUMMARIES OF NATIONAL PREVENTION STRATEGIES}

\section{INTRODUCTION}

In 1983, the National Institute for Occupational Safety and Health (NIOSH) published a suggested list of leading work-related diseases and injuries. Scientists at the Institute had developed this list as a guide for setting priorities and allocating resources within the Institute, and as a focal point for discussion among occupational health professionals throughout the country. NIOSH then undertook the preparation of proposed national strategies for the prevention of each condition on the list.

In May 1985, NIOSH and the Association of Schools of Public Health (ASPH) co-sponsored a national symposium for the in-depth evaluation of proposed strategies for the first five conditions: occupational lung diseases, musculoskeletal injuries, occupational cancers, severe occupational traumatic injuries, and occupational cardiovascular diseases. Under the direction of 51 expert panelists, the more than 450 symposium participants-representing academia, management, organized labor, professional associations, and voluntary organizations--discussed, revised, elaborated, and further developed the strategies.

In October of 1986, the second NIOSH National Symposium on the Prevention of Leading Work-Related Diseases and Injuries was convened. This symposium presented and modified the second five of the "ten leading work-related diseases and injuries." Like the first, it was a resounding success. These symposia provided an opportunity for discussion, modification, and input to the strategies that were developed by NIOSH. We now have the first "national" plan to eliminate, by preventing, negative health effects of work. These strategies generally include four parts: definitions, description of the nature of the problem, depiction of the preventive measures that can now be taken, and depiction of the knowledge required to move forward. The specific content of these strategies is diverse, reflecting the many professionals whose ideas are there; however, the attempt to emphasize "basics" undergirds each.

At these symposia, a new national vision was introduced--a vision that unsafe working conditions are no longer tolerable and that clear and understandable steps can be taken to prevent the leading occupational diseases and injuries. Throughout these National Prevention Strategies, common themes emerge: (1) An important component in each prevention strategy is surveillance. Surveillance is needed to accurately estimate the incidence of the disorder, to identify the population at risk, to direct the most effective preventive measures where they are needed, and to measure the impact of intervention. (2) The strategies also focus on scientific research. Research is needed to develop the specific knowledge and understanding on which prevention depends. (3) Another integral component is training. Effective communication through education, technology transfer, the dissemination of information, and training is required to reach the full potential of prevention. Well-trained workers, knowledgeable managers, and fully informed occupational safety and health professionals are essential elements in any prevention program. (4) Finally, the strategies emphasize the importance of applying and adapting existing knowledge to prevent occupational diseases and injuries. Research results are 
only effective in preventing such conditions if they are applied in the workplace. Useful information is already available, and ways must be found to target and apply it where it will do the most good.

Out of the symposia and the subsequent voluminous exchange between NIOSH and the participants came the National

Strategies for the Prevention of Work-Related Diseases and Injuries. They have been published and widely disseminated, and are designed to serve as working documents to guide $\mathrm{NIOSH}$, other agencies, business, labor, and academia to work more cohesively toward providing for safe and healthful working conditions. 


\section{OCCUPATIONAL LUNG DISEASES}

The lung is both a target organ and a portal of entry for toxic substances. The likelihood of toxic exposure to the lung can be high; for example, an estimated 1.2 million U.S. workers are potentially exposed each year to silica dust alone. Although occupational lung disease is caused by the inhalation of toxic substances in the work environment, the association between occupational exposure and lung disease is not always apparent or simple. The occurrence of multiple or mixed exposures, the non-specificity of symptoms, the relatively long latency for these diseases, and the independent or synergistic effects of cigarette smoking may all confound the recognition of occupational factors in lung disease.

Classifying lung disease by the type of occupational exposure that leads to it permits rapid identification of toxicants and the application of available control technology. Major types of exposure include inorganic dusts (silica, asbestos, coal dust), organic and metallic dusts (cotton, grain, metallic salts, antibiotics), gases and fumes (nitrogen, methane, ammonia, phosgene), viable aerosols (bacteria, viruses), and respiratory carcinogens (arsenic, chromium, coke oven emissions). Four occupational lung diseases that are deemed preventable are asbestosis (caused by exposure to asbestos), byssinosis (cotton dust), silicosis (silica), and coal workers' pneumoconiosis (coal dust). These have been targeted in the 1990 objectives of the U.S. Public Health Service for elimination of new cases among workers newly exposed after 1985 (USDHHS, 1980). These diseases and their causative agents will be cited as examples in the following prevention strategy. Methods for their control may be adapted for most other occupational lung diseases.

\section{Disease descriptions}

The asbestos-related diseases include nonmalignant fibrogenic effects on the lung parenchyma and pleural plaques as well as malignant neoplasms of the lung and the serosal linings of the chest and abdomen (mesothelioma). The latency is $\geq 15$ years for asbestosis and 20-40 years for malignancies. Synergistic effects of smoking increase the risk of lung cancer.

Byssinosis includes both acute (reversible) and chronic lung disease. The effects may be due to specific causal agents in the dust of certain varieties of cotton or other vegetable fibers.

Silicosis may be acute or chronic (nodular pulmonary fibrosis) and affects workers in foundries, stone quarries, sand and gravel operations, and mines. Latency is long, and disease progresses even after exposure ends.

Coal workers' pneumoconiosis (CWP) shows a clear dose-response relationship to coal-dust exposure. Enforcing lower dust standards in both Great Britain and the United States has reduced the incidence of this disease. When workers with early, simple CWP are identified, serious disabling disease may be prevented by transferring the workers to lower-dust environments.

\section{Implementing what we know}

Surveillance: Environmental surveillance of hazardous agents is needed to identify occupations, industries, and worksites with potential for high incidence of occupational respiratory disease (e.g., asbestos-removal operations, industries using cottons with high levels of endotoxins, and ground silica). Current environmental surveillance should continue, and activities for prevention should be targeted to the locations identified. Disease surveillance of workers 
is also important and can help determine pre-existing conditions (reduced ventilatory function), early development of disease (simple CWP), or hypersusceptibility to given agents (acute reactions to cotton dusts). Interventions, such as reducing further exposure, should focus on the affected workers.

Substitution: Hazardous agents can often be replaced by less hazardous and noncarcinogenic substitutes. Cottons that cause less acute responses in humans (e.g., high-grades, blends, or washed cottons and synthetic substitutes) can be used; and silica can be banned as an abrasive blasting material, with nontoxic materials substituted.

Control: Technology is already available to control many hazardous exposures through engineering design and automation, ventilation, and isolation. Although silica exposures above legal limits are still occurring, control can nearly always be achieved through engineering or substitution once exposure is recognized. Personal protective devices (e.g., respirators), however, should not be considered primary protection mechanisms because they rely on human intervention and may not provide the level of protection determined in the laboratory.

Incentives and Regulation: Economic incentives, such as lower insurance premiums, will often stimulate the adoption of control measures. More often, regulatory enforcement is needed for effective control of exposure levels. The permissible exposure limit for asbestos should be reduced, as recommended by $\mathrm{NIOSH}$, to the lowest measurable level-- 100,000 fibers $/ \mathrm{m}^{3}$, and OSHA should require a dust-control and monitoring plan before any work involving asbestos exposure begins. Present silica standards range from $33 \mathrm{ug} / \mathrm{m}^{3}$ to $98 \mathrm{ug} / \mathrm{m}^{3}$ and should be unified. The 1970 coal dust standard $\left(2 \mathrm{mg} / \mathrm{m}^{3}\right.$ with medical monitoring) appears to reduce the incidence of CWP, and the authority of federal inspectors to shut down coal mines where hazards are severe may help to enforce compliance.

Education: Both the Mine Safety and Health Act and the Occupational Safety and Health Act place responsibility on employers to provide safe, healthful workplaces. Workers should be told about hazardous exposures and available control measures, and then workers and managers should cooperate to control exposures through technology transfer, changes in work practices, implementation goals, and periodic assessment. Technical information already available should be used to increase awareness of work-related lung problems and to produce clear, easily understood texts on control for small as well as large-scale operations. Educational programs targeted to engineers, managers, occupational health professionals (including primary care physicians), and workers should cover the nature of the work environment and how to assess and control work exposures. State and local health departments can provide expertise and leadership for these programs. Although workers' compensation provides financial relief after exposures occur, awareness is needed before exposure through adequate warnings and product labeling.

Tobacco smoking may have additive and/or synergistic effects on the development of lung disease, both for smokers and for others exposed to tobacco smoke. Labor management policies are needed for smoking in the workplace, and appropriate state legislation on smoking in public places could also be used to limit workplace smoking.

\section{What knowledge do we need?}

Research: Several research needs have been suggested. Substitute agents should be tested to determine their toxicity before they are used. Studies should determine whether serious effects result from episodic, 
low-level exposures to pulmonary irritants and whether long-term effects follow acute responses. Workers exposed to asbestos should be studied to determine dose-response relationships, the effects of intermittent and short-term high exposures, the pathogenicity of various asbestos fibers (e.g., "short" fibers) and asbestos substitutes, and the significance of pleural changes and pleural plaques. Studies should also identify the fiber-release potential of in-place asbestos materials, the relative risks and benefits of asbestos removal, and the effectiveness of removal practices. The relationship in cotton workers of acute responses and chronic respiratory disease can be clarified if normal annual decrements in lung function are determined. Research on exposure to silica should include doseresponse relationships, particularly at low levels and for mixed dusts containing silica. Analysis of current MSHA and OSHA environmental data on exposure to silica will help identify hazardous industries, locations, and specific processes. The carcinogenic properties of quartz also need study. The problem of hypersensitivity pneumonitis and the relationship between smoking and diffuse lung fibrosis should be investigated. Host risk factors (e.g., smoking and atopy) must also be examined.

Hazard Detection and Disease Diagnosis: Better methods are needed to measure airborne concentrations of hazardous substances and to enhance environmental surveillance, especially for mixed dusts in underground and surface coal mines. More sensitive techniques must be developed for screening workers to recognize early signs of disease (particularly at the cellular level) and to predict susceptibility to lung diseases. An operational definition of silicosis will help standardize diagnosis and reporting.

Incentives and Regulation: Incentives and educational materials should be available to encourage the efficient use of strategies for controlling exposures. The mandate for medical surveillance in the current Cotton
Dust Standard should be reassessed to determine whether new recommendations from NIOSH are needed. Results of long-term studies on the adverse health effects of dust exposure (including nonpneumoconiotic lung diseases, such as bronchitis and emphysema) will help in setting total dust regulations for both coal mining and general industry. Data on the relative causality of exposures to carcinogens and on exposure-response measurements will help in setting effective exposure standards.

Control: When the exact etiologic agent(s) of byssinosis are identified, their removal by cultivating or processing cotton can be facilitated, and effective controls and exposure standards can be developed. Changes in mining techniques necessitate that mine planning and the design and installation of new equipment be based on forecasting and predictive techniques, such as predictive models. For example, the increased use of longwall mining, the continuous use of mining equipment, and the increased rates at which coal is broken all require new approaches to control. The characteristics of respirable dust will need to be correlated with coal seam and mining methods; and new technology implement intermittent dust sources.

\section{Summary}

This prevention strategy cannot succeed on the basis of any one element alone; all must be addressed to prevent occupational lung diseases. Thus, although problem areas can be identified by environmental and medical surveillance, follow-up and elimination or reduction of exposure are also needed. Surveillance must be coupled with exposure control (e.g., work practices, automation, ventilation, incentive systems, strict enforcement of exposure standards) and other important elements described here. Health promotion and development of workplace smoking policies, while not always directly related to occupational exposures, are additional important elements. 


\section{MUSCULOSKELETAL INJURIES}

Musculoskeletal injuries include both acute and chronic injury to the muscles, tendons, ligaments, nerves, joints, bones, and supporting vasculature. These injuries may be sprains, strains, inflammations, irritations, and dislocations. In the medical literature, this broad class of physical symptoms or complaints is collectively referred to as wear-and-tear disorders, overuse injuries, osteoarthrosis, degenerative joint diseases, chronic microtraumas, and cumulative trauma disorders.

To find preventive measures for these injuries, it is helpful to identify contributing elements and to look at these elements in the four main categories outlined by the Canadian Health Fields Model.

Environmental Hazards: A workplace hazard to the musculoskeletal system is called a traumatogen, or a source of biomechanical stress that results when job demands exceed the worker's strength or endurance.

Human Biologic Factors: Innate qualities, such as physical size, strength, range of motion, work endurance, and the integrity of the musculoskeletal system, influence a worker's ability to perform a job safely.

Behavioral or Lifestyle Factors: Such factors as insufficient sleep or recovery from exertion, job dissatisfaction, obesity or lack of adequate physical fitness, unhealthy diet, and substance abuse may increase a worker's risk of musculoskeletal strain or injury.

Inadequacies in Health Care Systems: A lack of medical knowledge or of appropriate training in the etiology, diagnosis, and treatment of musculoskeletal problems may result in inadequate health care.

Much remains to be learned about the causes of work-related musculoskeletal injuries. Because few of these injuries are accepted as coming only from work, the workplace hazard must often be identified to define an occupational injury. High physical stress can frequently be traced to ordinary work activities, including repetitive or sustained lifting, bending, twisting, climbing, reaching, gripping, pinching, rubbing, kneeling, and squatting, as well as vibration from equipment. Sometimes these activities are performed in awkward postures and involve high forces.

\section{Scope of the National Problem}

Although present surveillance systems are inadequate and estimates of the national problem may not be accurate, awareness is growing that these injuries result in significant human suffering, loss of productivity, and economic burden to the country. High risk industries include manufacturing, construction, and food processing. In the 1977 Health Interview Survey of the National Center for Health Statistics, musculoskeletal injuries ranked first in frequency among health problems that affect the quality of life. They are the leading cause of disability in the working years, affect 19 million persons annually, and involve nearly half the workforce at some time in their working life. The frequency and impact of these disorders are expected to increase in the future, and some increases are already evident with modern office technology. Although this equipment is designed to reduce physical labor, it often generates new, pervasive, and even more insidious sources of biomechanical stress. 
An important first step in preventing musculoskeletal injuries is identifying their causes, but this is often difficult because of the many complex etiologic factors, long latency, effects of aging, and lack of standardized diagnostic criteria. Many biomechanical hazards, however, could be eliminated if knowledge already available were put to use (e.g., redesigning work processes or tools to impose less biomechanical stress). A management concept of "working smarter is better than working harder" will maintain better production levels than a demanding work schedule, since it reduces time lost due to work injuries. And, finally, cooperation on common prevention problems can be fostered among key professionals from different backgrounds (e.g., engineers and health care personnel) by dispensing and applying accumulated knowledge.

\section{Tactical Areas of a Prevention Strategy}

The present, inadequate surveillance systems do not separate chronic from acute musculoskeletal injuries nor do they have standard terminology for defining such conditions. New systems of both health and hazard surveillance are needed to identify occupations with a high incidence of musculoskeletal injuries and to define types and ranges of work-related biomechanical stresses. Multi-level data bases for the country, the states, and local areas will increase awareness within the medical community of the benefits of prevention and thereby help implement a prevention strategy.

Health professionals, engineers, and scientists must cooperate in using surveillance and clinical data to identify causes and effects from the interacting variables that produce musculoskeletal injuries. For example, (1) low back pain results from interacting job factors (e.g., load weight, location, and frequency of materials handling) and personal factors (age, gender, strength, fatigue, postural stress, trauma, emotional stresses, degenerative changes, congenital defects, physical fitness, and body awareness); (2) biomechanical analyses of hand and arm motions, repetition rates, amounts of force, and postural factors have helped identify stresses leading to carpal tunnel syndrome and tenosynovitis; and (3) injuries to lower extremities, mainly the knee, result from repetitive loading, constant kneeling, squatting, and contact with specialized tools. New evaluation and laboratory techniques are now available but more are needed to clarify the stress patterns.

The three approaches for controlling risk factors are redesigning jobs or tools, training workers, and selecting workers for specific jobs. (1) The use of ergonomics to design new jobs and tools is better than personal protective equipment or safe work practices, but this is still an undeveloped science, and research is needed on anatomic, mechanical, physical, and human factors. While initial costs and complications of overlapping stresses have prevented widespread use of ergonomics, the high costs of workers' compensation and rising insurance premiums may make ergonomics attractive for reducing medical costs and lost time from injuries and for increasing worker productivity. (2) The preventive value of training programs that teach employees specific work practices for safety and hygiene has been difficult to evaluate. Current programs seek to increase worker awareness of hazards and to help them participate in hazard control through problem-solving techniques. (3) Screening employees for specific jobs is difficult because of the wide variety of job demands and the range of individual physical capacities. Radiologic screening for back problems, although largely discredited, is still widely used and may pose a radiation 
hazard. Thus, ergonomics is the preferred approach, with employee selection and training as secondary elements.

Because awareness is essential for implementing any prevention strategy, information should be disseminated to help change attitudes and behavior of both management and workers, especially in the many small businesses that employ 25 or fewer workers. To accomplish this, the Educational Resource Centers (ERCs), medical schools, and schools of business can provide personnel trained in ergonomics for service at regional levels and can produce guides for users to prevent and control cumulative trauma. Modern technology for disseminating public service messages should also be explored.

\section{Action plan}

The knowledge and skills to implement many of the recommendations below are now available; others must await future advances. For now, the availability of trained health professionals and their degree of cooperation will determine progress in combating musculoskeletal problems in the workplace.

Committee: A multidisciplinary National Committee for Occupational

Musculoskeletal Disorders should be established with representatives from industry, labor, academia, professional groups, and government. It could function as an advisory body to prevent musculoskeletal injuries by coordinating national efforts in research, training, and prevention and by promoting clinical and scientific consensus on definitions, diagnostic criteria, surveillance terms, and criteria for the outcomes of these injuries.

Training: More clinical personnel should be trained in the etiology of musculoskeletal disorders, and, with the help of the National Research Council's National Academy of Engineers and others, design engineers could be trained in biomechanics and ergonomics. Workers should be trained to participate in the redesign of jobs, tools, and workstations. Young investigators could be encouraged through post-doctoral grants and research assistantships to seek advanced training in preventing musculoskeletal injuries.

Surveillance and Research: Innovative surveillance systems must be developed with cooperating federal, state, and local officials to improve the understanding of the nature, extent, and magnitude of musculoskeletal problems. Longitudinal studies, evaluations of ergonomic hazards, and assessments of health effects of new emerging technologies (robots, electronic office operations) are needed. Grants from NIOSH and the National Science Foundation can promote research on etiology and prevention and on the relationship of certain job tasks to resultant injuries or disorders.

Coordinating Group Activities: State and local health agencies, universities, and community health groups could, through a grant mechanism, evaluate workplaces to identify traumatogens, determine the efficacy of proposed countermeasures and prevention strategies, and conduct demonstration studies in select, high-risk industries. The Institute of Industrial Engineers, industrial hygiene organizations, equipment manufacturers, and others could develop and test means for controlling cumulative trauma. The proposed National Committee could help coordinate activities of OSHA, MSHA, AIHA, and state and industry groups to formulate guidelines for ergonomic control and could encourage standard-setting groups, such as the American National Standards Institute, to develop consensus standards. The Committee could also evaluate the benefits of a national ordinance or generic standard for controlling biomechanical hazards, similar to the Swedish ordinance regulating work postures and working movements (Danielson, et al, 1983). 
Dissemination: The DHHS Office of

Disease Prevention and Health Promotion

along with local and regional health agencies could convey the true costs of musculoskeletal injury (in terms of economics and human suffering) to public and professional health societies through an awareness program. A model for dissemination should identify target groups, the types of messages needed, effective media, procedures for evaluating the effectiveness of information programs, and overall marketing plans for dissemination. The proposed National Committee could promote an interchange of information on basic research through symposia and workshops; a national clearinghouse of information could be established; and the results of worksite studies should be published in trade and management magazines. Labor and management should explore new ways of informing workers, especially those in small businesses and industries, of the causes, risk factors, prevention, and treatment of occupational musculoskeletal disorders. The occupational health nurse must be recognized as a first-line link between worker and health professionals, and worker-participation programs, such as the Ergonomic Task Force, should be employed to help introduce ergonomic changes. 
Cancers induced by occupational exposures usually occur decades after the exposures take place. Most observed associations between exposure and occupational cancer involve tumors of a common type, such as lung cancer. Specific cancers sometimes occur in such a high fraction of workers that the work-related association is inescapable. In 1775, Sir Percivall Pott first identified an excess risk of cancer in an occupational group--cancer of the scrotum in chimney sweeps. This led to the first demonstrated prevention of cancer development in workers by interrupting the interactions of agent, environment, and host that take place as a result of workplace exposures. Since then, several other occupations have been shown to pose an increased risk of cancer, and, in the 20th century, other specific carcinogens have been identified as well.

Three health actions for prevention, outlined in the 1979 Surgeon General's Report on Health Promotion and Disease Prevention (USDHEW, 1979), can be applied to work-related exposures to carcinogens: health protection (activities to reduce exposure, such as redesigning the job), health promotion (helping workers develop and improve behaviors for good health, such as stopping the use of tobacco with its additive or synergistic effects on workplace exposures), and health services (although less satisfactory than the above, early detection may permit treatment and even cure of some cancers).

\section{Scope of the problem}

Conservative estimates attribute 17,000 cancer deaths each year to workplace exposures. Although over 100,000 workers are potentially exposed to the 21 chemicals now regulated by OSHA as carcinogens (NIOSH, 1978), adding the agents OSHA is currently considering for regulation and those recommended by NIOSH for control as carcinogens increases the total of potentially exposed workers to 3-9 million. Since such exposures are neither ubiquitous nor homogeneous but affect distinct populations to varying degrees, the cancer rates in specific populations may be substantially higher than expected.

\section{Preventive actions}

This strategy presents a continuum of potentially effective techniques for preventing occupational cancer, including what can be done now and what additional knowledge is needed.

\section{Identifying and evaluating carcinogens:} Epidemiologists, toxicologists, industrial hygienists, and safety engineers should coordinate efforts in research on carcinogens. Increased support for such research will help improve methods in epidemiology, toxicology, industrial hygiene, and screening. A committee of government, industry, labor, and academic experts should prepare a list of agents that warrant toxicologic and epidemiologic study and set priorities for research.

Setting standards: The most familiar mechanism for setting standards is through NIOSH recommendations to OSHA, which then promulgates standards. NIOSH can also provide technical assistance to MSHA, state governments, companies, and insurance carriers for setting standards. Additional recommendations come from such voluntary groups as the American Conference of Governmental Industrial Hygienists and the American Industrial Hygiene Association. To avoid the time needed to regulate carcinogens on an agent-by-agent basis, OSHA has promulgated a carcinogen policy that will help clear the backlog of unregulated carcinogens. More effort is needed to identify carcinogens in the workplace and to 
disseminate information to all potentially exposed groups, such as by a broad hazard communication standard. Some gaps in information must still be filled before priorities for epidemiologic and toxicologic studies can be set.

Elimination and substitution: When the risks of using an agent in the workplace exceed the benefits, the most effective way to eliminate exposure is to eliminate the agent. More detailed information is needed on the carcinogenic properties of agents currently used in the workplace and their possible substitutes. Lists of potential carcinogens, substitutes, and replacements should be developed and broadly disseminated.

Control technology: Engineering controls that enclose a system or provide ventilation are preferable to personal protective devices or work practices because they are perceived as less likely to fail. Studies should evaluate the effectiveness of control technologies and should identify examples of effective controls for specific agents.

Information from these studies could be disseminated by a national clearinghouse, especially to small businesses.

Personal protective devices: Personal protective devices are necessary when the use of a carcinogen is essential and engineering controls are neither available nor adequate. Devices must be matched to specific agents because exposure may take place through inhalation, ingestion, or skin absorption. Some devices may even introduce hazards by interfering with vision, dexterity, or worker comfort. NIOSH should continue to certify respirators and alert users to possible failures or defects. A clearinghouse could be established to disseminate state-of-the-art information on personal protective devices.

Environmental monitoring: Environmental monitoring measures the amount of a carcinogen in the workplace, assesses the adequacy of engineering controls, and determines the need for personal protective devices. Validated strategies for such monitoring are needed, and NIOSH, MSHA, OSHA, industry, and others should press for better and more precise analytic methods that are as accurate in the field as the laboratory. NIOSH should continue to assure the accuracy of laboratory testing, and a surveillance system should be developed to collect, evaluate, and disseminate the results of environmental monitoring.

Biologic monitoring: Both the inherent biologic characteristics of individuals and the absorption of specific carcinogens can be determined by biologic monitoring. The efficacy of current methods must be assessed under field conditions and new methods developed where necessary. The value of new and current methods for determining the individual enzymatic constitution of workers and predicting carcinogenic risk must be measured. The proficiency of commercial laboratories that perform biologic testing should be ascertained. Surveying the results of current biologic monitoring will help identify worksites where exposures to carcinogens occur.

Medical screening: Evaluating the efficacy of such medical screening techniques as urinary and sputum cytology will enhance early detection of occupational cancers and thus permit treatment and awareness of risk. State-of-the-art information should also be updated and disseminated in NIOSH recommendations and in OSHA and MSHA regulations. We need to know the effectiveness of medical screening techniques and subsequent therapy and more effective methods of identifying populations with past exposure to carcinogens.

Health promotion: As an adjunct to the overall prevention strategy, health promotion can help eliminate personal behaviors--such as smoking--that may act 
synergistically with workplace exposures. Professional organizations, like the American Occupational Medical Association, the American Association of Occupational Health Nurses, and the American Industrial Hygiene Association, can be enlisted to help sensitize the health care establishment to specialized needs of certain occupational populations.

Interaction between occupational exposures and personal health behaviors must be more clearly delineated.

Therapeutic health care and rehabilitation: Although the field of clinical oncology has burgeoned, training of personnel has lagged. Efforts by NIOSH, professional organizations, and the National Cancer Institute ( $\mathrm{NCI}$ ) are needed to increase educational materials, training programs, and certification for physicians and nurses in the field of occupational cancer. Placing experienced personnel in state and local agencies would increase awareness. Information from attempts at medical intervention is needed to assess the adequacy of early detection, therapy, and risk-reduction techniques. Identifying populations with increased risk of cancer or past exposures to carcinogens, particularly in small firms or those not covered by regulation, will help ensure timely application of diagnostic and therapeutic services.

Surveillance of disease: Because most cancers have such a long latency, surveillance of current disease may not identify current exposures. Nevertheless, some cancers may be sentinel health events that identify populations in need of medical intervention. Surveillance schemes should be evaluated for effectiveness. Acute illnesses, such as chrome dermatitis, may signal current exposures to carcinogens. Experienced personnel in local and state agencies can encourage interest in cancer detection, reporting, and prevention.

Record systems, such as those collected by the Internal Revenue Service, the Social
Security Administration, and Workers' Compensation, may aid epidemiologists.

Surveillance of exposure: The long latency also makes difficult the directing of society's resources to workplaces with the greatest potential for exposure to carcinogens. Although data collected in OSHA and MSHA compliance programs may help identify the extent and level of exposure to both regulated and unregulated carcinogens, better systems of surveillance are needed.

Compliance activities: OSHA conducts some inspections in response to requests and others targeted to "high-risk" industries, based on high infraction rates. OSHA's current policy should be evaluated to determine whether it adequately covers all potentially exposed workers. A national system should also target inspections to plants using regulated or suspected carcinogens, since the effects of exposure will not be manifest for 20-40 years.

\section{Education of workers and managers:} NIOSH, OSHA, MSHA, NCI, and others should strengthen their educational programs for workers and employers. A broad hazard communication standard could be effective in promoting worker awareness. The value of behavioral approaches and job-design factors in controlling cancer in the workplace should be established.

Free-market forces for prevention:

Economic incentives, such as ensuring coverage by the insurance industry and compensation for victims of occupationally induced cancer, will help to encourage measures that prevent such cancers. The difficulty of establishing a causal relationship between exposure and disease must, of course, be overcome. 


\section{SEVERE OCCUPATIONAL TRAUMATIC INJURIES}

Severe occupational traumatic injuries, including those sustained in work-related motor vehicle accidents, comprise such serious and disabling injuries as amputations, fractures, severe lacerations, eye losses, acute poisonings, and burns and may result in worker deaths. Accidents, in general, and the adverse effects that result from them are the leading cause of loss of potential productive years of life in this country. The National Institute for Occupational Safety and Health (NIOSH) estimates that at least 10 million persons suffer traumatic injuries on the job each year; about three million ( 30 percent) injuries are severe, and at least 10,000 are fatal (CDC, 1984). Occupational injuries in 1983 resulted in 80 million lost workdays and an estimated \$33.4 billion in wage, insurance, medical, and administrative costs. These figures may even underestimate the total costs to industry and do not include the immeasurable toll in human suffering. Although rates of occupational fatalities and disabling injuries have fallen since the early 1970 s, due partly to a growing workforce, the actual numbers have declined slowly, if at all, since 1945 .

\section{Intervention}

Traditional approaches to preventing traumatic injuries or reducing their severity include removing hazards, placing barriers between hazards and workers, screening workers before employment, analyzing job hazards, improving job and tool design, complying with regulatory and consensus standards, and training workers to avoid hazards. The following strategy will take a dual approach, discussing the actions that can be taken immediately and then the long-term efforts for the future.

\section{Epidemiology}

In efforts to study the etiology of workplace injuries and fatalities, the discipline of epidemiology can serve as a common thread by helping to identify high-risk exposures and factors, evaluate both potential risk factors and appropriate control strategies, and assess progress in the control of traumatic injuries. As a key component in the epidemiologic process, surveillance must be applied both as an initial activity to establish baseline information and as a continuing activity to characterize how the national occupational safety experience is changing. Four basic aspects of occupational trauma must be considered: the task, the working environment, the machine, and the worker; modification of any one of these will affect the whole system. An overriding consideration must always be the needs of employers who manage these complex industrial systems.

\section{What can we implement now?}

Evaluation of effective safety programs has established that the most important component is management's commitment from the top down. Management accepts responsibility for tying all elements of the workplace together so that the interactions of task, environment, machine, and worker, as well as the energy releases associated with these interactions, can occur with the least possible unforeseen interruption.

Task-oriented strategies: Although safe work practices for hazardous operations and control methods for energy sources are available, failure to use them is responsible for a large number of occupational injuries and deaths. Employers are either unaware of hazards and control strategies or unable or unwilling to implement them. Job-hazard analysis plus timely reassessment or monitoring can help employers anticipate 
rather than react to hazards and should have a major impact on reducing national injury and death rates.

Environment-oriented strategies: While the physical environment of the workplace is the most obvious and the most amenable to change, the psychosocial and political/economic environments warrant further study for their impact on injuries. Over the past 50 years, studies of illumination, temperature, noise, vibration, relative humidity, and the layout and condition of the facility have resulted in guidelines to control these potential physical stressors. Failure to apply the guidelines results from cost constraints, inadequate dissemination of information, and improper management of safety programs. Prevention programs in the private sector have demonstrated trauma reductions and should be encouraged in other companies.

Machine-oriented strategies: The various forms of energy associated with machines, if not adequately controlled, can result in traumatic injuries to workers. Regulatory and consensus standards now exist to protect workers from interaction with industrial machines. Many of these standards propose placing barriers between the worker and the energy sources, such as guards on moving parts of machinery or protective equipment worn by the workers. Manufacturers are now producing safer and more functional machines, and procurement procedures should require the purchase of machinery that meets current standards.

Human-oriented strategies: The worker is the most complex entity in the workplace system and, as the employer's most valuable resource, should be carefully nurtured and protected. Effective information dissemination, education, and training of workers can have an immediate positive impact on the incidence of work-related injuries and deaths. As soon as hazards are identified, known intervention methods should be applied and workers should be supplied with the tools and knowledge to avoid traumatic injuries.

Knowledgeable, well-trained workers can avoid injury even during hazardous work, while untrained, uninformed workers can be injured under almost risk-free conditions. Thus, training is an integral component of trauma prevention. Although safety training begins in childhood, most job safety is learned on the job. Some regulatory agencies require training, but the degree and level of training vary widely. Model training programs could ensure more uniform and basic training in hazard awareness and trauma control. Employees in high-risk occupations should be the primary targets for such training, and retraining in different occupations will be important for workers who suffer permanent disabling injuries at work.

\section{What knowledge do we need?}

For management to select and operate safety programs efficiently, they must have access to cost-effective, scientifically proven methods that reduce injuries.

Task-oriented strategies: Although established countermeasures for occupational injuries may represent the best judgment of the trauma control community, they have not, through rigorous scientific studies, been demonstrated to be effective. Such measures would be more readily accepted if their effectiveness and cost benefit were known.

Environment oriented strategies: The influence of certain physical agents on the incidence of occupational traumatic injuries should be more carefully defined. The psychosocial environment, as it influences the perception of hazard and risk taking, is amenable to modification through advertising, information dissemination, and social interaction. Messages through the mass media should be specific, supportable, and persuasive enough to alter public 
perception so that occupational traumatic injuries and deaths are no longer considered either morally acceptable events or "chance" occurrences that are beyond human control.

Changes in the workforce and workplace, e.g., increasing numbers of women and of certain ethnic minorities and the increased use of computers and automated or programmable machines (robots), present unique and dynamic challenges for the prevention of traumatic injuries. Past failures to anticipate potential hazards of "new" technologies must not be repeated. New techniques for recognizing, analyzing, and mitigating hazards and for managing risk are emerging and should be nurtured, perhaps by establishing a center for research into the non-mechanistic arena of safety.

Increasing attention is being paid to the complex economic forces that influence the incidence of occupational traumatic injury and fatality. This is evident from the creation of a Workers' Compensation Research Institute and from analyses of the economic incentives and disincentives associated with workers' compensation. Employers are beginning to recognize the negative economic impact of traumatic injuries in lost workdays, high medical costs, loss of productivity, and increased insurance rates and liability claims. Data specific for industry and occupation would be helpful in these areas. Studies should be undertaken of the cost relationships of compensation, disability, and product liability insurance from the perspective of occupational trauma.

Machine-oriented strategies: Although present safety concepts involve barriers around hazardous machine parts, workers continue to experience injuries. Further studies are needed on the efficacy of these barriers and on the motivational and behavioral factors involved in their use. Standards for machine safety should be re-evaluated, and the technical basis for each standard should be understood by users. As faster and more efficient machines are developed, care must be taken to design safe methods of feeding and removing stock from the machine and to limit the speed within human tolerances.

Human-oriented strategies: As the workforce ages, traumatic injuries may increase because older workers are slower to react, have reduced ranges of motion, and are less tolerant of environmental changes such as extreme heat or cold. Although older workers are more cautious, the decreasing supply of younger workers may force the older ones to remain longer in high-risk jobs, thus increasing exposure to the hazards of traumatic injury.

Technology can be viewed on four levels: (1) workers supply both power and control, (2) tools supply power, and workers control it, (3) both power and information are supplied, and workers direct; and (4) power, control, and information are supplied in self-monitoring systems, and workers only intervene if something goes wrong. As technology progresses toward levels 3 and 4, and as service jobs become more prominent, training will become increasingly important. The adequacy of training policies and practices will require constant evaluation.

Little research has been directed to the relationship of human behavior to safe work activity, e.g., why workers circumvent safety devices or ignore safety rules when rescuing others. Most studies have focused on economic factors, but more attention to motivational issues is needed. Management should find ways to enlist the interest and cooperation of workers so that workers, unions, and management can work together to better understand and overcome hazards inherent in the workplace. The impact of such cooperation, e.g., quality circles in the automobile industry, needs further evaluation. 
The roles of alcohol and drug abuse are well known in highway trauma but less understood in occupational settings. The work-related effect of these substances and their possible interaction with chemicals in the workplace require further study.

NIOSH should cooperate with agencies that have responsibilities in areas of personal behavior and substance abuse and should increase their awareness of worker needs.

Risk-taking, a fundamental quality of the American spirit, is rewarded in society and the workplace, but must be tempered when it contributes to occupational trauma. Other aspects of human behavior, such as reactions to major life events (death, divorce, financial troubles), may also impact occupational safety. The increasing availability of employee counselors reflects the value employers are placing on the inental well-being of workers.

Rehabilitation of severely injured workers, while not preventive, can mitigate the severity of trauma by reducing prolonged disability, loss of income, and the impaired quality of life. Such evidence of management's commitment to employee well-being lends credibility to its prevention-oriented programs. Better techniques for diagnosis of injuries are needed, and sufficient time must be allowed to ensure the mental, psychological, and physical conditioning of workers for return to the workplace.

\section{Recommendations}

What can be done now: Model programs can be developed for successful prevention of occupational trauma and implemented through a workplace-specific, self-evaluation approach. Self evaluation involves the work force in anticipating and identifying hazards, developing and discriminating among existing controls, and tailoring the tools to a specific industry. Such evaluation should be voluntary and focused on high-risk industries and specific worker populations that may be high risk and/or neglected by regulations.

Research on the prevention of occupational trauma, especially interdisciplinary research, should be stimulated by such means as national grant programs. The results of these and similar studies must be easily accessible, perhaps through broadened information centers, and should be available in both hard copy and through electronic access. A knowledge of injury-control methods should be brought to the attention of educational institutions, professional societies, accreditation bodies, and state and local agencies so that educational institutions will be influenced to adopt trauma-control courses or modules into their curricula. Education and training models for specialists, managers, supervisors, and workers should include techniques for identifying, evaluating, and controlling hazards, and ranking the consequences of hazards; guidelines for selecting training materials and methods; and methods for evaluating training and post-training management.

Enforcement agencies should use their resources and authority to ensure that appropriate safeguards are installed and used, especially on mechanical power presses. All guards should be integral, non-removable parts of the machine design, and workers and managers alike should clearly understand the hazard posed by the machine and the value of the guard. Existing occupational consensus standards and codes should be reevaluated and a technical basis established for each so that new information can be easily incorporated as it emerges. The results of product liability litigation should be monitored for their influence on product designers and to identify potential increased risk to workers. Findings should be widely disseminated to responsible groups. 
Longer term actions: Surveillance of occupational traumatic injury is currently limited by the inadequacies and the redundancies of existing documentation and reporting systems. A national surveillance system is needed that will include information on products, engineering controls, personal protective equipment, job title and tasks, worker characteristics (training, experience, and shift factors), compliance with standards, and location of accident--in short, the optimal elements to fulfill all current and anticipated uses of such data. All possible sources must be tapped, including reports from hospitals, medical examiners, and accident investigations. Until such a system is developed, existing systems can be expanded and the collection of industry-specific data can be explored. In addition, ways might be found to release--for trauma-control research--data that are currently protected by the Privacy Act, while still protecting the sensitive nature of the data.

Epidemiologic studies are needed to describe the magnitude and characteristics of specific traumatic injuries and to evaluate the efficacy of specific prevention measures. These studies can reduce current information gaps, such as incorrect statistics on traumatic injury, unsubstantiated conclusions about what influences the risk of injury (training, worker behavior, experience, supervision), and data on the feasibility and success of prevention measures.

The continuing toll of occupational injuries suggests that current programs are not working, perhaps because resources are not available or because the personnel involved are not familiar with specific problems in specific industries. A possible solution to be explored is the formation of private, nonprofit, industry-specific associations for research (not regulatory) purposes (e.g., the Construction Safety Association of Ontario). Existing national programs could help promulgate regulations, develop scientific methods, and generate research tools for the associations.

Chemicals, medications, and other substances, encountered through both personal use and workplace exposure, may increase the risk of traumatic injury. These hazards must be identified, workers should be screened for susceptibility to them, and effective employee assistance programs should be made available nationwide. 


\section{OCCUPATIONAL CARDIOVASCULAR DISEASES}

Cardiovascular diseases, e.g., ischemic heart disease and hypertensive, cerebrovascular, and peripheral vascular diseases are the leading cause of disability and death in the United States, accounting for almost a million deaths $(986,000)$ in 1984 (NCHS, 1986). Direct and indirect economic costs amounted to approximately $\$ 102.4$ billion in 1983. The 34 percent decline in coronary heart disease since 1972 demonstrates the potential effectiveness of programs directed at risk factors for such diseases. Coronary heart disease, hypertension, and related entities are included in this prevention strategy because of their high incidence, whereas the less common arrhythmias, cardiomyopathies, and other forms are more directly related to specific occupational exposures. These latter conditions are given specific emphasis here because of their vulnerability to intervention in the workplace.

\section{Risks and the workplace}

Millions of workers are currently exposed to work-related factors; chemical, physical, and psychosocial, associated with increased risk of cardiovascular disease. Many personal risk factors are also known. Some personal factors are unalterable, e.g., age, gender, and family history; others are alterable, e.g., cigarette smoking, dietary intake, hypertension, excessive alcohol intake, obesity, diabetes, inadequate physical activity, and behavioral pattern. Preventive programs directed at the alterable risk factors are effective in reducing the occurrence of cardiovascular disease, and the workplace is an excellent site for disseminating messages and programs designed to change these personal risk factors. Where possible, this strategy will combine the two approaches: preventing work-related risk factors and enhancing the prevention of personal risk factors.
Cardiotoxic exposures in the workplace: Several chemical and physical agents--such as carbon disulfide, carbon monoxide, halogenated hydrocarbons, nitroglycerine, heat, and noise--are known to increase the risk of cardiovascular disease. In addition, nearly 1,500 chemicals have been identified with possible cardiovascular effects. The complexity of the disease process, the long latency, and the diversity of workplace exposures during a given lifetime make the study of relationships between occupational exposures and cardiovascular disease difficult.

Reducing exposures to known cardiotoxins requires identifying the exposures, communicating with exposed workers, complying with current exposure criteria, implementing control technology and environmental control programs, improving monitoring, developing protective equipment, and adopting new or improved exposure standards. Ideally, these environmental efforts should be combined at the worksite with efforts to reduce such personal risks as smoking, elevated blood cholesterol, elevated blood pressure, and sedentary lifestyle. Individual situations, however, must dictate the balance between these two approaches.

Better medical, epidemiologic, and toxicologic studies will be needed to determine the specific effects of chemical and physical agents on the cardiovascular system and the interaction of these agents with personal lifestyle factors. An epidemiologic group for cardiovascular disease could be formed within NIOSH to help focus that agency's studies and to coordinate a program with outside groups; coordination with the National Heart, Lung, and Blood Institute will be particularly important. New methods must be developed to screen chemical substances, delineate mechanisms of toxicity, monitor 
exposures, and assess the value of training, education, and information dissemination.

Psychosocial factors: Studies showing an association of work-related psychosocial factors with increased risk of cardiovascular disease have linked specific factors to specific manifestations of disease. Inconsistent results from some of these studies may be due to slightly different methodologies and to lack of control for other risk factors. Further research is sorely needed to determine the specific underlying factors that cause increased risk of cardiovascular disease, to assess workplace psychosocial factors, to determine the job-related stress of new technologies, and to evaluate the effectiveness of programs designed to correct the problems.

Health promotion: Even for occupational and industrial groups with increased risk primarily from personal factors, the prevention of cardiovascular disease related to these factors is a worthy goal. The workplace is a highly attractive site for delivering health promotion and employee assistance programs. Success of such programs will require union and management cooperation, employee involvement, adequate allocation of resources, control at the local level, attention to ethical issues, confidentiality of medical information, and voluntary participation. These programs should be made increasingly available, especially to high risk groups. Structured follow-up and evaluations should be included to assess the overall effectiveness of the efforts.

\section{Summary}

Although our knowledge of the relationship between workplace exposures and cardiovascular disease is incomplete, the morbidity and mortality resulting from cardiovascular disease in this country is extensive. Important steps should be taken now to help reduce this toll. 


\section{References:}

1. The Association of Schools of Public Health under a cooperative agreement with the National Institute for Occupational Safety and Health (1986): Proposed National Strategies for the Prevention of Leading Work-Related Diseases and Injuries, Part 1.

Washington, D.C.

2. CDC (1983): Leading Work-Related Diseases and Injuries--United States (Occupational Lung Diseases). MMWR 32:24-6, 32.

3. CDC (1984): Leading Work-Related Diseases and Injuries--United States (Severe Occupational Traumatic Injuries). MMWR 33:213-5.

4. Danielson $\mathrm{G}$, Edstrom R, Lindh $\mathrm{G}$ (1983): Ordinance Concerning Work Postures and Working Movements. Regulation (AFS 1983:6) issued by the National Board of Occupational Safety and Health. Stockholm, Sweden.

5. National Center for Health Statistics (1986): Monthly Vital Statistics Report. Advance Report of Final Mortality Statistics, 1984. Vol. 35, \#6, Suppl. 2. Washington, D.C.

6. NIOSH (1978): Analysis of data gathered in the National Occupational Hazard Survey, 1972-1974 (unpublished).

7. U.S. Department of Health, Education, and Welfare, Public Health Service (1979): Healthy People: The Surgeon General's Report on Health Promotion and Disease Prevention. Washington, D.C.: Office of the Assistant Secretary for Health, and Surgeon General, DHEW (PHS) Publication No. 79-55071. U.S. Department of Health and Human Services, Public Health Service (1980): Promoting Health/Preventing Disease: Objectives for the Nation. Washington, D.C.: U.S. Government Printing Office. 
Since antiquity, certain chemical and physical agents have been recognized as having detrimental effects on human reproduction. For example, the effect of industrial lead poisoning in inducing abortions was noted by the Romans and again in the first decade of this century (6). Evidence from more recent laboratory studies and clinical investigations indicates that a wide range of microbiologic, physical, and chemical agents, such as Brucella, rubella, ionizing and nonionizing radiation, heat and vibration, tobacco, alcohol, and certain drugs, can adversely affect reproductive outcomes. At least 50 chemicals--including heavy metals, such as lead and cadmium glycol ethers, organohalide pesticides, organic solvents, and chemical intermediates, such as styrene and vinyl chloride--in widespread use in industry have been shown to produce impairment of reproductive functions in animals (7).

Until recently, the potential hazards to human reproduction posed by occupational exposures received little attention. However, adverse effects after thalidomide exposure in the 1960 s and the occurrence in 1970 of methylmercury poisoning among residents of Minamata, Japan, dramatically demonstrated the teratogenic potential of chemical exposures. Those events and the increasing entry of women into the workforce focused greater attention on the potential hazards to female reproductive functions of occupational exposures. In the late 1970 s, the demonstration of sterility among male workers exposed to dibromochloropropane was described; this drew attention to the concomitant potential for hazards to male reproductive function ( 8 ).

Occupational exposures can produce a wide range of adverse effects on reproduction. The effects of parental exposure before conception to agents toxic to reproductive functions may be evident as reduced fertility, unsuccessful fertilization or implantation, or an abnormal fetus.

Maternal exposure after conception may result in death of the fetus or structural and functional abnormalities in the newborn. Other possible adverse outcomes include spontaneous abortions (both early and late), major and minor birth defects, perinatal death, low birth weight, altered sex ratio, developmental or behavioral disabilities, and transplacental exposure to carcinogen (9-11).

Estimates of the prevalence of adverse reproductive outcomes indicate that these events occur with considerable frequency in the U.S. population. For example, an estimated 560,000 infant deaths, spontaneous abortions, and stillbirths occur each year. The March of Dimes estimates that 200,000 live infants with some type of birth defect--benign or disabling--are born in the United States each year (9). The causes of most of these adverse outcomes are unknown. For example, 6-30 percent of the infertile couples have no recognized anatomic or physiologic abnormalities to account for the infertility (10); neither the etiology of sperm abnormalities nor the cause of sister-chromatid exchange in spontaneous abortions has been established $(11,12)$. The causes for as many as $65-70$ percent of the birth defects are not known (13).

Maternal Exposures: Studies of occupational reproductive hazards to date have consisted mainly of epidemiologic surveys of pregnancy outcomes following maternal exposures. Such studies have shown increased rates of spontaneous abortions among laboratory and chemical workers $(14,15)$ and among workers exposed to lead (16), ethylene oxide (17), and anesthetic gases $(18,19)$. Studies of adverse outcomes of pregnancy, however, are subject to several methodologic limitations. For example, the detection of rare outcomes, 
such as birth defects, requires the study of several thousand pregnancies, and retrospective studies are subject to problems of recall and misclassification, both of reproductive events and of exposures $(20,21)$. The timing, duration, and frequency of exposure before and during pregnancy may criticaliy affect reproductive outcomes (22). For example, exposure to ionizing radiation during the first trimester may result in microcephaly and mental retardation, and exposure during the third trimester may produce low birth weight and neonatal death (11). Other studies have been limited by the selection of inadequate comparison groups or the failure to examine the influence of other factors, such as alcohol and tobacco consumption or maternal age, that affect reproductive outcomes.

Paternal Exposures: Since azoospermia (absence of living spermatozoa in the semen) and oligospermia (subnormal concentration of spermatozoa) were reported in 1977 among workers exposed to dibromochloropropane (8), at least 14 studies have examined the quality of semen in workers exposed to lead, carbon disulfide, anesthetic gases, ionizing radiation, toluenediamine, dinitrotoluene, carbaryl, and several other pesticides (10). Adverse effects on the quality of semen were reported in workers exposed to lead or ionizing radiation. In other studies, e.g., of exposures to ethylene dibromide, results were inconclusive because of problems in design of the study or inadequate numbers of participants (10). CDC recently used data collected by the Metropolitan Atlanta Congenital Defects Program to examine the risk of serious structural birth defects among the children of male Vietnam veterans; no statistically excessive risks were noted (23). In general, relatively few studies have been conducted of reproductive outcomes associated with paternal exposures (9).
Extent of potential exposures: Estimates have been made of the number of workers potentially exposed to selected agents known or suspected to be toxic to reproductive function. NIOSH estimates that approximately 200,000 workers are potentially exposed to various glycol ethers (24), several of which exhibit marked testicular toxicity in animals (25). An estimated 9 million workers are exposed to radiofrequency- microwave radiation (26), which has been shown to cause embryonic death and impaired fertility in animals but which has yet to be studied adequately in humans. NIOSH has estimated that approximately 50,000 personnel in hospital operating rooms are potentially exposed to waste anesthetic gases, and 139,000 hospital and other industrial workers may be exposed to ethylene oxide (24); both agents have been linked to an increased risk of spontaneous abortions in humans.

The extent to which occupational exposures in American workers produce adverse reproductive outcomes is largely unknown. However, the information presented here suggests that the problem is both widespread and serious. Epidemiologic and toxicologic research into the reproductive effects of occupational exposures is in its infancy. There is a continuing effort to elucidate the etiology of adverse reproductive outcomes, such as fetal chromosomal abnormalities or abnormal spermatogenesis and to develop improved animal models for screening agents for possible mutagenic and toxic effects related to human reproduction. Registries for the surveillance of outcomes of reproduction, such as CDC's Birth Defects Monitoring Program (9), and improved methodologies developed to evaluate such parameters as 
quality of semen (12) and outcomes of pregnancy (20), will permit further identification of specific occupational hazards to reproduction. When such hazards are identified and controlled in the workplace, the prevention of reproductive disorders in the population as a whole will be substantially improved.

Reported by Industrywide Studies $\mathrm{Br}$, and Surveillance Br, Div of Surveillance, Hazard Evaluations, and Field Studies, National Institute for Occupational Safety and Health, CDC. 


\section{References}

1. CDC. Leading work-related diseases and injuries--United States. MMWR 1983;32:24-6, 32.

2. CDC. Leading work-related diseases and injuries--United States MMWR 1983;32:189-91.

3. CDC. Leading work-related diseases and injuries--United States. MMWR 1984;33:125-28.

4. CDC. Leading work-related diseases and injuries--United States. MMWR 1984;33:213-5.

5. CDC. Leading work-related diseases and injuries--United States. MMWR 1985;34:219-22, 227.

6. Hamilton A. Women in the lead industries. Bureau of Labor Statistics Bulletin No. 253. Washington, D.C.: U.S. Department of Labor, 1919. In: Hunt V. Work and the health of women. Boca Raton, Florida: CRC Press, Inc. 1979.

7. Barlow SM, Sullivan FM. Reproductive hazards of industrial chemicals: an evaluation of animal and human data. London: Academic Press, 1982.

8. Whorton D, Krauss RM, Marshall S, Milby TH. Infertility in male pesticide workers. Lancet 1977;ii:1259-61.

9. Bloom AD, Paul NW, eds. Guidelines for studies of human populations exposed to mutagenic and reproductive hazards: proceedings of conference held January 26-27, 1981, in Washington, D.C. sponsored by Centers for Disease Control. White Plains, New York: March of Dimes Birth Defects Foundation, 1981.

10. Ratcliffe JM. Altered fertility. In: Review of occupational hazards to reproductive health. Geneva, Switzerland: World Health Organization (in press).

11. Strobino BR, Kline J, Stein Z. Chemical and physical exposures of parents: effects on human reproduction and offspring. Early Hum Dev 1978;1:371-99.
12. Wyrobek AJ. Methods for evaluating the effects of environmental chemicals on human sperm production. Environ Health Perspect 1983;48:53-9.

13. Wilson JG. Environment and birth defects. New York: Academic Press, 1973.

14. Strandberg M, Sandback K, Axelson O, Sundell L. Spontaneous abortions among women in hospital laboratory. (Letter) Lancet 1978;i:384-5.

15. Hemminki K, Franssilla E, Vainio $H$. Spontaneous abortions among female chemical workers in Finland. Int Arch Occup Environ Health 1980;45:123-6.

16. Nordstrom S, Beckman L, Nordenson I. Occupational and environmental risks in and around a smelter in northern Sweden. V. Spontaneous abortion among female employees and decreased birth weight in their offspring. Heriditas 1979;90:291-6.

17. Hemminki $K$, Mutanen $P$, Saloniemi I, Niemi ML, Vainio H. Spontaneous abortions in hospital staff engaged in sterilising instruments with chemical agents. Br Med J 1982;285:1461-3.

18. Cohen EN, Gift HC, Brown BW, et al. Occupational disease in dentistry and chronic exposure to trace anesthetic gases. J Am Dent Assoc 1980;101:21-31.

19. Cohen EN, Brown BW, Bruce DL, et al. Occupational disease among operating room personnel: a national study. Anesthesiology 974; 41:321-40.

20. Selevan SG. Design considerations in pregnancy outcome studies of occupational populations. Scand J Work Environ Health 1981;7:76-82.

21. Buffler PA. Some problems involved in recognizing teratogens used in industry. Contributions to epidemiology and biostatistics 1979;1:118-37. 
22. Gordon JE. Assessment of occupational and environmental exposures. In: Bracken, MB, ed. Perinatal epidemiology. New York: Oxford University Press (in press).

23. Erickson JD, Mulinare J, McClain PW, et al. 'Vietnam veterans' risks for fathering babies with birth defects. JAMA 1984;252:903-12.

24. National Institute for Occupational Safety and Health. National

Occupational Hazard Survey. Projected estimates of potentially exposed workers. Cincinnati, Ohio: National Institute for Occupational Safety and Health, December 1977 (DHEW [NIOSH] publication no. 78-114).

25. National Institute for Occupational Safety and Health. Glycol ethers. Current Intelligence Bulletin No. 39. Cincinnati, Ohio: National Institute for Occupational Safety and Health, 1983 (DHHS [NIOSH] publication no. 83-112).

26. Centaur Associates, Inc. final report; study of radio frequency and microwave radiation (phase 1). Prepared for the Occüpational Safety and Health Administration; 1982. 


\section{NEUROTOXIC DISORDERS}

Diseases of the nervous system resulting from toxic exposures in the workplace were known as early as the first century A.D., when Pliny identified palsy as a manifestation of lead poisoning among workers exposed to lead dust (7). In 1557, Jean Fernel linked gingival pigmentation, tremor, and behavioral changes to occupational mercury poisoning (8); in the nineteenth century, Delpech recognized rubber processing as the cause of the bizarre psychoses occurring among French workers who manufactured condoms and balloons in small cottage industries. Later, carbon disulfide was implicated as the specific neurotoxic agent (9).

Industrial hygiene practices have improved in the twentieth century, and some animal models of neurotoxic disease have been developed. In addition, workers who become ill often draw attention to outbreaks of neurotoxic diseases. Despite the prior identification of acrylamide as neurotoxic in animals, its neurotoxicity in humans was first recognized in the 1950s, when several Japanese workers involved in a pilot production project developed peripheral neuropathy (10). During the 1960 s and early 1970s, dozens of cases of neuropathy occurred among Japanese and Italian workers exposed to solutions containing $n$-hexane during the manufacturing of shoes (11). Subsequently, high doses of $n$-hexane were found to be neurotoxic in exposed animals. In the past 15 years alone, outbreaks of serious human neurotoxicity occurred among workers exposed to three substances not previously known to be neurotoxic: the chlorinated hydrocarbon, chlordecone, which caused opsoclonus, tremor, disturbances of gait, and changes in personality (12); and two hexacarbons, methyl-n-butyl ketone and 2-t-butylazo-2-hydroxy-5-methylhexane, both of which caused a predominantly peripheral neuropathy $(13,14)$.
Nature of Neurotoxic Disorders:

Neurotoxic disorders are on the NIOSH list of Ten Leading Work-Related Diseases and Injuries (1) because of their potential severity--as exemplified by the neurotoxicity of chlordecone--and because of the large number of workers potentially at risk. A conservative estimate of the workers exposed full time to one or more neurotoxic agents is 7.7 million (15). The number of potentially neurotoxic chemicals found in the workplace exceeds 850 .

Clinically, symptoms and signs of neurotoxicity can be diverse. Depending on the intensity of exposure, the molecular configuration of the agent, and the mechanism of toxicity, either central or peripheral neurologic effects may predominate. Most neurotoxic chemicals, however, affect both the central and peripheral nervous systems. Because the symptoms of peripheral neuropathy are more specific and the nerves themselves more directly accessible to precise diagnostic examinations, the effects of neurotoxic agents on the peripheral nervous system are usually more easily identified than effects on the central nervous system (CNS). Early symptoms of peripheral neuropathy may include numbness, tingling, or pain in the feet or hands. As the disease progresses, clumsiness or incoordination due to both sensory and motor changes may develop. Production workers may find their ability to do usual work partially or fully impaired. Chemicals used extensively in industry, which cause peripheral neuropathy when present in sufficiently high and persistent concentrations, include: lead, n-hexane, acrylamide, carbon disulfide, mercury, and methyl bromide $(17,18)$. Several chemicals are known to cause selective impairment of cranial-nerve function, including dysfunction of the fifth cranial nerve (trichloroethylene) (18). 
The effects of neurotoxic agents on the CNS present a far wider range of disturbances $(16,18,19)$. At times, the most striking effects are changes in mood and personality (20). High levels of exposure to manganese or carbon disulfide produce psychoses and suicidal tendencies. Delusions and hallucinations may result from exposure to high concentrations of solvents, such as methylene chloride. Manifestations of cognitive dysfunction, such as reduced attention span, lack of alertness, and memory loss, are prominent neurotoxic effects that may occur in addition to personality changes after exposure to many solvents and to asphyxiants, such as carbon monoxide. Other neurologic effects occur under certain restricted conditions of exposure to unique chemical substances.

Although research into the neurobehavioral effects of industrial chemicals is relatively new, early results suggest that occupational neurotoxicity may be a larger problem than previously suspected. Sensitive methods for evaluating subtle losses in cognitive function have only recently been applied to the evaluation of exposed workers. Because of the complexity of the nervous system and the variety of potentially neurotoxic exposures, the true scope of this health hazard in the workplace is unknown.

Studies of the neurotoxicity of workplace chemicals demonstrate the problems encountered in recognizing occupational disease in general. Despite occasional large and dramatic outbreaks of neurotoxic disorders, such as those mentioned above, more often small numbers of workers in many workplaces are chronically exposed to neurotoxic agents that subtly and slowly alter nervous-system functions. Several neurotoxic syndromes mimic diseases of nonoccupational and "idiopathic" etiology, e.g., the toxic axonopathy associated with exposure to various metals and solvents, the parkinsonian syndrome of chronic intoxication with manganese, and the organic brain syndrome of chronic solvent intoxication. Because of these similarities to other nonoccupational diseases, such cases are frequently not identified as occupational in origin. In addition, many physicians are not trained to take an adequate occupational medical history (21). For these reasons, the prevalence of occupational neurologic disease is unknown, and important causal relationships between chemicals and disease remain obscure.

The prevention of neurotoxicity among workers will require strategies such as those suggested in the 1990 Objectives for improving the nation's health (22), developed by the U.S. Public Health Service: (1) analyses of structural analogues of known neurotoxic agents in an effort to predict the neurotoxicity of untested chemicals; (2) continuing search for animal models of disease; (3) ongoing research in establishing an acceptable human exposure level for identified neurotoxic agents; (4) epidemiologic evaluations of suspected neurotoxicity; (5) development of simple screening tools for use on asymptomatic populations exposed to known neurotoxic agents; and (6) premanufacturing and premarket testing of new chemicals as required by the Toxic Substances Control Act (23). As in the prevention of other work-related diseases, however, the most direct and effective method for preventing neurotoxic illness will continue to be the environmental control of exposures to neurotoxic chemicals. Such efforts as the substitution of less toxic substances where possible, engineering controls, teaching appropriate work practices, and educating workers about the potential neurotoxicity of chemicals will aid a comprehensive prevention effort.

Reported by Div of Biomedical and Behavioral Science, and Div of Surveillance, Hazard Evaluations, and Field Studies, National Institute for Occupational Safety and Health, CDC. 
1. CDC. Leading work-related diseases and injuries--United States. MMWR 1983;32:24-6, 32.

2. CDC. Leading work-related diseases and injuries--United States. MMWR 1983;32:189-91.

3. CDC. Leading work-related diseases and injuries--United States. MMWR 1984;33:125-8.

4. CDC. Leading work-related diseases and injuries--United States. MMWR 1984;33:213-5.

5. CDC. Leading work-related diseases and injuries--United States. MMWR 1985;34:219-22, 227.

6. CDC. Leading work-related diseases and injuries--United States. MMWR 1985;34:537-40.

7. Hunter D. The diseases of occupations. Sixth edition. London: Hodder and Stoughton, 1978;251.

8. Chang LW. Mercury. In: Spencer PS, Schaumburg HH, eds. Experimental and clinical neurotoxicology. Baltimore, Maryland: Williams \& Wilkins, 1980;508-26.

9. Seppalainen AM, Haltia M. Carbon disulfide. In: Spencer PS, Schaumburg $\mathrm{HH}$, eds. Experimental and clinical neurotoxicology. Baltimore, Maryland: Williams \& Wilkins, 1980;356-73.

10. Le Quesne PM. Acrylamide. In: Spencer PS, Schaumburg HH, eds. Experimental and clinical neurotoxicology. Baltimore, MD

11. Spencer PS, Couri D, Schaumburg HH. n-hexane and methyl n-butyl ketone. In: Spencer PS, Schaumburg HH, eds. Experimental and clinical neurotoxicology. Baltimore, Maryland: Williams \& Wilkins, 1980;456-75.

12. Taylor JR, Selhorst JB, Calabrese VP. Chlordecone. In: Spencer PS, Schaumburg $\mathrm{HH}$, eds. Experimental and clinical neurotoxicology. Baltimore, Maryland: Willias \& Wilkins, 1980;0407-21.
13. Allen N, Mendell JR, Billmaier DJ, Fontaine RE, O'Neill JO. Toxic polyneuropathy due to methyl n-butyl ketone. An industrial outbreak. Arch Neurol 1975;32:209-18.

14. Horan JM, Kurt TL, Lanđrigan $\overline{\mathrm{PJ}}$, Melius JM, Singal M. Neurologic dysfunction from exposure to 2-t-butylazo-2-hydroxy-5-methylhexane (BHMH): a new occupational neuropathy. Am J Public Health 1985;75:513-7.

15. National Institute for Occupational Safety and Health. National Occupational Hazard Survey, 1972-74. Cincinnati, Ohio: National Institute for Occupational Safety and Health, 1977. (DHEW [NIOSH] publication no. 78-114).

16. Anger WK, Johnson BL. Chemicals affecting behavior. In: O'Donoghue JD, ed. Neurotoxicity of Industrial and Commercial Chemicals. Boca Raton, Florida: CRC Press (in press).

17. O'Donoghue JL, Nasr AN, Raleigh RL. Toxic neuropathy--an overview. J Occup Med 1977;19:379-82.

18. Baker EL. Neurologic and behavioral disorders. In: Levy BS, Wegman DH, eds. Occupational health: recognizing and preventing work-related disease. Boston: Little, Brown and Co., 1983: 317-30.

19. Johnson BL, Baker EL, Gilioli R, Xintaras C, eds. Prevention of neurotoxic illness in working populations. Geneva: World Health Organization (in press).

20. Baker EL, Bus JS, Cranmer JM, et al. Workshop on neurobehavioral effects of solvents--consensus summary. Neurotoxicology 1985;6:99-102.

21. Goldman RH, Peters JM. The occupational and environmental health history. JAMA 1981;246:2831-6. 
22. U.S. Public Health Service.

Occupational safety and health. In:

Promoting health/preventing disease:

objectives for the nation. Washington,

D.C.: U.S. Department of Health and Human Services, Fall 1980; 39-43.

23. Toxic Substances Control Act. Public

Law No. 94-469, 90, Stat. 2003, 1976.

Maryland: Williams \& Wilkins, 1980;309-25. 
Occupational deafness was first documented among metalworkers in the sixteenth century (8). Since then, workers have experienced excessive hearing loss in many occupations associated with noise. Noise-induced loss of hearing is an irreversible, sensorineural condition that progresses with exposure. Although hearing ability declines with age (presbycusis) in all populations, exposure to noise produces hearing loss higher than that resulting from the natural aging process; this is caused by damage to nerve cells of the inner ear (cochlea) and, unlike some conductive hearing disorders, cannot be treated medically.

While loss of hearing may result from a single exposure to a very brief impulse noise or explosion, such traumatic losses are rare. In most cases, noise-induced hearing loss is insidious. Typically, it begins to develop at 4,000 hertz ( $\mathrm{Hz}$, or cycles per second) in the hearing range of $20 \mathrm{~Hz}$ to $20,000 \mathrm{~Hz}$ and spreads to lower and higher frequencies. Often, material impairment has occurred before the condition is clearly recognized.

Such impairment is usually severe enough to permanently affect a person's ability to hear and understand speech under everyday conditions. Although the primary frequencies of human speech range from $200 \mathrm{~Hz}$ to $2,000 \mathrm{~Hz}$, research has shown that the consonant sounds, which enable people to distinguish words such as "fish" from "fist," have still higher frequency components. As a result, an average hearing threshold (lowest audible sound level) at separate frequencies of $1,000 \mathrm{~Hz}$, $2,000 \mathrm{~Hz}$, and $3,000 \mathrm{~Hz}$ is used widely to define material impairment caused by noise $(10,11)$. Recent estimates by the Occupational Safety and Health Administration (OSHA) indicate that about $9,400,000$ U.S. production workers (7,900,000 active and 1,500,000 retired) either now work or have worked in industrial locations where noise-exposure levels are 80 decibels (dBA) or higher. This estimate includes most noisy workplaces in the United States, except agricultural, mining, construction, transportation, and government (11). At exposure levels below 80 decibels (weighted to the approximate response of the human ear), an increased risk of hearing loss caused by occupational noise has not been found. Based on the average hearing threshold level at $1,000 \mathrm{~Hz}$, $2,000 \mathrm{~Hz}$, and $3,000 \mathrm{~Hz}$, OSHA estimates that $1,624,000$ (17 percent) production workers have at least mild hearing loss resulting from their occupational noise exposures; $1,060,000$ (11 percent) have material hearing impairment; and 473,000 (5 percent) have moderate to severe impairment (11). These estimates generally agree with NIOSH survey findings, which indicate that one-fourth of persons 55 years of age or older who have been exposed over their working lifetime to an average of about $90 \mathrm{dBA}$ have developed a material hearing impairment caused by occupational noise exposure $(10,12)$. An estimated $\$ 835$ million will be paid in workers' compensation claims for occupational hearing impairment for the 10 -year period 1978-1987 (13).

Occupational noise-induced loss of hearing is preventable. In its 1990 Objectives for the Nation, the U.S. Public Health Service set an objective that "By 1990, the prevalence of occupational noise-induced hearing loss should be reduced to 415,000 cases" (14). This objective relates to the number of cases of hearing loss that result in moderate to severe impairment. However, it is important to note that if the number of moderate to severe impairments is reduced, the number of mild hearing loss and of material impairments would be reduced proportionately. OSHA has estimated that 
within 10 years, the number of cases of noise-induced hearing impairment can be reduced by 20 percent if all workers exposed to noise levels higher than $85 \mathrm{dBA}$ wear personal hearing protectors (earplugs or muffs) and receive on the average a $15 \mathrm{dBA}$ noise reduction (11). However, this estimate hinges on effective use of hearing protectors to an extent that has not yet been demonstrated for all workers. NIOSH field investigations of industrial workers who routinely use earplugs indicate average noise reduction ranging from $7 \mathrm{dBA}$ to $20 \mathrm{dBA}$, depending on the type of plug used (15).

A noise-control/hearing-conservation program is the most important step in eliminating occupational hearing loss. Such a program must include:

1. Reduction of noise through engineering controls, and the purchase of new, noise-engineered equipment.

2. Proper fit of personal hearing-protection devices.

3. Education of workers and managers about certain characteristics of noise-induced loss of hearing.

4. Proper periodic audiometric testing and notification of workers who are developing hearing loss.

5. Visible commitment of management and workers to the program.

The joint efforts of management, labor, and health-care providers are needed to establish effective hearing-conservation programs in industry. All interested groups must work together to achieve the goal of protecting workers' hearing.

Reported by Physical Agents Effects Br, Div of Biomedical and Behavioral Science, National Institute for Occupational Safety and Health, CDC. 
1. CDC. Leading work-related diseases and injuries--United States. MMWR 1983;32:24-6, 32.

2. CDC. Leading work-related diseases and injuries--United States. MMWR 1983;32:189-91.

3. CDC. Leading work-related diseases and injuries--United States. MMWR 1984;33:125-8.

4. CDC. Leading work-related diseases and injuries--United States. MMWR 1984;33:213-5.

5. CDC. Leading work-related diseases and injuries--United States. MMWR 1985;34:219-22, 227.

6. CDC. Leading work-related diseases and injuries--United States. MMWR 1985;34:537-40.

7. CDC. Leading work-related diseases and injuries--United States. MMWR 1986;35:113-6, 121-3.

8. Alberti (1591), cited by Bunch CC. Traumatic deafness.

In: Fowler EP Jr, ed. Medicine of the ear, Chapter X (Reprinted, Translations of the Beltone Institute for Hearing Research, No. 23, 1970).

9. Michael PL. Physics of sound.

In: NIOSH. The industrial environment--its evaluation and control. Cincinnati, Ohio: National Institute for Occupational Safety and Health, 1973.

10. NIOSH. Criteria for a recommended standard . . . occupational exposure to noise. Department of Health, Education, and Welfare, Health Services and Mental Health Administration, 1972; (NIOSH) publication no. HSM 73-11001.

11. Occupational Safety and Health Administration. Final regulatory analysis of the hearing conservation amendment. Department of Labor, 1981, GPO No. 723-860/752 1-3.
12. Schmidek ME, Layne MA, Lempert BL, Fleming RF. Survey of hearing conservation programs in industry. Cincinnati, Ohio: National Institute for Occupational Safety and Health, 1975; HEW publication no. (NIOSH) 75-178.

13. Ginnold RE. Occupational hearing loss. Workers compensation under state and federal programs. Environmental Protection Agency report no. EPA 550/9-79-101, 1979.

14. U.S. Public Health Service. Promoting health/preventing disease: objectives for the nation. Washington, D.C.: Department of Health and Human Services, 1980;39-43.

15. Lempert BL, Edwards RG. Field investigations of noise reduction afforded by insert-type hearing protectors. Am Ind Hyg Assoc J 1983;12:894-902. 


\section{DERMATOLOGICAL CONDITIONS}

A worker's skin is directly exposed to the occupational environment and is susceptible to a large number of dermatological injuries and other conditions. Complete data on the extent and cost of dermatological injuries are not available; however, dermatological conditions other than injuries accounted for 37 percent of the 106,100 occupational illnesses recorded in 1983 in the Bureau of Labor Statistics (BLS) Annual Survey of Occupational Injuries and Illnesses (1). Results from the BLS Annual Survey for 1972-1976 indicated that 20-25 percent of all occupational dermatological conditions resulted in lost time from work (average 10-12 lost workdays) (2). Similar data based on workers' compensation claims have been reported from California and South Carolina $(3,4)$. Assuming that only 2-10 percent of cases are actually reported, the annual cost of occupational dermatological conditions resulting from lost worker productivity, medical care, and disability payments may range between $\$ 222$ million and $\$ 1$ billion $(5,6)$.

Because 10-15 percent of requests that NIOSH receives for health hazard evaluations involve skin complaints, and because the economic impact of work-related dermatological conditions is substantial, NIOSH has included dermatological conditions on its list of Ten Leading Work-Related Diseases and Injuries in the United States (7).

Dermatological Injuries: Dermatological injuries are usually described as the immediate adverse effects on skin that result from instantaneous trauma or brief exposure to toxic agents involving a single incident in the work environment (1). Skin injuries may constitute 23-35 percent of all injuries $(8,9)$. Thus, based on $4,748,000$ injuries of all types, and a full-time worker population of $74,750,000$ for 1983 (1), an estimated 1,070,000-1,650,000 dermatological injuries may occur yearly, with an estimated annual rate of skin injury of 1.4-2.2 per 100 full-time workers. The highest percentage of skin injuries are due to lacerations/ punctures (82 percent), followed by burns (chemical and other) (14 percent) (8).

Other Dermatological Conditions: Other dermatological conditions, "illnesses of the skin," may also result from exposure to environmental factors or toxic agents associated with employment. However, they usually result from more sustained or cumulative exposures and involve longer intervals between exposure and occurrence of disease. These conditions include contact dermatitis, infection, acne, and skin cancer. Workers' compensation claims data from California suggest that 95 percent of these occupational skin conditions are either contact dermatitis ( 90 percent) or infections (5 percent) (3). Field investigations in the 1950s showed that at least 80 percent of occupational contact dermatitis cases may be caused by the irritating direct cytotoxic effects of causal agents rather than immunologically mediated allergic reactions (10). The highest number of other occupational skin conditions $(23,017)$ in 1984 occurred in the manufacturing sector; the highest incidence rate $(28.5 / 10,000$ full-time workers) involved the combined agriculture/forestry/fishing division. The clinical course for occupational contact dermatitis is relatively poor. In three studies, complete resolution occurred in 25 percent of workers affected; 50 percent improved but had periodic recurrences; and 25 percent developed persistent dermatitis as severe as or worse than the original condition (11-13). Contact dermatitis often necessitates job changes or modifications. Despite these, however, complete resolution may occur in only a limited proportion of cases. 
Prevention of Work-Related Dermatological

Disorders: The most effective prevention

measures are engineering controls that

eliminate exposures of the skin to chemical, physical, or mechanical agents through isolation, containment, or redesign of industrial processes. Substitution of less toxic substances through chemical engineering may also be effective (14). Protective clothing should be selected on the basis of resistance to both chemical and physical hazards, as well as on the relative permeabilities to specific chemical exposures. Effective cleaning of skin and clothing is important, but workers should not wash vigorously or excessively with harsh soaps and detergents (15). Barrier creams have been suggested as alternatives, although their effectiveness has not yet been established (16). Prevention strategies should always include education of workers and management.

Expanded activities concerning occupational dermatological conditions include improved methods for surveillance of occupational skin disease and vigorous research in dermatotoxicology to identify preventable risk factors and facilitate effective interventions at early stages.

Reported by Div of Periodic Surveys and Supplementary Data Systems, Office of Occupational Health and Safety Statistics, Bureau of Labor Statistics, US Dept of Labor; Occupational Dermatology Activity, Industrywide Studies $\mathrm{Br}$, Surveillance $\mathrm{Br}$, Div of Surveillance, Hazard Evaluations, and Field Studies, Data Analysis Section, Div of Safety Research, National Institute for Occupational Safety and Health, CDC. 
1. Bureau of Labor Statistics. Occupational injuries and illnesses in the United States by industry, 1983. Washington DC: US Department of Labor, Bureau of Labor Statistics, June 1985.

2. Wang CL. Occupational skin disease continues to plague industry. Monthly Labor Review 1979;102:17-22.

3. Occupational Disease Statistics Unit, Division of Labor Statistics and Research. Occupational skin disease in California (with special reference to 1977). San Francisco: California Department of Industrial Relations, 1979.

4. Keil JE, Shmunes E. The epidemiology of work-related skin disease in South Carolina. Arch Dermatol 1983;119:650-4.

5. National Institute for Occupational Safety and Health, Office of Health Surveillance and Biometrics, National Occupational Hazard Survey. Pilot study for development of an occupational disease surveillance method. Rockville, Maryland: National Institute for Occupational Safety and Health, 1975, HEW (NIOSH) publication no. 75-162.

6. Mathias CG. The cost of occupational skin disease. Arch Dermatol 1985;121:332-4.

7. CDC. Leading work-related diseases and injuries--United States. MMWR 1983;32:24-6, 32.

8. Bureau of Labor Statistics.

Supplementary data system. Unpublished data.

9. Consumer Product Safety Commission. National Electronic Injury Surveillance System. Unpublished data.

10. Schwartz L, Tulipan L, Birmingham DJ. Occupational diseases of the skin. 3rd ed. Philadelphia: Lea and Febiger, 1957.
11. Hellier FF. The prognosis in industrial dermatitis. $\mathrm{Br}$ Med J 1958;1:196-8.

12. Burrows D. Prognosis in industrial dermatitis. Br J Dermatol 1972;87:145-8.

13. Fregert S. Occupational dermatitis in a 10-year period. Contact Dermatitis 1975;1:96-107.

14. Adams RM. Allergen replacement in industry. Cutis 1977;20:511-6.

15. Mathias CG. Contact dermatitis: when cleaner is not better. Occup Health Saf 1984;Jan:45-50.

16. Orchard S. Barrier creams. Dermatol Clin 1984;2:619-29. 
There is increasing evidence that an unsatisfactory work environment may contribute to psychological disorders. Studies have shown that factors contributing to an unsatisfactory work environment may include work overload, lack of control over one's work, nonsupportive supervisors or co-workers, limited job opportunities, role ambiguity or conflict, rotating shiftwork, and machine-paced work (1-4). Psychological disorders that can result from such factors may be classified as a) affective disturbances, e.g., anxiety, irritability, b) behavioral problems, e.g., substance abuse, sleep difficulties, c) psychiatric disorders, e.g., neuroses, and d) somatic complaints, e.g., headache, gastrointestinal symptoms. In addition to psychological disorders, stressful working conditions may have a systemic influence, possibly affecting the etiology and/or prognosis of other disease states, as suggested by recent studies of stress-related immunologic suppression (5).

Although databases currently available for determining the extent of work-related psychological disorders are limited, several indicators suggest that these problems impose substantial health and financial costs in the United States. A recent study in California showed that claims for the development of "work-related neuroses" more than doubled during 1980-1982; claims for all other disabling work-related injuries during the same period actually decreased by about one-tenth (6). A study of representative medical claims throughout the country showed that during 1980-1982 claims for "mental stress" that developed gradually, e.g., a chronic problem unrelated to a single traumatic incident or to any physical work-related disorder accounted for about 11 percent of all occupational disease claims (7). Average medical costs and indemnity payments in 1981-1982 for these forms of mental stress actually surpassed the average amounts for other occupational diseases (7). The American Psychiatric Association now lists occupational stress in its Diagnostic and Statistical Manual as a subcategory of the major diagnostic axis of "psychosocial stress" (8).

There are increasing data on the relationship between specific working conditions and psychological disorders. For example, in a questionnaire survey of over 2,000 workers in 23 different occupations, strong occupational differences were found in psychosocial job stressors and in somatic and affective complaints (1). Ratings of boring, repetitive job tasks and role ambiguity were more prominent among several classes of blue-collar workers, e.g., assembly-line workers, fork-lift truck drivers, and machine operators, than among white-collar professionals, e.g., professors and family physicians. The most satisfied occupational groups were physicians, professors, and white-collar supervisors. Groups experiencing the highest levels of job stressors and their resultant ill effects were assemblers and relief workers on machine-paced assembly lines. NIOSH investigators ranked 130 occupations by rate of admission to community mental health centers in Tennessee to determine the relative risk of psychological or stress-related disorders by occupation (9). Heading the list were jobs in health care, service occupations, and blue-collar factory work--which tend to be characterized by stress-producing conditions such as a lack of control over the job by the worker, repetitive work, shift work, and a responsibility for others. In other studies, workers on night and rotating shifts (including the health-care occupations) reported more disturbances of sleep, altered eating habits, and higher rates of visits to clinics, absences due to sickness, and on-the-job injuries than did those on fixed day shifts (10-12). 
Work environments characterized by technological innovation have also been investigated; a major focus has been on office work influenced by the introduction of computers $(13,14)$. Adverse working conditions, e.g., poorer physical environment, reduced job control, and social support tend to be reported more frequently by workers using new technology office equipment such as video display terminals. Some of these conditions have been linked to chronic stress-related disorders $(4,15)$.

Worksite studies by NIOSH have revealed that job stresses may contribute to acute disturbances among groups of workers, including those termed "mass psychogenic illness" (16). The sudden appearance of symptoms, usually in response to some "trigger factor" such as a strange odor, may result in spread of the apparent "illness" throughout the plant, with symptoms such as headaches, dizziness, and nausea. Investigations often fail to detect specific physical or chemical causative agents. However, factors such as heavy work load, strained labor/management relations, and physical discomfort at work may be present and related to the reporting of symptoms.

Emerging trends in technology, the economy, and demographic characteristics of the work force may lead to increased risk for psychological disorders. For example, a 26 percent increase is projected for employment in the health services, an area that may be associated with elevated risk $(9,17)$. Computers and robots are expected to affect 7 million factory jobs and 39 million office jobs (18). According to some forecasters (18), possible consequences may include job displacement, reduced skill requirements, and lower-paying jobs. It has been projected that in the next decade, nine of every ten new jobs will be in the service sector (19). Routine service jobs may not provide the compensation and benefits associated with the more traditional industrial and manufacturing jobs (18). Six of ten new jobs in the next decade will be filled by women (19), and dual job/home role demands and constrained occupational opportunities for women may result in an adverse impact on their mental health.

A prevention strategy for psychological disorders should take into account both the causal mechanisms and the factors that perpetuate these disorders. Work-related psychological disturbances are known to be influenced by both the physical and psychosocial characteristics of given job situations. Moreover, these factors operate in concert with factors unrelated to the job, such as life events; familial demands and support; and the traits, capacities, and needs of the workers themselves, e.g., personality, age, sex, experience/learning. The interaction of these variables is complex, and the relative influence of each is not thoroughly understood. Nevertheless, approaches to prevent work-related psychological disorders should still be taken using the information currently available.

Stress-reduction techniques, e.g., meditation, biofeedback, muscle relaxation, cognitive restructuring, and anxiety management have been taught to both blue- and white-collar workers in work-site training sessions. Follow-up studies have shown decreases in psychophysiologic activity, e.g., muscle tension and blood pressure levels, and reductions in subjective reports of anxiety, sleep disturbances, and other health complaints with each technique (20). However, improvement in all these parameters persisted less than 3 months after training ended.

Stress management treats only the symptoms of the problem--not the cause. Therefore, efforts to control risk factors at the worksite are also important. Some previously described suggestions for controlling worksite risk factors for psychological disorders are listed below (21). These suggestions appear to have merit for 
reducing work-related psychological disorders, but further evaluation and study are needed for a complete understanding of their impact.

Work schedule: Design work schedules to avoid conflict with demands and responsibilities unrelated to the jot.

Schedules for rotating shifts should be stable and predictable, with rotation in a forward (day-to-night) direction.

Participation/control: Allow workers to provide input for decisions or actions affecting their jobs.

Workload: Ensure assignments are compatible with the capabilities and resources of the worker, and allow for recovery from especially demanding physical or mental tasks.

Content: Design tasks to provide meaning, stimulation, a sense of completeness, and an opportunity to use skills.

Roles: Define work roles and responsibilities clearly.

Social environment: Provide opportunities for social interaction, including emotional support and help directly related to one's job.

Future: Avoid ambiguity in matters of job security and career development.

In addition to evaluation of these suggested actions, efforts are needed to advance the understanding of work-related psychological disorders and of methods appropriate for their control, including:

1. Improving the systems for surveillance of psychological disorders in the work force as related to working conditions.

2. Improving research techniques for investigating stressful working conditions and their health consequences.
3. Improving training of occupational health professionals and workers in recognizing stressful workplace conditions and signs of worker stress and in effecting remedial measures.

4. Furthering the development of mental health components in occupational health and safety programs.

Reported by Div of Biomedical and Behavioral Science, National Institute for Occupational Safety and Health, CDC. 
1. Caplan RD, Cobb S, French JR, Harrison RV, Pinneau SR. Job Demands and Worker Health: main effects and occupational differences. Cincinnati, Ohio: National Institute for Occupational Safety and Health. (DHEW [NIOSH] publication no. 75-160), 1975.

2. Holt RR. Occupational stress. In: Goldberger L, Bresnitz S, eds. Handbook of Stress. New York: The Free Press, 1982.

3. Beehr TA, Newman JE. Job stress, employee health, and organizational effectiveness: a facet analysis, model, and literature review. Personnel Psychology 1978;31:665-99.

4. Karasek RA. Job demands, job decision latitude, and mental strain. Journal of Occupational Behavior 1979;24:285-307.

5. Kiecolt-Glaser JK. Stress and the immune function. In: Measures of job stress: a research methodology workshop. Workshop sponsored by NIOSH, New Orleans, Louisiana, 1985.

6. California Workers' Compensation Bulletin, April 20, 1983.

7. National Council on Compensation Insurance. Emotional stress in the workplace--new legal rights in the eighties. New York 1985.

8. American Psychiatric Association. Diagnostic and Statistical Manual of Mental Disorders, 3rd ed. Washington, DC: American Psychiatric Association, 1980.

9. Colligan MJ, Smith MJ, Hurrell JJ Jr. Occupational incidence rates of mental health disorders. J Human Stress 1977;3:34-9.

10. Smith MJ, Colligan MJ, Frockt IJ, Tasto DL. Occupational injury rates among nurses as a function of shift schedule. Journal of Safety Research 1979;11:181-7.
11. Colligan MJ, Frockt IJ, Tasto DL. Frequency of worksite clinic visits and sickness absence among nurses as a function of shift. Applied Ergonomics 1979;10:79-86.

12. Smith MJ, Colligan MJ, Tasto DL. Health and safety consequences of shift work in the food processing industry. Ergonomics 1982;25:133-44.

13. Smith MJ, Cohen BG, Stammerjohn LW. An investigation of health complaints and job stress in video display operations. Human Factors 1981;23:387-400.

14. Sauter S, Gottlieb M, Jones C, Dodson V, Rohrer K. Job and health implications of VDT use: initial results of the Wisconsin-NIOSH study. Communications of the ACM 1983;26:784-94.

15. House JS, Wells JA. Occupational stress, social support, and health. In: McLean A, Black G, Colligan M, eds. Reducing Occupational Stress: Proceedings of a Conference. Washington, DC, 1978. (DHEW publication no. 78-140.)

16. Schmitt N, Colligan MJ, Fitzgerald $M$. Unexplained physical symptoms in eight organizations: individual and organizational analyses. Journal of Occupational Psychology 1980;53:305-17.

17. Silvestri GT, Lukasiewicz JM. Occupational employment projections: the 1984-95 outlook. Monthly Labor Review, November 1985:42-57.

18. Bezold C, Carlson RJ, Peck JC. The future of work and health. Dover, Massachusetts Auburn House, 1986. 
19. Bureau of Labor Statistics. Bureau of Labor Statistics News.

Washington, DC: Department of Labor, November 1985.

20. Murphy LR. Occupational stress management: review and appraisal. Journal of Occupational Psychology.

21. Levi L. Preventing Work Siress.

Reading, Massachusetts:

Addison-Wesley, 1981. 


\title{
NIOSH PROJECTS BY PROGRAM AREAS
}

\author{
Occupational Lung Diseases \\ Musculoskeletal Injuries \\ Occupational Cancers \\ Severe Occupational Traumatic Injuries \\ Occupational Cardiovascular Diseases \\ Disorders of Reproduction \\ Neurotoxic Disorders \\ Noise-Induced Hearing Loss \\ Dermatological Conditions \\ Psychological Disorders \\ Agriculture-Related Projects \\ Construction-Related Projects \\ Assistance Requests \\ Administration
}

Other 


\section{EVALUATION OF MESOTHELIOMA PRODUCTION BY ASBESTOS SUBSTITUTES}

Purpose: This project will evaluate the toxicity/carcinogenicity of two modified chrysolite asbestos products which have been proposed as safe substitutes for asbestos through intrapleural implantation in rats. The toxicity/carcinogenicity of these substitute materials will be evaluated and compared to untreated asbestos materials.

DBBS, Stanley F. Platek

CAN 376 Dates: 10/84-09/92

\section{ASBESTOS REMOVAL CONTROL TECHNOLOGY ASSESSMENT}

Purpose: This work evaluates glove bags, a control to prevent asbestos release into the work environment during removal of pipe lagging. Limitations of this control and ways to overcome them will be identified and disseminated to personnel doing asbestos abatement work.

DPSE, Phillip A. Froehlich

CAN 408 Dates: 10/84-09/91

\section{IMPLEMENT ASBESTOS CONTROLS DURING BRAKE SHOE REPLACEMENT}

Purpose: This project will disseminate NIOSH evaluated asbestos controls for the brake shoe replacement industry through the use of technology transfer agents in the Ohio Community College System.

DPSE, Theodore F. Schoenborn

CAN 409 Dates: 01/88-09/92

\section{CONTROL OF EXPOSURES DURING AUTO BODY REPAIR}

Purpose: This project will document, develop, and disseminate appropriate control measures to protect workers from the health hazards of auto body repair.

DPSE, William A. Heitbrink

CAN 410 Dates: 10/90-09/93

\section{ANALYTICAL METHODS FOR INORGANIC SUBSTANCES}

Purpose: In response to needs arising from NIOSH Prevention Strategies, analytical methods for inorganic or organic substances in air or other matrices will be developed. Also, new analytical chemistry techniques will be evaluated for application to industrial hygiene sampling and analytical needs.

DPSE, Eugene R. Kennedy CAN 413 Dates: $01 / 86-C$

\section{IDENTIFICATION OF INTERVENTION POINTS IN WOOD DUST EXPOSURE}

Purpose: The study results will be used by DPSE/MCRB to prioritize equipment for control development and to evaluate specific high-exposure tasks. Work practices to lower risk may be identified.

DPSE, Thomas C. Cooper

CAN 414 Dates: 10/90-09/91 


\section{TECHNOLOGY TRANSFER FOR DPSE PROJECTS}

Purpose: This project will transfer the technology developed in DPSE so that control and monitoring innovations are widely available for adoption, and patentable discoveries are commercialized to ensure the widest possible usage.

DPSE, Theodore F. Schoenborn

CAN 416 Dates: 10/87-C

\section{APPLICATION OF PROCESS HAZARD ANALYSIS FOR AGRICULTURAL CHEMICALS}

Purpose: This project will identify and recommend preventive measures for ammonia releases in agricultural applications.

DPSE, Amy A. Beasley

CAN 423 Dates: 10/89-09/91

\section{HHE ANALYTICAL CHEMISTRY SUPPORT}

Purpose: This project provides timely analytical chemistry services to the HHE program by assuring rapid turnaround of requests for sample analyses and method development. It is projected that 6,900 HHE field samples will be analyzed and 4 sampling/analytical methods will be developed or modified under this project during FY 1990.

DPSE, John L. Holtz CAN 425 Dates: $10 / 85-C$

\section{MINING AND RESPIRATORY DISEASE RESEARCH ANALYTICAL SUPPORT}

Purpose: This project will provide analytical chemistry support to mining investigations, respiratory disease studies, and safety research. Analytical chemistry support will be given to studies of fibrous minerals combined with other mineral dust. Analytical support to NOHS mining will be completed during FY 1990.

DPSE, Donald D. Dollberg CAN 426 Dates: 10/84-C

\section{PILOT STUDY: EVALUATION OF PROCESS CONTAINMENT FOR BIOAEROSOLS}

Purpose: This project will identify improved methods of evaluating bioprocess containment and identify specific equipment for evaluation.

DPSE, Paul A. Jensen

CAN 429 Dates: 10/86-09/91

\section{A NATIONAL CONSTRUCTION INDUSTRY CONTROL TECHNOLOGY DATABASE}

Purpose: This project will evaluate the feasibility of a national database, potentially including physical, biological, and chemical agents, as well as chronic trauma.

DPSE, James A. Gideon

CAN 434 Dates: 10/89-C 


\section{A METHOD FOR SAMPLING AND ANALYSIS OF INDOOR AIR FOR ORGANIC COMPOUNDS}

Purpose: The sampling and analytical method developed will provide data on worker exposure to vapor-phase organic compounds found in indoor air. These data will be used by the Industrial Hygiene Community to study health effects reported in exposed populations. Results of these studies will provide recommendations for exposure reduction.

DPSE, Eugene R. Kennedy

CAN 436 Dates: 10/89-12/92

\section{ANALYTICAL METHODS FOR ORGANIC COMPOUNDS}

Purpose: Analytical methods for organic and inorganic compounds in workplace air and other matrices of industrial hygiene interest will be developed. New analytical chemistry techniques will be evaluated for application to industrial hygiene problems. This will advance the state of the art of identifying and quantifying worker exposure to toxic chemicals.

DPSE, Robert A. Lunsford

CAN 437 Dates: 10/82-C

\section{ANALYTICAL METHOD FOR TOTAL ISOCYANATE IN AIR}

Purpose: An analytical method for total isocyanate group in workplace air will be developed. In addition to accurately measuring worker exposure, this method will enable the investigation of the importance that exposure to prepolymer isocyanate and polyurethane-bound isocyanate has on worker health.

DPSE, Robert P. Streicher

CAN 439 Dates: 10/89-09/92

\section{METHODS FOR EVALUATING INDOOR AIR VENTILATION SYSTEMS}

Purpose: This project will develop and document procedures to effectively evaluate building ventilation systems and to provide the necessary information to correct the problems.

DPSE, Mazen Y. Anastas

CAN 442 Dates: 10/88-09/91

\section{EVALUATION OF TOXIC GAS MONITORS FOR INDOOR AND WORKPLACE AIR}

Purpose: By conducting laboratory and field evaluations of portable instrumentation, the project will provide data and information on the application and maintenance of gas monitors in an indoor air or workplace monitoring situation.

DPSE, Jerome P. Smith

CAN 443 Dates: 10/89-09/92

\section{REVISION OF THE NIOSH MANUAL OF ANALYTICAL METHODS}

Purpose: This project provides a collection of current NIOSH analytical methods for use in health hazard evaluations, industry-wide studies, and control technology assessments.

DPSE, Peter M. Eller

CAN 445 Dates: 10/82-C 


\section{ANALYTICAL METHODS FOR ASBESTOS FIBERS}

Purpose: The project will investigate methods 7,400 and 7,402 and suggest improvements if needed. Automated fiber counting and standard analytical techniques will be evaluated for interferences. Techniques for preparing specific-size fractions of asbestos fibers will be evaluated.

DPSE, Paul A. Baron

CAN 448 Dates: 10/84-09/91

\section{PARTICLE SAMPLER PERFORMANCE TESTING}

Purpose: This goal will be accomplished by producing sampler performance criteria and associated testing. Freedom from instrumentation specification will provide the flexibility necessary for the development of new samplers. Flexibility with no compromise of performance is expected because of new instrumentation available.

DPSE, David L. Bartley

CAN 455 Dates: 10/89-09/92

\section{QUALITY ASSURANCE (EXTERNAL)}

Purpose: NIOSH will continue to rate laboratories in the PAT program, a joint project of NIOSH and AIHA. Proficiency ratings are based on the analytical results reported for quality audit samples that include carcinogens (e.g., asbestos and benzene). In addition, laboratory performance will be documented in publications.

DPSE, Jensen H. Groff

CAN 458 Dates: $10 / 82-\mathrm{C}$

\section{MAINTENANCE AND CALIBRATION}

Purpose: This project will: (1) provide repair, calibration of field and direct-reading equipment for (DPSE ECTB, DSHEFS

IWSB, DTMD, and some state labs);

(2) provide electronic repair and fabrication support for direct-reading instrument development; (3) complete final version of a system for wireless transmission of environmental data in the workplace.

DPSE, Ronald Kovein

CAN 459 Dates: $10 / 82-C$

\section{GAS AND VAPOR MEASUREMENT TECHNIQUES}

Purpose: The photo-optical study may lead to a very versatile system for surveillance of airborne pollutants in the workplace, producing real-time mapping of pollutants, improving estimates of personal exposure, and evaluating effectiveness of control methods.

DPSE, Harley V. Piltingsrud

CAN 496 Dates: 10/84-12/90

\section{PULMONARY RESPONSE TO COTTON DUST}

Purpose: This project will validate and extend an animal model for byssinosis, develop more sensitive measurements of human response, and determine the effectiveness of various treatments of cotton in removing the etiologic agent.

DRDS, Vincent Castranova CAN 102 Dates: 10/88-09/91 


\section{ENDOTOXIN DETECTION IN COTTON DUST}

Purpose: Knowledge related to which endotoxins are the most toxic will lead to standard development based on measurements of etiologic agents. Relative toxicity of the most likely etiologic agent (endotoxin) will be studied and defined so that intervention techniques can be applied at cultivation or processing.

DRDS, Stephen A. Olenchock

CAN 104 Dates: 10/88-09/91

\section{PATHOLOGY ANALYSIS OF THE NCWAS AND EM SUPPORT}

Purpose: The results obtained from the autopsy program will aid in evaluating the effectiveness of the coal mine dust standard.

DRDS, Val Vallyathan

CAN 105 Dates: 10/71-C

\section{INDUCTION OF DNA-ADDUCT IN THE LUNGS BY INDUSTRIAL CHEMICALS}

Purpose: This project will establish and evaluate the efficacy of the lung cell DNA adduct analysis, a molecular methodology, for the detection, and assessment of the potential carcinogenic hazards of chemicals and complex mixtures to which workers are exposed.

DRDS, Wen Zong Whong

CAN 106 Dates: 10/89-09/92

\section{EFFECT OF SILICA EXPOSURE ON THE LUNG: BIOCHEMICAL/PATH STUDIES}

Purpose: Lung cells will be exposed to freshly cleared or aged silica in vitro and in vivo and cellular reactions to these exposures will be compared to determine the relationship between surface characteristics of dust and its biological reactivity.

DRDS, Vincent Castranova

CAN 113 Dates: 10/89-09/92

\section{ASSESSMENT OF THE CARCINOGENIC POTENTIAL OF SELECTED DUSTS}

Purpose: The project will determine whether silica, talc, and man-made fibers can cause cell transformation and oncogene expression in mammalian cells.

DRDS, Tong Man Ong

CAN 116 Dates: 10/89-09/92

\section{ANIMAL AND EXPOSURE FACILITY SUPPORT FOR DRDS}

Purpose: This project provides animals to NIOSH researchers for the purposes of defining etiologic agents, animal models of ORD, pathogenetic and defense mechanisms, and naturally occurring variability in exposures which cause or influence occupational lung disease.

DRDS, Kenneth C. Weber

CAN 123 Dates: 10/80-C 


\section{VALIDATION STUDIES OF IN SITU ASSAY SYSTEMS IN OCCUPATIONAL SETTING}

Purpose: This project will develop and characterize a biological assay system to provide methods for the detection and monitoring of genotoxic agents and potential carcinogens in the workplace environment, and for the detection and assessment of potential health hazards to workers.

DRDS, Tong Man Ong

CAN 124 Dates: 07/86-09/92

\section{CENTERS FOR AGRICULTURAL RESEARCH, EDUCATION AND DISEASE AND INJURY}

Purpose: The Centers' program, through cooperative agreements with several facilities, will expand existing programs and establish new model programs in agricultural health and safety.

DRDS, Stephen A. Olenchock

CAN 130 Dates: 10/89-02/93

\section{NHANES III SUPPORT}

Purpose: This project will provide support to the respiratory disease part of NHANES. Pulmonary function equipment will be maintained, training provided, and quality control performed to insure a uniform approach to data collection.

DRDS, John L. Hankinson

CAN 135 Dates: 10/87-09/95

\section{MICROBIAL EXPOSURES IN AGRICULTURE}

Purpose: This project will provide data on the quantitative and qualitative distribution of microorganisms in respirable dust associated with a variety of agricultural processes. Such data are needed to understand the mechanism of acute febrile illness associated with exposure and to develop appropriate intervention strategies.

DRDS, Stephen A. Olenchock CAN 147 Dates: 10/89-02/93

\section{INFLAMMATORY AGENTS IN AGRICULTURAL DUSTS}

Purpose: This project will evaluate the inflammatory potential of, and the inflammatory reaction to, selected agricultural dusts. This information will provide a basis for determining the types of dusts likely to produce pulmonary inflammation.

DRDS, Daniel M. Lewis

CAN 148 Dates: 10/89-09/92

\section{ROLE OF FUNGAL SPORES IN ORGANIC DUST TOXIC SYNDROME (ODTS)}

Purpose: This project will help to provide an understanding of the role of fungal spores in the etiology of ODTS through isolation of pure preparations of fungal spores, and through investigations of the effects of those spores on cellular components of the immune system.

DRDS, William G. Sorenson

CAN 150 Dates: 10/89-09/93 


\section{EMERGING TECHNOLOGY FOR RESPIRATORY DISEASE EVALUATIONS}

Purpose: This project will refine current technologies and develop new tools to allow more efficient and sensitive detection of occupational respiratory disease. Field studies of airway responsiveness permit identification of risk factors for the sensitization of workers.

DRDS, John L. Hankinson

CAN 152 Dates: 10/88-09/91

\section{EVALUATION OF ROLE OF} INTERFERON SYSTEM IN OCCUPATIONAL ASTHMA ASSOCIATED WITH AGRICULTURAL DUST

Purpose: This project will determine the effects of in vitro exposure to grain dusts, dust extracts, and microbial agents on the production of Interferon by Alveolar Type II cells and macrophages. Dose-response and time-course studies will be conducted.

DRDS, Nicholas Hahon

CAN 154 Dates: 10/89-09/92

\section{EMERGING PROBLEMS IN ENVIRONMENTAL EXPOSURE ASSESSMENT}

Purpose: This project collects pilot data and assesses the adequacy of existing historical data, determining the feasibility of developing a research project.

DRDS, Michael A. McCawley CAN 158 Dates: 10/85-C

\section{DEVELOPMENT OF BIOASSAYS: IDENTIFY HEALTH RISKS OF ASBESTOS SUBSTITUTES}

Purpose: This project will develop in vitro and in vivo methodologies to evaluate the potential toxicity of asbestos and asbestos substitutes. Particles having different dimensions but identical chemistry will be tested to determine the importance of morphology on toxicity.

DRDS, Vincent Castranova

CAN 160 Dates: 10/89-09/92

\section{SURVEILLANCE OF LUNG DISEASE AGENTS IN SMALL BUSINESSES}

Purpose: This project will characterize exposures to lung disease agents, safety hazards, and use of engineering controls and protective equipment in selected potentially hazardous small businesses.

DRDS, Brian Kovak

CAN 162 Dates: 11/87-09/91

\section{AGRICULTURAL DUST: ELUCIDATION DISEASE MECHANICS WITH ANIMAL MODEL, BIOMARKERS}

Purpose: This project will help physicians to understand the time course of the cellular response, airway reactivity, and airway inflammation following exposure to selected agricultural dusts. Knowledge of these responses will aid in the prevention and treatment of lung diseases resulting from exposure to agricultural dusts.

DRDS, David G. Frazer

CAN 163 Dates: 10/89-09/92 


\section{NATIONAL OCCUPATIONAL HEALTH SURVEY OF MINING}

Purpose: This project will collect data on the mining work force and their potential exposures to fibers, asbestos, silica, and various chemical exposure agents. The data will identify worker groups, jobs, and industries at risk from exposure to toxic substances or harmful physical agents.

DRDS, Dennis W. Groce

CAN 164 Dates: 10/82-09/92

\section{AGRICULTURAL DUSTS: ANHMAL MODELS OF ASTHMA}

Purpose: The animal model will mirror worker pulmonary response to grain and wood dust inhalation, as well as dust-induced airway hyper-reactivity. Animal responses will be compared to published human responses. The toxicities of the dusts will be assayed biologically with proven and new in vitro airways preparations.

DRDS, Jeffrey S. Fedan CAN 165 Dates: 10/89-09/93

\section{EFFECTIVE SILICA INDICES FOR RESPIRABLE MINERAL DUST}

Purpose: This project will develop methods determining surface composition of respirable quartz distinguishing biologically available and unavailable quartz surface. It will identify initial interactions/properties of respired dusts, which distinguish the disease-inducing potential of insoluble respirable particles.

DRDS, William E. Wallace

CAN 167 Dates: 10/84-09/92

\section{ENVIRONMENTAL HAZARD SURVEILLANCE}

Purpose: This project will collect, analyze, and disseminate exposure data of dust contaminants in mining and manufacturing industries. High-risk occupations and industries will be determined.

DRDS, Alwin L. Dieffenbach CAN 173 Dates: 10/82-C

\section{TECHNICAL AND STATISTICAL SUPPORT}

Purpose: This project will design and analyze data for other branches in DRDS. Under this project, statisticians will also give statistical advice to other investigators, review protocols and manuscripts, and assist in writing manuscripts and final reports.

DRDS, Richard D. Kennedy CAN 176 Dates: 10/89-C

\section{SILICOSIS AND CANCER IN METAL MINERS}

Purpose: The association between silica, silicosis, and cancer will be evaluated in a cohort of metal miners.

DRDS, Robert M. Castellan

CAN 177 Dates: 10/89-09/93 


\section{RADIOLOGICAL AND PATHOLOGICAL CORRELATION IN CWP}

Purpose: The amount and type of pathological abnormality will be determined in lungs of a large number of autopsy cases. Correlation will be made between these findings and radiological abnormalities. The results will provide important information on the extent of pathological disease in coal miners in general.

DRDS, Michael D. Attfield

CAN 178 Dates: 10/89-09/92

\section{SILICOSIS IN SURFACE MINERS EXAMINED IN SURVEILLANCE PROGRAM}

Purpose: This project will provide for the collection of detailed work histories and smoking histories of surface coal miners having pneumoconiosis and a group of matched controls. A case-control analysis will be used to determine whether or not an association exists between silicosis and highrisk jobs such as drillers and bulldozer operators.

DRDS, Robert M. Castellan

CAN 180 Dates: 10/89-09/92

\section{MEDICAL FIELD TEAM TECHNICAL SUPPORT}

Purpose: This project will provide technical support in the collection of data from actual work sites throughout the country to enable an accurate determination of the prevalence or progression of respiratory occupational health problems, and provide in-house technical support services.

DRDS, Gregory C. Spransy

CAN 182 Dates: 10/87-C

\section{NATIONAL STUDY OF CWP AND RELATED RESEARCH}

Purpose: This continuation project includes a number of tasks and studies dealing with specific questions or hypotheses relating to lung disease in coal miners. As these questions are answered, new tasks will be added as necessary until the outstanding problems are resolved.

DRDS, Michael D. Attfield

CAN 183 Dates: 10/83-C

\section{IDENTIFICATION OF LONGWALL MINERS FOR ASSESSMENT AND PREVENTION OF CWP}

Purpose: This project will assist in determining the effectiveness of the coal dust standard in preventing occupational lung disease in miners potentially at risk of overexposure to coal mine dust due to their work in longwall mining. This will be accomplished by maintaining a database of longwall miners and periodically examining their medical data.

DRDS, Joseph Costello

CAN 184 Dates: 10/89-C

\section{OCCUPATIONAL RESPIRATORY DISEASE SURVEILLANCE IN AGRICULTURE}

Purpose: This project will support the NIOSH program of Occupational Disease Surveillance by analyzing existing secondary data sources to identify high-risk occupations (by agricultural sector, geographic region, etc.) for further evaluation, research, or public health intervention.

DRDS, Karl J. Musgrave

CAN 186 Dates: $10 / 89-C$ 


\section{ENDOTOXIN EXPOSURE/ACUTE \\ RESPIRATORY EFFECTS IN \\ AGRICULTURAL WORKERS}

Purpose: This project will analyze data previously collected by NIOSH in order to evaluate the exposure-response relationship between acute respiratory effects and inhalational exposure to airborne endotoxin in agricultural workers.

DRDS, Robert M. Castellan

CAN 187 Dates: 10/89-03/92

\section{SILICOSIS RISK IN THE CONSTRUCTION INDUSTRY}

Purpose: This project will provide data to estimate the prevalence and the potential risk of silicosis in selected segments of the construction industry.

DRDS, Robert M. Castellan

CAN 188 Dates: 10/89-03/94

\section{HEALTH RISK OF EXPOSURE TO ASBESTOS SUBSTITUTES IN INSULATION WORK}

Purpose: This project will provide data to estimate the prevalence of dust-induced disease in a selected group of insulation workers.

DRDS, Robert M. Castellan

CAN 189 Dates: 10/89-09/92

\section{FARM FAMILY SURVEY: RESPIRATORY DISEASE TECHNICAL SUPPORT}

Purpose: This project will provide technical support for occupational respiratory disease activities to the U.S. Farm Family Health and Hazard Survey.

DRDS, Robert M. Castellan CAN 190 Dates: 10/89-09/95

\section{DEVELOPMENT OF RESPIRATORY DISEASE SURVEILLANCE SYSTEMS}

Purpose: This project will compile, analyze, and disseminate information for use as the basis of Occupational Respiratory Disease Surveillance Systems. Reports will provide support for other O.L.D. projects by identifying worker groups at high risk, and by describing trends over time.

DRDS, Rochelle B. Althouse CAN 192 Dates: 10/90-C

\section{EMERGING PROBLEMS IN OCCUPATIONAL RESPIRATORY DISEASE}

Purpose: This project will provide an administrative mechanism to permit DRDS epidemiologists to become familiar with specific industries, hazards, or occupational lung diseases in order to develop welldefined research projects.

DRDS, Robert M. Castellan CAN 193 Dates: 10/90-C 


\section{MEDICAL TECHNICAL SUPPORT}

Purpose: By providing medical technical support, this project enables other research projects as well as health hazard evaluations to collect high quality data for use in their respective studies.

DRDS, John L. Hankinson

CAN 202 Dates: $10 / 87-\mathrm{C}$

\section{STUDIES OF AIRWAY CLOSURE AND EMPHYSEMA}

Purpose: This project is designed to provide information concerning the magnitude and consequences of surface forces that may act in the lung, and their role in the progression of lung disease. This knowledge may aid in the prevention and treatment of lung diseases resulting from tissue destruction due to abnormal surface forces.

DRDS, David G. Frazer

CAN 203 Dates: 10/90-09/93

\section{EFFECTS OF SILICA ON PULMONARY ENZYMES IN THE PATHOGENESIS OF LUNG CANCER}

Purpose: This project will, through controlled animal exposures to silica dust, determine whether a link between silica exposure and carcinogenicity can be developed in an animal model.

DRDS, Philip R. Miles

CAN 204 Dates: 10/90-09/93

\section{BYSSINOSIS PREVENTION}

Purpose: This project provides technical consultation and occupational health leadership to a government/industry/union task force for byssinosis prevention. It includes analysis of existing data, preparation of both NIOSH and task force reports, review of draft reports/research proposals from task force members and planning collaborative task force research.

DRDS, Edward L. Petsonk CAN 205 Dates: 10/81-09/91

\section{ASTHMA IN AND OUT OF THE WORKPLACE: CONFERENCE}

Purpose: This project will assist the New York Academy of Sciences with the planning and implementation of a research symposium on asthma in the workplace. This meeting will attract investigators from the international community to the first meeting of its kind to emphasize the growing problem of workplace exposure-induced asthma.

DRDS, Kenneth C. Weber CAN 206 Dates: 10/90-12/92

\section{AIRWAYS DISEASE IN MINERS}

Purpose: This project will identify environmental and constitutional risk factors which predict the development of severe lung impairment in coal miners and possibly in other dusty occupations.

DRDS, Edward L. Petsonk

CAN 212 Dates: 10/89-09/93 


\section{OCCUPATIONAL ASTHMA IDENTIFICATION METHODS}

Purpose: This project will develop simple, objective, standardized methods, and criteria for identifying cases of occupational asthma. This will encourage case reporting by physicians and surveillance efforts by state health departments.

DRDS, Edward L. Petsonk

CAN 213 Dates: 10/89-09/93

\section{ANALYSIS OF DATA FROM AN EGYPTIAN SILICA STUDY: USAID}

Purpose: This project provides technical support to Egypt in determining the prevalence of silicosis and exposure-response relationships in Egyptian industries.

DRDS, Robert M. Castellan

CAN 214 Dates: 10/86-05/91

\section{AGRICULTURAL DUSTS: FIELD-BASED EVALUATION-EXPOSURE AND ACUTE RESPIRATORY ILLNESS}

Purpose: This project will provide information on exposure and disease relationships to be used for prevention strategies.

DRDS, Gregory J. Kullman

CAN 215 Dates: 10/89-C
RURAL HOSPITAL NURSES: RESPIRATORY DISEASE TECHNICAL SUPPORT

Purpose: This project provides technical support on occupational respiratory diseases to the NIOSH Rural Hospital Nurses

Program.

DRDS, Elizabeth B. Knutti

CAN 216 Dates: 10/89-C

\section{EVALUATION/REHABILITATION OF OCCUPATIONAL RESPIRATORY DISEASE AND INJURY}

Purpose: This project will, through the development and implementation of a cooperative agreement with a major medical center, develop a model evaluation and rehabilitation program for occupational lung diseases and musculoskeletal disorders.

DRDS, John L. Hankinson

CAN 217 Dates: 10/89-09/93

\section{HAZARD SURVEILLANCE IN THE CONSTRUCTION INDUSTRY}

Purpose: This project will define the current respiratory exposures in various segments of the construction industry, and increase the ability of NIOSH to respond to requests for health hazard evaluations in this industry in a timely manner.

DRDS, Joseph E. Burkhart

CAN 218 Dates: 10/89-09/92 


\section{INDUSTRIAL HYGIENE TECHNICAL SUPPORT}

Purpose: This project quantifies levels of exposure to toxins, allergens, pathogens, hazardous dusts, and carcinogens. It provides services, environmental sampling, and review/comment on draft $\mathrm{NIOSH}$ documents.

DRDS, Jerry L. Clere

CAN 223 Dates: 10/82-C

\section{BIAS IN PARTICULATE EXPOSURE SAMPLING DEVICES}

Purpose: Computer models of fiber lung deposition will be developed if the published data is sufficient, and used to examine any biases, as a function of fiber distribution, between the current measure of fiber exposure (fiber counts from a total dust filter) and predicted lung deposition.

DRDS, Paul Hewett

CAN 224 Dates: 10/89-09/91

\section{FIBER TOXICITY: SURFACE PROPERTIES AND ANALYSIS}

Purpose: This project will use physical methods to reveal the surface properties of fibers, including surface and bulk composition, dimensions and surface area, using Auger, XPS, and EDX spectroscopy and BET surface analysis. Results will be correlated with the surface toxicity of native and surfactant-treated mineral fibers.

DRDS, William E. Wallace

CAN 225 Dates: 10/89-09/93

\section{ENVIRONMENTAL SURVEILLANCE OF SMALL COAL MINES}

Purpose: This project will examine and report on occupational health hazards found in small coal mines (mines with less than 20 miners).

DRDS, Kenneth D. Linch

CAN 226 Dates: 10/89-09/91

\section{PILOT ENVIRONMENTAL SURVEILLANCE OF ENDOTOXIN AT SELECTED COTTON GINS}

Purpose: This project will demonstrate the feasibility of determining the distribution of endotoxins in the U.S. cotton crop.

DRDS, Shib S. Bajpayee

CAN 227 Dates: 10/89-09/92

\section{EVALUATION SUPPORT TO NIOSH COAL WORKERS' SURVEILLANCE PROGRAM}

Purpose: Through review and evaluation of policies, procedures and support systems for the surveillance program, more accurate data will be generated to facilitate public health decision making.

DRDS, Mitzie L. Martin

CAN 228 Dates: 10/89-09/91 


\section{COMPUTER SUPPORT}

Purpose: Computer support in terms of Parklawn Computer Center charges, data entry, and programming support will be provided to all DRDS projects.

DRDS, Karen Hilling

CAN 232 Dates: 10/87-C

\section{AUTOPSY PROGRAM: PROGRAM OPERATION}

Purpose: This project will provide data about Coal Workers' Pneumoconiosis and will aid in assessing the effectiveness of the coal dust standard.

DRDS, Mitzie L. Martin

CAN 233 Dates: $05 / 71-\mathrm{C}$

\section{CHARACTERIZATION OF WELDING FUMES}

Purpose: This project will determine if welding fumes should be characterized by simple total fume measurements (traditional), or by mass or elemental distribution measurements coupled with minute volume measurements. It will determine if the particle size distribution and specific surface areas of different types of welding fumes are significantly different.

DRDS, Paul Hewett

CAN 234 Dates: 10/90-09/91
COAL MINER MEDICAL SURVEILLANCE: RECEIVING CENTER OPERATION

Purpose: This project provides for the collection and recording of data related to the $x$-ray surveillance program. The data are then available for research and analysis in surveillance and related projects.

DRDS, Mitzie L. Martin CAN 235 Dates: 08/70-C

\section{DIESEL PARTICULATE MEASUREMENTS}

Purpose: The carcinogenicity of diesel exhaust in the underground mine will be measured using a variety of different samplers while the feasibility of conducting a mortality study of miners exposed to diesel exhaust is explored.

DRDS, Rebecca S. Stanevich

CAN 236 Dates: 10/88-09/91

\section{RESPIRABLE GENOTOXIC PARTICULATE EXPOSURE MEASUREMENT MONITORING}

Purpose: This project will develop and apply methods to collect and measure the genotoxic dose associated with respirable particulate exposures in a manner predictive of their fate in the lung.

DRDS, William E. Wallace

CAN 237 Dates: 10/88-09/94 


\section{WHERE'S THE ENDOTOXIN?}

Purpose: This project will design, build, and test biologically and analytically relevant endotoxin samplers.

DRDS, William G. Jones

CAN 238 Dates: 10/88-09/91

\section{COAL DUST POSITION PAPER}

Purpose: This project will provide a critical evaluation of information on the health risks associated with exposure to coal dust. The evaluation will be used to develop a position paper that will provide a recommendation to the OD, NIOSH, concerning the need to develop a document (e.g., CD, CIB) addressing the hazards of exposure to coal dust.

DSDTT, Eileen D. Kuempel

CAN 053 Dates: 10/90-09/91

\section{GENERAL PRINCIPLES OF OCCUPATIONAL MEDICAL SCREENING (CD)}

Purpose: This project will develop a medical screening document with (1) a section on general principles, (2) a protocol with respiratory screening tests, and (3) an assessment of respiratory toxins regulated by OSHA.

DSDTT, Ralph D. Zumwalde

CAN 055 Dates: 10/90-09/92

\section{MAN-MADE MINERAL FIBERS POSITION PAPER}

Purpose: This project will provide a critical evaluation of information concerning occupational exposure to man-made mineral fibers. The evaluation will be used to develop a position paper that will provide a recommendation to OD, NIOSH, concerning the need to develop a man-made mineral fibers document.

DSDTT, Clayton B. Doak

CAN 088 Dates: 10/89-09/91

\section{ACRYLAMIDE-CURRENT INTELLIGENCE BULLETIN (CIB)}

Purpose: This project will provide a critical evaluation of the health risks associated with exposure to acrylamide. This evaluation will be used to develop a CIB that will report new data concerning the potential carcinogenic and reproductive effects of acrylamide.

DSDTT, Vlasta B. Molak CAN 089 Dates: 10/89-09/91

\section{GENERAL PRINCIPLES OF EXPOSURE ASSESSMENT}

Purpose: This project will develop, for OSHA, a draft decision logic and supporting criteria for assessing exposure.

DSDTT, Jerome P. Flesch

CAN 107 Dates: 10/90-09/91 


\section{UPDATE OF NIOSH AND OSHA OCCUPATIONAL SAFETY AND HEALTH GUIDELINES}

Purpose: This project will update all of the existing 333 guidelines originally developed under a joint project between NIOSH and OSHA by including appropriate new toxicity information on each guideline and making necessary revisions on other sections to include relevant new information and procedures. The project will be done under an IA with OSHA.

DSDTT, John J. Whalen

CAN 108 Dates: 10/90-09/92

\section{HEALTH AND SAFETY HAZARDS AMONG COSMETOLOGISTS ALERT}

Purpose: This project will develop an Alert that identifies the health and safety hazards associated with the cosmetology profession. The Alert will make recommendations for preventing such hazards.

DSDTT, Laurence D. Reed

CAN 109 Dates: 10/89-09/91

\section{EXPOSURE TO AIR CONTAMINANTS DURING LASER SURGERY ALERT}

Purpose: This project will develop an Alert that identifies the health hazards associated with laser surgery. The Alert will make recommendations for preventing such hazards.

DSDTT, Laurence D. Reed

CAN 110 Dates: 10/89-09/92

\section{INTERIM-RECOMMENDED EXPOSURE LIMITS (I-RELS) GUIDELINES}

Purpose: This project will develop data quality criteria for laboratory, industrial hygiene, and epidemiology data, define significant health effects end points, and develop and apply guidelines for extrapolation of health effects data to derive recommended occupational exposure limits.

DSDTT, Robert W. Mason

CAN 122 Dates: 10/89-C

\section{SURFACE COAL MINERS CRITERIA DOCUMENT}

Purpose: This project will provide a critical evaluation of information concerning occupational lung disease in surface coal miners. The evaluation will be used to develop a criteria document which will provide criteria for a recommended standard for the prevention of occupational lung diseases in surface coal miners.

DSDTT, Clayton B. Doak/Henry S. Chan CAN 136 Dates: 10/89-09/91

\section{AN EPIDEMIOLOGIC STUDY OF IAQ}

Purpose: This study will address the relationships between Indoor Air Quality (IAQ) and symptoms of disease including respiratory effects, headaches, and skin and eye irritation; and determine if inadequate ventilation is associated with these symptoms.

DSHEFS, David P. Brown

CAN 527 Dates: 10/89-09/93 


\section{COHORT MORTALITY STUDY OF ANTIMONY SMELTER WORKERS}

Purpose: This epidemiologic study will assess the association between exposure to antimony and the risk of developing lung cancer.

DSHEFS, Teresa M. Schnorr

CAN 533 Dates: 10/83-09/91

\section{MORTALITY STUDY OF WORKERS EXPOSED TO TOLUENE DIISOCYANATE}

Purpose: This epidemiologic study will assess the association between exposure to TDI and the risk of developing respiratory cancer.

DSHEFS, Teresa M. Schnorr

CAN 534 Dates: 06/83-06/91

\section{LABORER'S UNION HEALTH PROGRAM}

Purpose: This project will develop specific programs for health promotion and disease prevention for laborers. NIOSH and other centers in CDC will serve as resources to assist the Laborer's National Health and Safety Fund in developing and implementing these programs.

DSHEFS, Paul A. Schulte

CAN 558 Dates: 10/88-09/91

\section{URANIUM MINERS-LOW DOSE INVESTIGATION}

Purpose: This epidemiologic study will assess the association between exposure to low levels of radon daughters and the risk of developing lung cancer.

DSHEFS, Robert J. Roscoe

CAN 567 Dates: 10/82-09/91

\section{BERYLLIUM RETROSPECTIVE COHORT INVESTIGATION}

Purpose: This epidemiologic study will assess the association between exposure to beryllium and the risk of developing lung cancer and other respiratory/cardiovascular diseases.

DSHEFS, Elizabeth M. Ward

CAN 583 Dates: 10/81-06/91

\section{SURVEILLANCE DATA MICROCOMPUTER SYSTEM}

Purpose: The project will provide a mechanism to respond quickly and efficiently to requests for occupational exposure data on specified agents or tradename products. Development of the system will permit in-depth analysis and investigation of occupational exposure data without reliance on costly mainframe data processing.

DSHEFS, R.O. Young and W.K. Sieber CAN 586 Dates: 10/90-09/93 


\section{DATA ACQUISITION, MANAGEMENT AND EVALUATION (DAME)}

Purpose: Sources of hazard surveillance type data including exposure levels will be identified and acquired. New information will be provided to appropriate parties in a similar manner, as was done for the EPA lead data. Special emphasis will be directed to agricultural information sources.

DSHEFS, L. Murthy and J.F. Mastromauro CAN 587 Dates: 10/90-C

\section{MORTALITY STUDY OF BUTADIENE PRODUCTION WORKERS}

Purpose: This study will evaluate the association between risk of hematopoietic cancer and employment in butadiene refining operations.

DSHEFS, Elizabeth M. Ward

CAN 597 Dates: 10/90-09/91

\section{SIMULATED WORKPLACE PROTECTION FACTORS}

Purpose: This project will develop more accurate methods of measuring respirator performance which will improve NIOSH respirator certification and respirator performance, which in turn will reduce worker exposure to toxic chemicals.

DSR, Donald L. Campbell

CAN 786 Dates: 01/88-09/91

\section{LIQUID PARTICULATE CHALLENGE TO REPLACE DOP}

Purpose: This project will develop improved performance standards for respirators and will enable respirator manufacturers to produce respirators that will better protect workers from airborne contaminants.

DSR, Ernest S. Moyer

CAN 812 Dates: 10/90-06/93

\section{PROTECTIVE TECHNOLOGY BRANCH MANAGEMENT}

Purpose: This project wili provide management and guidance for the implementation of National Prevention Strategies involving investigative laboratory and field research with all types of respirators, chemical, and other protective clothing and equipment, and safety control systems and associated physiology responses to the use of such equipment.

DSR, John E. Parker

CAN 785 Dates: 10/85-C

\section{CHEMICAL WEAPONS CONVENTIONAL VERIFICATION TECHNICAL ASSISTANCE}

Purpose: The Institute will provide technical data and consultation on chemical protective clothing, respirators, and decontamination.

DSR, John E. Parker

CAN 818 Dates: 10/90-09/91 


\section{ORGANIC VAPOR CHALLENGE TO REPLACE CARBON TETRACHLORIDE}

Purpose: This project will develop improved organic vapor and gas performance standards for cartridges and will enable respirator manufacturers to produce respirators that will better protect workers from airborne organic vapor/gas contaminants.

DSR, Ernest S. Moyer

CAN 828 Dates: 10/89-09/92

\section{"USE TEST" FOR SCBA PERFORMANCE EVALUATION}

Purpose: This project will modify current "Use Test" performance requirements and test procedures to reflect advancements in continuous, on-line measurement technology, the wide variety of improved SCBA available, and the physiological basis for appropriate test protocols.

DSR, Nina L. Turner

CAN 829 Dates: 10/89-09/92

\section{WORKPLACE PROTECTION FACTOR (WPF) STUDY}

Purpose: This project will develop methods and evaluate for measurements of WPFs for half- and full-face air purifying particulate respirators (APPR). WPFs will be measured at work sites.

DSR, Barry G. Pallay

CAN 832 Dates: 10/86-09/91

\section{PROJECTED RESPIRATOR WPF VALUES}

Purpose: This project will (1) develop analytical techniques, based on instantaneous facepiece pressure, to estimate the workplace performance of positive-pressure SCBA, and (2) apply this method to positive-pressure SCBAs used in firefighting.

DSR, Donald L. Campbell

CAN 837 Dates: 10/89-09/91

\section{PROMULGATION OF 42 CFR 84}

Purpose: This project will increase worker protection from airborne contaminants by upgrading the certification standards and increasing the safety and reliability of respirators.

DSR, Nancy J. Bollinger

CAN 839 Dates: 01/87-09/91

\section{EVALUATION, CERTIFICATION, AND COORDINATION ACTIVITIES}

Purpose: This project will provide judgment and guidance to the legislatively mandated respirator and coal mine dust personal sampler certification programs which will help to increase worker protection from airborne contaminants.

DSR, Nancy J. Bollinger

CAN 852 Dates: 05/72-C 


\section{AIR PURIFYING RESPIRATOR TESTING}

Purpose: This project will increase worker protection from airborne contaminants by (1) approving respirators in accordance with regulations, (2) through the audit and complaints program assuring that respirators in the marketplace comply with regulations, and (3) providing expert advice on respirator applications.

DSR, Christopher C. Coffey

CAN 853 Dates: $05 / 72-\mathrm{C}$

\section{ATMOSPHERE SUPPLIED RESPIRATOR TESTING}

Purpose: This project will increase worker protection from airborne contaminants by (1) approving respirators in accordance with regulations, (2) through the audits and complaints program assuring that respirators in the marketplace comply with regulations, and (3) provide expert advice on respirator applications.

DSR, Samuel L. Terry

CAN 854 Dates: 05/72-C

\section{COAL MINE DUST PERSONAL SAMPLER UNIT}

Purpose: This project will increase worker protection from airborne contaminants by certifying CMDPSU which will provide more accurate measurements of particulate levels for MSHA compliance purpose.

DSR, Joan R. Allender

CAN 855 Dates: 05/72-C

\section{QUALITY ASSURANCE DOCUMENTATION CONTROL}

Purpose: This project will increase worker protection from airborne contaminants by (1) evaluating quality assurance of respirator manufacturers, and (2) through an in-plant audit program assuring that respirators are reliable.

DSR, Theodore A. Pettit

CAN 857 Dates: 05/72-C

\section{QUANTIFICATION OF INDUSTRIAL RESPIRATOR USE}

Purpose: This information is necessary to quantify the benefits of certified respirators to the American worker. This project will also serve to identify specific knowledge gaps in the use of respirators and to focus future research.

DSR, Timothy R. Merinar

CAN 858 Dates: 10/90-03/91

\section{DEVELOPMENT OF ALVEOLAR AND THORACIC PERSONAL DUST SAMPLER}

Purpose: This project will permit particle size-dependent over-estimates to be characterized for CMDPSU samplers. The true miner's deposited dose will be more accurately determined for epidemiological studies, and will serve as a better monitoring/sampling instrument for evaluating the toxicological effectiveness of coal mine exposure control technologies.

DSR, John M. Dower

CAN 859 Dates: 10/90-09/92 


\section{LABORATORY MODIFICATION NEEDED FOR IMPLEMENTATION OF NEW REGULATIONS}

Purpose: This project will increase the safety and reliability of certified respirators by improving test criteria, therefore increasing protection from airborne contaminants.

DSR, Christopher C. Coffey

CAN 863 Dates: 10/89-09/91

\section{SAFETY AND HEALTH FOR OCCUPATIONAL PROFESSIONALS (SHOP)}

Purpose: This project specifically conducts education and training programs to implement information dissemination strategies in Occupational Lung Diseases, Musculoskeletal Injuries, Psychological Disorders, and Disorders of Reproduction.

DTMD, Michael J. Colligan

CAN 766 Dates: 10/88-C

\section{INDOOR AIR QUALITY INITIATIVE}

Purpose: Informational materials, lectures, courses and other training materials will be developed, tested, and used in NIOSH/ERC continuing education programs.

DTMD, Pantelis G. Rentos

CAN 769 Dates: 10/88-09/94

\section{AGRICULTURAL SAFETY AND HEALTH}

Purpose: Provide for the development of the educational resources to prepare various disciplines with knowledge to reduce fatalities, diseases, and injuries in the agricultural sector.

DTMD, John T. Talty

CAN 772 Dates: 10/89-C

\section{SMALL BUSINESS INITIATIVE}

Purpose: Provide for the educational component of the NIOSH small business initiative. These instructional materials will create an awareness of, and provide knowledge on, occupational hazards, their health effects, and control strategies to reduce the hazards.

DTMD, James B. Walters

CAN 774 Dates: 10/88-C

\section{AUDIO VISUAL/GRAPHICS SUPFORT SERVICES}

Purpose: Numerous educational curriculum modules and technical documents, both written and video, require information to be provided in the form of graphic illustration or other visual presentation. This project will produce such materials in support of the dissemination of the NIOSH strategies.

DTMD, Glenda M. White

CAN 777 Dates: 10/89-C 


\section{OCCUPATIONAL LUNG DISEASES}

\section{PROJECT EPOCH}

Purpose: This project will provide an ongoing educational program for physicians and residents in the primary care specialties to improve their skills in recognizing and treating occupational diseases.

DTMD, Norbert J. Berberich

CAN 790 Dates: 10/89-09/94 


\section{ERGONOMIC RISKS FROM TOOL USAGE AND DESIGN}

Purpose: This project will evaluate the effects of tool usage and design factors that contribute to hand/wrist disorders. Prototype control studies will be conducted to illustrate improved tool design.

DBBS, Daniel J. Habes

CAN 244 Dates: 10/87-09/93

\section{BIODYNAMICS OF FREQUENT ASYMMETRIC LIFTING}

Purpose: This project will provide biomechanical data on the capacity of young and older workers to safely perform frequent, asymmetric lifting tasks.

DBBS, Thomas R. Waters

CAN 246 Dates: 10/89-09/94

\section{AGE AS AN ERGONOMIC RISK FACTOR}

Purpose: This project will identify age, gender, and occupational groups at risk for musculoskeletal disorders and validate NOES findings with the Bureau of Labor Statistics (BLS) and the Finnish Institute of Occupational Health (FIOH) incidence data.

DBBS, Francis J. Winn

CAN 250 Dates: 10/90-09/93

\section{SHOULDER/NECK MUSCLE TENSION FOR REPETITIVE WORK}

Purpose: This project will develop control techniques in the form of work/rest ratios for reducing shoulder and neck fatigue from overhead work.

DBBS, Vernon P. Anderson

CAN 260 Dates: 10/85-09/92

\section{BIOMOLECULAR MARKERS OF CHRONIC TRAUMA}

Purpose: This project will identify biomolecular markers which will be used to detect the development of occupationally related joint injury at an early, pre-clinical stage. Those workers most vulnerable to this condition can potentially be identified before irreversible damage occurs and moved to a less physically demanding job.

DBBS, James P. Mastin

CAN 344 Dates: 10/88-09/92

\section{DEVELOPMENT OF AN INTERVENTION MODEL FOR MUSCULOSKELETAL INJURIES}

Purpose: This project will involve an intervention program or plan to reduce identified musculoskeletal problems.

DPSE, James H. Jones

CAN 422 Dates: 10/88-09/91 


\section{ERGONOMIC INTERVENTIONS FOR THE BEVERAGE DELIVERY INDUSTRY}

Purpose: Provide recommendations to reduce injury during beverage crate handling, and disseminate such information to equipment manufacturers and users.

DPSE, James D. McGlothlin

CAN 424 Dates: 10/90-09/93

\section{CUMULATIVE TRAUMA DISORDERS POSITION PAPER}

Purpose: The evaluation will be used to develop a position paper that will provide a recommendation to OD, NIOSH, concerning the need to develop a policy document addressing cumulative trauma disorders.

DSDTT, Austin F. Henschel CAN 138 Dates: 10/89-09/91

\section{CARPAL TUNNEL STUDY}

Purpose: This study will give an estimate of the incidence of work-related carpal tunnel syndrome seen in the offices of primary care doctors and provide insight into the operation of priorities based on surveillance methods.

DSHEFS, Eugene Freund

CAN 507 Dates: 11/88-09/91

\section{SENTINEL HEALTH EVENT FOLLOW- BACK}

Purpose: Project will provide a surveillance system to identify where preventable occupational diseases are occurring. This will assist in direct prevention and help prioritize further research.

DSHEFS, Paul J. Seligman

CAN 518 Dates: 10/85-09/92

\section{P.C. VERSION OF LIFE TABLE ANALYSIS SYSTEM}

Purpose: This project will improve the overall research program by providing state-of-the-art methods.

DSHEFS, David P. Brown

CAN 526 Dates: 10/88-09/92

\section{EVALUATION OF UPPER EXTREMITY MUSCULOSKELETAL DISORDERS}

Purpose: This study will assess the feasibility of conducting large-scale industrywide studies of manufacturing and service workers involved in repetitive work of the upper extremities.

DSHEFS, Laurie A. Piacitelli

CAN 528 Dates: 10/89-09/93 


\section{NATIONAL ESTIMATE OF WORK-RELATED CUMULATIVE TRAUMA DISORDERS}

Purpose: Project will provide a national estimate of the burden of cumulative trauma injuries and disabilities which will be used for prevention strategy and intervention development.

DSHEFS, Shiro Tanaka

CAN 546 Dates: 10/89-09/91

\section{SURVEYOR TRAINING}

Purpose: This project will identify and provide the training and data needed by cooperative agreement states to assess the chemical, physical, biological, and safety hazards in the agricultural sector.

DSHEFS, David H. Pedersen

CAN 566 Dates: 10/89-09/92

\section{RURAL HOSPITAL DISEASE/INJURY SURVEILLANCE AND FOLLOW-BACK}

Purpose: This project will both gather surveillance data and provide technical assistance to the rural nurses project.

DSHEFS, L.L. Cameron and E. Freund CAN 568 Dates: 10/89-C

\section{OCCUPATIONAL AND SAFETY SURVEILLANCE THROUGH HEALTH DEPARTMENTS AND NURSES IN AGRICULTURAL COMMUNITIES}

Purpose: Provide community-based surveillance and intervention by assigning nurses in rural communities.

DSHEFS, Eugene Freund

CAN 585 Dates: 10/90-09/95

\section{SELECTED SURVEILLANCE SURVEY DATA DISSEMINATION}

Purpose: Prepare NIOSH reports in hard copy and diskette form and peer-reviewed journal articles on: (1) 1974-1983 trends in occupational health services, (2) occupational exposure to ergonomic stress, and (3) occupational exposure to physical agents.

DSHEFS, W.K Sieber and D.H. Pedersen CAN 590 Dates: 10/90-09/92

\section{DEVELOPMENT OF INDUSTRY-WIDE MUSCULOSKELETAL STUDIES}

Purpose: This project will assess the prevalence of Musculoskeletal Disorders (MD) in a number of industries, develop methods to identify and measure exposures associated with $\mathrm{MD}$, and hold a conference on the prevention of MD.

DSHEFS, Marie H. Sweeney

CAN 596 Dates: 10/90-09/95 


\section{MUSCULOSKELETAL INJURIES IN AGRICULTURE}

Purpose: This project will recommend procedures to reduce the biomechanical stresses to the musculoskeletal system for high-risk agricultural jobs.

DSR, Thomas G. Bobick

CAN 806 Dates: 10/90-09/93

\section{NIOSH ATLAS OF LOW BACK} TESTS/MEASURES: CLINICAL TRIALS

Purpose: The NIOSH Low Back Atlas has established a series of standardized diagnostic tests/measures which have the potential to classify low back musculoskeletal injuries. The clinical trials proposed in this study will serve to develop and validate the discriminate validity of the Low Back Atlas for assessing low back injuries.

DSR, Thomas $\mathrm{K}$. Hodous

CAN 815 Dates: 10/87-09/91

\section{ERGONOMIC TECHNICAL ASSISTANCE/RESEARCH IDENTIFICATION}

Purpose: This project will reduce biomechanical stress to the musculoskeletal system by providing recommendations for improving task, tool, and work station design on selected jobs.

DSR, Roger C. Jensen

CAN 822 Dates: 10/87-09/91

\section{PROJECT SHAPE}

Purpose: This project will increase OSH awareness through instructional materials in the engineering profession. In turn, engineering efforts to prevent occupational hazards through engineering design and other engineering functions will occur.

DTMD, John T. Talty

CAN 775 Dates: 10/88-C 


\section{METHODS FOR ASSESSING WORKER EXPOSURE TO ELECTROMAGNETIC FIELDS}

Purpose: This project will determine the methodologies and instrumentation to be employed in assessing worker exposures to EMFS.

DBBS, Joseph D. Bowman

CAN 266 Dates: 10/90-09/92

\section{EXPERIMENTAL MODEL FOR HUMAN BLADDER CARCINOGENESIS}

Purpose: A laboratory research model will be developed to mimic the continuum of phases associated with human bladder carcinogenesis. These include the initial exposure phase and culminate in malignancy. Biochemical events associated with selected phases will be examined for potential as biomarkers for effect.

DBBS, Russell E. Savage, Jr.

CAN 285 Dates: 10/90-09/93

\section{TEMPORAL FACTORS INFLUENCING CARCINOGENICITY OF INDUSTRIAL CHEMICALS}

Purpose: This project will provide information needed to justify short-term exposure limits for rapid acting carcinogens as assessed by this dose-rate study.

DBBS, William J. Moorman

CAN 313 Dates: 10/85-09/92

\section{BIOLOGICAL MONITORING FOR ARYL AMINES}

Purpose: This project will investigate analytical techniques for detection of accessible tissue DNA or hemoglobin adducts for use in biomonitoring of industrial carcinogens. The ultimate goal is the development of a routine analytical procedure which indicates exposure and relates qualitatively and/or quantitatively to carcinogenesis.

DBBS, Kenneth L. Cheever

CAN 314 Dates: 10/85-09/92

\section{IMMUNOLOGICAL MARKERS OF HERBICIDE EXPOSURE}

Purpose: Project will identify immunologic changes in animals and humans resulting from exposure to the model agent herbicide, alachlor. Specific immune system damage may be a major mechanism of disease production. Alachlor antibodies will be identified which can serve as an indicator of exposure.

DBBS, Raymond E. Biagini

CAN 343 Dates: 10/89-09/93

\section{VALIDATION STUDIES IN OCCUPATIONAL IMMUNOTOXICOLOGY}

Purpose: Develop, refine, and validate in selected population of human subjects a sensitive, reproducible screening battery of tiered immunotoxicity tests to assess subtle, relevant, immunotoxicologic changes in humans.

DBBS, Gerry M. Henningsen

CAN 345 Dates: 10/90-09/95 


\section{INHALATION TOXICOLOGY AND RESEARCH SUPPORT}

Purpose: This project will provide resources for the development of generation techniques, measurement methods, and quality control procedures for inhalation chamber exposure atmospheres for NIOSH inhalation toxicology research and the conduct of the inhalation exposures required for DBBS research and collaborative research with other divisions (DRDS).

DBBS, Alexander W. Teass

CAN 379 Dates: 10/80-C

\section{ANIMAL HUSBANDRY SERVICES}

Purpose: This project will manage and utilize resources to provide efficient animal husbandry and effective health surveillance for experimental animals used for DBBS research programs.

DBBS, Douglas D. Sharpnack

CAN 385 Dates: 10/76-C

\section{DIAGNOSTIC AND RESEARCH PATHOLOGY}

Purpose: This project will provide gross and microscopic examination/diagnosis for experimental animal tissues and consultation pathology services for NIOSH research studies.

DBBS, Richard A. Salomon

CAN 386 Dates: 10/76-C

\section{PARTICULATE AND TISSUE ANALYSIS RESEARCH AND SERVICE}

Purpose: This project will use electron microscopy and microprobe analysis to investigate fiber durability and transport following intrapleural implantation in rats and to size quartz particles being used in an inhalation study. Electron microscopy and particle analysis support will be provided to other NIOSH research programs as requested.

DBBS, Robert D. Riley

CAN 387 Dates: 10/76-C

\section{APPLIED CONTROL TECHNOLOGY STUDIES}

Purpose: This project provides for dissemination of the results of control technology studies to industry, labor, and other agencies. It also provides for the investigation of emerging problems and control techniques. These may include substances for which regulatory action is considered, new processes, or manufacturing technologies, etc.

DPSE, James A. Gideon

CAN 403 Dates: 10/80-C

\section{CONTROL TECHNOLOGY FOR NIOSH SURVEILLANCE ACTIVITIES}

Purpose: This project will disseminate control information directly to plants with cases of silicosis, and will develop guidelines for state follow-back of health hazards.

DPSE, Dennis M. O'Brien

CAN 404 Dates: 10/88-C 


\section{CONTROL TECHNOLOGY FOR SMALL BUSINESS}

Purpose: Develop and disseminate control technology information to radiator repair shops which have been selected as a small business for intervention.

DPSE, John W. Sheehy

CAN 415 Dates: 10/88-03/92

\section{CONTROL OF FORMALDEHYDE EXPOSURES IN EMBALMING PROCEDURES}

Purpose: This project will develop improved methods for the control of formaldehyde during the embalming process.

DPSE, Michael G. Gressel

CAN 417 Dates: 10/88-12/90

\section{CONTROL OF WOOD DUST FROM WOODWORKING PROCESSES}

Purpose: Results of this project will be used to increase the efficiency of emission controls for woodworking processes including hand sanding and sawing. Technology will be applicable to a number of processes although the control criteria will be developed with a focus on reduction of wood dust emissions.

DPSE, Jennifer L. Topmiller

CAN 430 Dates: 10/90-09/93

\section{A SAMPLING AND ANALYTICAL METHOD FOR AIRBORNE DIESEL-EXHAUST PARTICLES}

Purpose: A sampling and analytical method for diesel-exhaust particles in workplace air will be developed. This project will provide support for exposure surveillance and health effects evaluations.

DPSE, Mary E. Birch

CAN 438 Dates: 10/89-03/92

\section{PORTABLE MASS SPECTROMETER OR FTIR EVALUATION}

Purpose: The goal will be achieved through the evaluation of a gas chromatography/mass spectrometer for use in the field by trained industrial hygienists where present monitoring techniques are inadequate.

DPSE, Harley V. Piltingsrud

CAN 444 Dates: 10/89-12/92

\section{ENGINEERING CONTROL ASSISTANCE}

Purpose: The project will provide engineering control design and support to DSHEFS and will develop control research projects consistent with Institute goals. Engineering support of DSHEFS projects will provide control recommendations to solve worker exposure problems.

DPSE, Robert T. Hughes

CAN 446 Dates: 01/88-C 


\section{DEVELOPMENT OF ANALYTICAL METHODS FOR AGRICULTURAL CHEMICALS}

Purpose: This project will develop five sampling and analytical methods for pesticides or herbicides in air. Many of these compounds are suspected of causing cancer, reproductive disorders or neurotoxic disorders.

DPSE, Eugene R. Kennedy

CAN 447 Dates: 10/90-09/92

\section{APPLIED MONITORING STUDIES}

Purpose: This project will provide monitoring instrumentation selection and support to other NIOSH divisions. Monitoring support to DSHEFS projects will provide recommendations for monitoring worker exposures through the use of direct reading instruments.

DPSE, Judd C. Posner

CAN 456 Dates: 10/89-C

\section{COMPREHENSIVE ANALYTICAL CHEMISTRY SERVICES}

Purpose: This project coordinates requests from NIOSH researchers for analytical chemistry support for all NIOSH projects which require chemical analyses. The project also provides overall laboratory administration of sample analyses performed either on contract or in the NIOSH laboratories.

DPSE, Donald D. Dollberg CAN 482 Dates: 10/83-C

\section{ANALYTICAL SUPPORT TO DBBS RESEARCH AND IWSB/DSHEFS}

Purpose: Analytical support to DBBS and IWSB/DSHEFS will be provided in the areas of (1) inhalation studies of toxic substances, (2) chemical characterization of complex mixtures such as diesel emissions and pesticides, and (3) industry-wide studies of DMF workers and methanol as a vehicle fuel.

DPSE, John L. Holtz

CAN 483 Dates: $10 / 85-\mathrm{C}$

\section{ANALYTICAL CHEMISTRY SUPPORT TO DPSE RESEARCH}

Purpose: This project provides for chemistry support to DPSE research activities. Sampling and analytical support will be given to the control technology program's attempts to prevent the exposure of workers to hazardous levels of chemical agents. New measurement methods for asbestos will also be evaluated.

DPSE, Donald D. Dollberg CAN 484 Dates: 10/85-C

\section{CONTROL OF PARTICULATE AND GASEOUS AGENTS BY AIR CURTAIN TECHNOLOGY}

Purpose: Control design criteria will be developed for processes where contaminants are emitted over a large area or where local exhaust is not possible (bench top operations). While focused on reduction of formaldehyde and wood dust, technology will be generically applicable to a number of other processes.

DPSE, Vladimir Hampl

CAN 492 Dates: 10/85-04/91 


\section{TOXICITY STUDIES OF MILD GASIFICATION PRODUCTS}

Purpose: This project will determine whether mild coal gasification products can cause DNA and chromosomal alterations or damages in bacterial and/or mammalian cells.

DRDS, Tong Man Ong

CAN 166 Dates: 10/90-06/93

\section{TOBACCO SMOKE IN THE OCCUPATIONAL ENVIRONMENT (CIB)}

Purpose: This project will provide a critical evaluation of the health risks associated with exposure to tobacco smoke. This evaluation will be used to develop a CIB that will report data concerning the potential carcinogenic and cardiovascular effects of tobacco smoke.

DSDTT, David M. Votaw

CAN 054 Dates: 10/90-09/91

\section{QUANTITATIVE RISK ASSESSMENT}

Purpose: This project will make QRA efforts to understand the basic mechanism of disease causation; evaluate the metabolic pathways of, and variation in response to, a particular substance; estimate the adverse health risks to humans; provide a basis for prioritizing the issues for regulatory recommendations and provide a component for decision making.

DSDTT, Leslie T. Stayner

CAN 085 Dates: 10/70-C

\section{ACETALDEHYDE/PROPANEDIAL/ CURRENT INTELLIGENCE BULLETIN (CIB)}

Purpose: This project will provide a critical evaluation of the health risks associated with exposures to acetaldehyde/propanedial. The evaluation will be used to develop a CIB that will report new data suggesting that acetaldehyde/propanedial are potential occupational carcinogens.

DSDTT, Brenda K. Boutin

CAN 127 Dates: 10/89-09/91

\section{RUBBER PRODUCTS MANUFACTURING POSITION PAPER}

Purpose: This project will provide a critical evaluation of the health hazards in the rubber products manufacturing industry. The evaluation will be used to develop a position paper that will provide recommendations to the OD, NIOSH, concerning the need to develop a document (e.g., CD, CIB) addressing the hazards from employment in this industry.

DSDTT, Faye L. Rice

CAN 139 Dates: 10/89-09/91

\section{ASPHALT POSITION PAPER}

Purpose: This project will provide a critical evaluation of information on the health risks associated with exposure to asphalt. The evaluation will be used to develop a position paper that will provide a recommendation to the OD, NIOSH, concerning the need to develop a document (e.g., CD, CIB) addressing the hazards of exposure to asphalt.

DSDTT, Crystal L. Ellison

CAN 144 Dates: 10/89-09/91 


\section{INDUSTRY-WIDE STUDY OF WORKERS EXPOSED TO 4,4'-METHYLENE DIANILINE}

Purpose: This study will use several innovative techniques and new analytical methods to sample for MDA. These new procedures will be compared to routine methods.

DSHEFS, Mark F. Boeniger

CAN 512 Dates: 10/84-09/90

\section{ESTIMATION OF EXPOSURES AND RELEASES FROM UNIT OPERATIONS}

Purpose: This project will help define historical exposures around unit operations increasing our understanding of process modeling.

DSHEFS, Thomas F. Bloom

CAN 519 Dates: 10/88-09/91

\section{REGISTRY OF DIOXIN WORKERS AND MORTALITY STUDY}

Purpose: This epidemiologic study will assess the association between exposure to dioxin and the risk of developing cancer, especially soft tissue sarcoma.

DSHEFS, Marilyn A. Fingerhut CAN 525 Dates: 10/79-09/92

\section{ENVIRONMENTAL AND HEALTH ASSESSMENT OF EXPOSURE TO ALACHLOR-ENHANCEMENT}

Purpose: This study will evaluate exposure to alachlor among agricultural applicators using environmental and biological exposure measurements. If feasible, the study will also include markers of genotoxicity.

DSHEFS, Wayne T. Sanderson CAN 529 Dates: 10/89-09/92

\section{EPIDEMIOLOGIC METHODS DEVELOPMENT}

Purpose: This epidemiologic methods project will improve the overall research program being conducted as part of the industry-wide studies program by maintaining state-of-the-art methods.

DSHEFS, Nelson K. Steenland CAN 532 Dates: 10/84-C

\section{MORTALITY STUDY OF WORKERS EXPOSED TO HALOWAX}

Purpose: This epidemiologic study will assess the association between exposure to halowax and the risk of developing cancer.

DSHEFS, Elizabeth M. Ward

CAN 536 Dates: 10/83-09/91 


\section{EPIDEMIOLOGICAL STUDY OF BLADDER CANCER AMONG WORKERS EXPOSED TO O-TOLUIDINE AND O-ANILINE}

Purpose: This study will assess the association between exposures at a chemical manufacturing plant and the occurrence of bladder cancer and heart disease.

DSHEFS, Elizabeth M. Ward

CAN 537 Dates: 10/88-09/91

\section{UPDATE OF COMPLETED COHORT MORTALITY STUDIES}

Purpose: These epidemiologic studies will assess the association between exposure and the risk of developing disease (primarily cancer).

DSHEFS, David P. Brown

CAN 542 Dates: 10/82-C

\section{MEDICAL, BIOMETRIC AND IH STUDY OF EMERGING PROBLEMS}

Purpose: Provide management and guidance for the implementation of the National Prevention Strategies involving epidemiologic research.

DSHEFS, Marilyn M. Fingerhut CAN 543 Dates: $10 / 79-C$

\section{EXPOSURE ASSESSMENT OF WORKERS EXPOSED TO ACRYLONITRILE}

Purpose: This project will help establish the link between acrylonitrile and cancer in humans and develop new methods for historical exposure assessment.

DSHEFS, John N. Zey

CAN 545 Dates: 10/88-09/92

\section{BERYLLIUM CASE CONTROL STUDY}

Purpose: This study will assess the relationship between level and type of beryllium exposure and risk of lung cancer.

DSHEFS, Wayne T. Sanderson

CAN 553 Dates: 10/88-09/92

\section{WORKER NOTIFICATION}

Purpose: Notification of workers regarding their risk of disease results in some prevention of the disease by encouraging screening, health promotion, and better awareness (education).

DSHEFS, Paul A. Schulte

CAN 554 Dates: 03/85-C 


\section{MULTIPLE CAUSE OF DEATH}

Purpose: The multiple-cause-of-death project will improve the overall research program being conducted as part of the industry-wide studies program by maintaining state-of-the-art methods.

DSHEFS, Nelson K Steenland

CAN 555 Dates: 10/88-09/92

\section{FEASIBILITY ASSESSMENTS FOR NEW TOPICS}

Purpose: This project will contribute to the resolution of the goal by (1) filling data gaps on exposure to agents, (2) locating suitable cohorts for epidemiologic investigations, and (3) determining the feasibility of epidemiologic investigations on exposure of interest.

DSHEFS, John M. Fajen

CAN 556 Dates: 10/88-09/92

\section{ETHYLENE OXIDE MORTALITY STUDY}

Purpose: This epidemiologic study will assess the association between exposure to ethylene oxide and the risk of developing leukemia.

DSHEFS, Nelson K. Steenland CAN 557 Dates: 10/82-09/91

\section{GENOTOXIC EFFECTS OF FORMALDEHYDE EXPOSURE OF MORTUARY SCIENCE STUDENTS}

Purpose: This project will assess the development of cytogenetic changes among students and staff at a college of mortuary science following exposure to formaldehyde.

DSHEFS, Anthony J. Suruda

CAN 569 Dates: 10/89-09/92

\section{EVALUATION OF RADON/RADON PROGENY EXPOSURES TO RADON MITIGATORS}

Purpose: This project will determine the factors involved in exposure to radon during mitigation activities.

DSHEFS, Thomas F. Bloom

CAN 573 Dates: 10/89-09/92

\section{COMPUTERIZATION OF IHS/IWSB FILES}

Purpose: This project will provide valuable information on exposure levels by year and by standard industrial classification for many suspect carcinogens.

DSHEFS, Thomas F. Bloom

CAN 574 Dates: 10/89-09/93 


\section{LUNG CANCER MORTALITY AMONG BLACK WORKERS}

Purpose: This project will seek to determine what factors are responsible for elevated lung cancer rates among black males.

DSHEFS, Nelson K. Steenland

CAN 575 Dates: 10/89-09/91

\section{CANCER SCREENING IN FARMERS}

Purpose: This project will develop a series of cancer control demonstration projects. It will also provide for a series of studies to identify barriers to effective cancer control and to evaluate markers of premalignant changes.

DSHEFS, Paul A. Schulte

CAN 577 Dates: 10/89-09/92

\section{BIOLOGICAL MARKERS OF OCCUPATIONAL BLADDER CANCER}

Purpose: This project will seek to determine (1) molecular changes that result from occupational exposure to aromatic amines, and (2) metabolic phenotypes that predispose workers to bladder cancer.

DSHEFS, Paul A. Schulte

CAN 584 Dates: 10/89-09/96

\section{NOES IMPROVEMENT THROUGH TREND ANALYSIS}

Purpose: Trend analysis will help to resolve differences between and within NOHS and NOES. In addition, important research information may be uncovered giving direction to future surveillance activities.

DSHEFS, L. Murthy and J.F. Mastromauro CAN 588 Dates: 10/90-09/92

\section{CONSTRUCTION TRADES SURVEILLANCE}

Purpose: Will identify excess risks for death in construction workers that can be targeted for intervention strategies and those that need further research. Project will assist a national union with the development of an in-house mortality surveillance program per the request from the Occupational Health Foundation, Building and Construction Trades Department.

DSHEFS, F.B. Stern and C. Robinson

CAN 594 Dates: 10/90-09/93

\section{COAL HYDROGENATION MORTALITY STUDY}

Purpose: This study will evaluate the association between exposure to the products of coal combustion and catalysis and respiratory disease and cancer mortality.

DSHEFS, Avima M. Ruder

CAN 598 Dates: 10/90-09/91 


\section{PENTACHLOROPHENOL PRODUCTION WORKERS MORTALITY STUDY}

Purpose: This study will evaluate the association between exposure to pentachlorophenol (and dioxin and furan contaminants in its production) and cancer mortality.

DSHEFS, Avima M. Ruder CAN 599 Dates: 10/90-09/92

\section{SUPPORT OF EPA'S ENVIRONMENTAL EPIDEMIOLOGIC PROGRAM}

Purpose: This study will assess the role of biological markers among workers who have been exposed to ethylene oxide.

DSHEFS, Paul A. Schulte

CAN 607 Dates: 10/85-09/91

\section{DRY CLEANING MORTALITY UPDATE AND CANCER MORBIDITY}

Purpose: This study will evaluate the association between exposure to perchloroethylene (and other dry-cleaning solvents) and cancer morbidity and mortality.

DSHEFS, Avima M. Ruder

CAN 622 Dates: 10/90-09/93

\section{EVALUATION OF EXPOS. AND ADVERSE HEALTH OUTCOMES IN THE CONSTRUCTION INDUSTRY}

Purpose: This project will assess the feasibility of conducting large-scale industrywide studies of exposure and adverse health outcomes in construction industry populations.

DSHEFS, Kenneth M. Wallingford

CAN 624 Dates: 10/90-09/92

\section{AGRICULTURE-RELATED EMERGING PROBLEMS}

Purpose: Collect information to determine if epidemiologic studies in the agriculture industry are feasible.

DSHEFS, Marilyn M. Fingerhut

CAN 625 Dates: 10/90-C

\section{JOB/EXPOSURE MATRIX}

Purpose: The project will provide researchers with techniques for assessing and utilizing exposure data to potential hazards included in a computerized industry/occupation/hazard matrix. Information will also be disseminated by presentations and peer-reviewed journal articles.

DSHEFS, William K. Sieber CAN 637 Dates: 10/85-C 


\section{OCCUPATIONAL MORTALITY \\ SURVEILLANCE VALIDATION}

Purpose: This project will contribute to occupational health research prioritization and ultimately aid in the prevention of work-related disease and lives lost.

DSHEFS, C.A. Burnett and C. Robinson CAN 639 Dates: 10/89-09/91

\section{COMPARATIVE OCCUPATIONAL MORTALITY ANALYSIS}

Purpose: This project will compare results from occupational mortality surveillance studies to (1) assess the extent to which associations are observed consistently in different populations and different time periods; and (2) generate hypotheses for further research.

DSHEFS, N. Lalich and J. Slag CAN 640 Dates: 10/89-09/92

\section{SPONSORSHIP OF 9TH INTERNATIONAL SYMPOSIUM OF EPIDEMIOLOGY IN OCCUPATIONAL HEALTH}

Purpose: The symposium will bring together people working in occupational epidemiology to share findings and applications in the NIOSH top ten leading work-related diseases and injuries.

DSHEFS, Lawrence J. Fine

CAN 643 Dates: 10/90-09/93

\section{ACCESS TO NOHS DATABASE- PROFILE DEVELOPMENT}

Purpose: Specific dissemination strategies will be developed for workers at risk of exposure to hazards that result in diseases.

DSHEFS, L.I. Murthy and J.A. Seta CAN 662 Dates: 10/78-C

\section{DRAKE REGISTRY AND SCREENING PROJECT}

Purpose: This study will develop a structure for identifying workers at high risk of disease and provide the opportunity for the delivery of services.

DSHEFS, Paul A. Schulte

CAN 894 Dates: 10/88-09/91

\section{PREVENTION OF BIOLOGICAL EXPOSURE IN HEALTH CARE WORKERS}

Purpose: This project will evaluate and then apply quick test methods to determine penetration of latex surgical gloves by viruses.

DSR, Stephen S. Berardinelli

CAN 817 Dates: 10/90-09/92 


\section{PERCUTANEOUS ABSORPTION TO EVALUATE THE STANDARD CPC PERMEATION METHOD}

Purpose: This project will evaluate the relative permeation of chemical protective clothing and human or animal skin with values found in the literature.

DSR, Gary P. Noonan

CAN 880 Dates: 10/88-09/91

\section{COURSES/MODULES DEVELOPMENT}

Purpose: This project will provide for the development of training materials for occupational safety and health practitioners and other target audiences identified in the prevention strategy documents through the continuing education network of NIOSH and the educational resource centers.

DTMD, Norbert J. Berberich CAN 765 Dates: 10/88-C

\section{HAZARDOUS SUBSTANCES TRAINING}

Purpose: This project will increase the occupational safety and health knowledge base of state, local, and other health professionals to carry out their responsibilities in the management of hazardous substance activities. This will help prevent major health and safety environmental problems nationwide.

DTMD, Bernadine B. Kuchinski

CAN 779 Dates: 10/89-C 


\section{ECONOMIC AND MANAGEMENT FACTORS IN THE CONTROL OF WORK EXPOSURES}

Purpose: This project will identify patterns of management which promote or prevent proper control of occupational exposures. Identifying these patterns will improve effective communication and technology transfers with employers and managers.

DSDTT, Heinz W. Ahlers

CAN 093 Dates: 10/89-09/92

\section{OCCUPATIONALLY RELATED HOMICIDES ALERT}

Purpose: This project will develop an Alert in conjunction with DSR that identifies the high-risk job categories and associated causal factors for occupational homicides. The Alert will make recommendations for preventing such homicides.

DSDTT, Laurence Reed

CAN 112 Dates: 10/89-09/91

\section{LOCKING AND TAGGING OF ENERGY SOURCES ALERT}

Purpose: This project will develop an Alert in conjunction with DSR that identifies the high-risk job categories and associated causal factors for deaths and injuries related to the inappropriate locking and tagging of hazardous energy sources. The Alert will make recommendations for preventing such injuries/deaths.

DSDTT, Laurence Reed

CAN 114 Dates: 10/89-09/91

\section{FALLS FROM SCAFFOLDS/ELEVATED SURFACES ALERT}

Purpose: This project will develop an Alert in conjunction with DSR that identifies the high-risk activities, job categories, and associated causal factors for injuries and deaths related to falls from scaffolds and elevated work areas. The Alert will make recommendations for preventing such injuries/deaths.

DSDTT, Laurence Reed CAN 128 Dates: 10/90-09/91

\section{CONFINED SPACES POSITION PAPER}

Purpose: This project will provide a critical evaluation of recent information on the health risks of working in confined spaces. The evaluation will be used to develop a position paper that will provide a recommendation to the OD, NIOSH, concerning the need to revise the Institute's criteria document on confined spaces.

DSDTT, Clayton B. Doak

CAN 146 Dates: 10/89-09/91

\section{SURVEY INSTRUMENT DESIGN: HAZARD QUESTIONNAIRE}

Purpose: Questions are purposely designed to provide information on occupational exposures in the agricultural sector.

DSHEFS, D.H. Pedersen and J.A. Seta CAN 579 Dates: 10/89-09/92 


\section{OCCUPATIONAL FATALITY INJURY SURVEILLANCE}

Purpose: This project will identify the number and rate of occupational fatalities occurring in the nation through establishment of a National Traumatic Occupational Fatality Database.

DSR, E. Lynn Jenkins

CAN 805 Dates: $10 / 84-C$

\section{FATAL ACCIDENT CIRCUMSTANCES AND EPIDEMIOLOGY-TECHNICAL ASSISTANCE}

Purpose: This project will identify personal, organizational, environmental and circumstantial risk factors contributing to occupational fatalities and injuries.

DSR, Virgil J. Casini

CAN 807 Dates: 10/83-C

\section{GRAIN HANDLING INJURY AND FATALITY PREVENTION}

Purpose: This project will develop a work practices guide to provide scientifically sound recommendations on safe work practices to reduce the hazards of working with grain and grain handling systems on the farm and in other industrial environments.

DSR, Roger C. Jensen

CAN 808 Dates: 10/89-09/93

\section{DEVELOPMENT OF A WORKPLACE HOMICIDE PREVENTION STRATEGY}

Purpose: This project will facilitate information transfer on workplace homicide among disciplines to serve as the foundation for NIOSH initiative in workplace homicide prevention. Deterrence and prevention strategies will be evaluated and efficacious strategies recommended for application in hazardous employments.

DSR, Catherine A. Bell

CAN 809 Dates: 10/89-09/92

\section{ROLLOVER PROTECTION FOR AGRICULTURAL TRACTORS}

Purpose: This project will reduce traumatic injuries and fatalities associated with agricultural tractors by evaluating the advantages and disadvantages of different rollover protection systems, making recommendations for effective intervention strategies, and supporting their implementation.

DSR, John R. Etherton

CAN 810 Dates: 10/89-09/92

\section{REDUCING THE RISK OF FALLS THROUGH ROOF OPENINGS AND SKYLIGHTS}

Purpose: This project will reduce the incidence of workers falling through skylights, and also through openings in elevated work surfaces by developing improved work practices.

DSR, Thomas G. Bobick

CAN 813 Dates: 10/89-09/91 


\section{REDUCING FALLS FROM LARGE OFF-ROAD CONSTRUCTION VEHICLES}

Purpose: This project will reduce the incidence of workers faliling during ingress and egress of large off-road construction vehicles by developing improved access system design.

DSR, Thomas G. Bobick

CAN 814 Dates: 10/89-09/91

\section{FAILURE ANALYSIS OF SUSPENDED SCAFFOLD HOISTING DEVICE}

Purpose: This project will analyze how suspended scaffold hoist devices fail, recommend methods of preventing failure, and evaluate controls in a laboratory setting.

DSR, Carl A. Angoli

CAN 816 Dates: 10/89-09/91

\section{QUANTIFICATION OF RISK FACTORS FOR FALLS FROM BUILDINGS UNDER CONSTRUCTION}

Purpose: This project will coordinate data from surveillance databases to estimate fatal injury rates due to falls and causes of injury in the construction industry. An accident reporting system in the construction industry will be developed and prevention strategies evaluated.

DSR, Gwendolyn Cattledge

CAN 825 Dates: 10/87-09/94

\section{OCCUPATIONAL TRAUMATIC INJURY SURVEILLANCE OF FARMERS}

Purpose: This project will promote a uniform agricultural traumatic injury surveillance system through extension safety specialists in various states, evaluate data acquired specifically from the agricultural industry, and perform analyses in support of interventions to reduce fatalities and traumatic injuries.

DSR, John R. Myers

CAN 827 Dates: 10/87-C

\section{DEVELOPMENT OF NEW METHODS FOR OCCUPATIONAL INJURY SURVEILLANCE}

Purpose: This project will develop new, and improve existing, methods of occupational injury surveillance. It will also provide statistical and epidemiologic support to various SFIB traumatic and musculoskeletal research projects.

DSR, Nancy Stout

CAN 834 Dates: 10/79-C

\section{STATE-BASED FATALITY SURVEILLANCE USING THE FACE MODEL}

Purpose: This project will enable individual states to perform occupational epidemiologic research through fatality accident investigations. This pilot study will evaluate the fatality notification system, data collection procedures, and costs involved in developing and conducting fatality investigation programs within state agencies.

DSR, John M. Dower

CAN 870 Dates: 10/88-09/91 


\section{DEVELOPMENT OF SURVEILLANCE METHODS FOR OCCUPATIONAL MOTOR VEHICLE INJURIES}

Purpose: This project will develop data sources and methods to monitor work-related motor vehicle injuries/fatalities and evaluate injury control strategies.

DSR, Janet J. Johnston

CAN 874 Dates: 10/88-09/93

\section{DSR SURVEILLANCE REPORT SERIES}

Purpose: This project will develop a form and format, using desktop publishing technology, to simplify, streamline, and speed up the process of dissemination of surveillance data and analyses.

DSR, Joel Z. Rabkin

CAN 876 Dates: 10/90-09/92

\section{U.S. FARM FAMILY HEALTH AND HAZARD SURVEY-INJURY SURVEILLANCE}

Purpose: This project will develop the model questionnaire to determine the severity of work-related injuries to agricultural operators.

DSR, Deborah D. Landen

CAN 877 Dates: 10/89-09/92

\section{STUDY OF LINEMAN-RELATED FATALITIES AND INJURIES}

Purpose: This project will identify potential injury risk factors for utility linemen and develop recommendations to reduce the risk of injury.

DSR, Deborah D. Landen

CAN 878 Dates: 10/86-09/93

\section{AGRICULTURAL HEALTH PROMOTION SYSTEM}

Purpose: This project will provide direct access to agricultural workers and their families by utilizing the existing USDA cooperative extension programs within land grant universities. This access will permit the dissemination of safety and health information through the largest agricultural outreach service in the United States.

DSR, David L. Hard

CAN 883 Dates: 10/89-C

\section{STATE MODEL CONSTRUCTION SAFETY AND HEALTH PROGRAM}

Purpose: This project will develop a model industrial safety and health program for the construction industry in a state. The purpose is to develop injury reporting systems and intervention modules to reduce industry-specific occupational injuries.

DSR, Ronald L. Stanevich

CAN 884 Dates: 10/89-09/93 


\section{SURVEILLANCE OF SITE SPECIFIC CONSTRUCTION SAFETY AND HEALTH PROGRAM}

Purpose: This project will require that all injuries sustained in the construction of the new ALOSH facility be reported and records of those injuries be maintained at the prime contractor level. Various techniques of identifying work situations likely to result in injury will be used to develop a contractor safety program self-evaluation tool.

DSR, Dwayne L. Smith

CAN 885 Dates: 10/89-09/95

\section{INDUSTRY SPECIFIC INJURY REPORTING SYSTEM}

Purpose: This project will develop and pilot test a surveillance system for a specific 4-digit SIC in construction, and will determine feasibility of gathering injury information and the utility of such information to an employer for prevention purposes.

DSR, Ronald L. Stanevich

CAN 887 Dates: 10/89-03/92

\section{INJURY MORTALITY IN ALASKA'S FISHING INDUSTRY}

Purpose: This project will coordinate death certificate cause-of-death data and coast guard reports on circumstances of death for all work-related fatalities during 1979-1989 in the Alaskan fishing industry.

DSR, Patricia G. Schnitzer

CAN 888 Dates: 10/90-09/91

\section{EVALUATION OF NURSING HOME BACK INJURY PROGRAM}

Purpose: This project will develop a protocol for a multi-site intervention evaluation of a comprehensive back injury prevention and control program in the nursing home industry.

DSR, Thomas K. Hodous

CAN 889 Dates: 10/90-09/91

\section{NATIONAL AGENDA FOR INJURY CONTROL.}

Purpose: This project will form a panel to develop a document that will serve as a follow-up to the National Prevention Strategies for the Prevention of Leading Work-Related Diseases and Injuries.

DSR, Janet J. Johnston

CAN 890 Dates: 10/90-06/91

\section{OCCUPATIONAL INJURY PREVENTION IN ALASKA}

Purpose: This project will develop a state-based field approach to the study and prevention of the leading types of work-related trauma. Prevention strategies will be identified, evaluated, and demonstrated in the Alaskan workplace.

DSR, Thomas R. Bender

CAN 893 Dates: 10/90-C 
SEVERE OCCUPATIONAL TRAUMATIC INJURIES

CONSTRUCTION SAFETY AND HEALTH TRAINING

Purpose: Collaboration will be conducted with key professional and trade groups in the construction industry to develop training materials for construction managers, foremen, apprentices, and vocational students. These academic construction technology programs will produce a cadre of "competent persons" for implementing the OSHA Standard 29 CFR 1926/1910.

DTMD, Walter E. Ruch

CAN 762 Dates: 10/89-C

PROJECT MINERVA

Purpose: This project will allow NIOSH to work collaboratively with an external academic-based organization to expedite the implementation of Project Minerva into the business school curriculum.

DTMD, Walter M. Hag

CAN 776 Dates: 10/88-C

97 


\section{INHIBITION OF INTERCELLULAR COMMUNICATION BY WORKPLACE CHEMICALS}

Purpose: In vitro methods will be developed and tested as alternatives to using whole animals for studying potential cardiac toxicants and evaluating mechanisms of action of known cardiac toxicants.

DBBS, Mark A. Toraason

CAN 288 Dates: 10/88-09/91

\section{EXPANSION OF DIRECT READING} INSTRUMENTATION CAPABILITIES

Purpose: The project will assess the value and usability of various direct-reading instruments, promote on-site measurements through training of personnel and

publication of studies of real-time monitors.

DPSE, Guy E. Burroughs

CAN 497 Dates: 10/88-09/91

\section{MORTALITY AND IH STUDY OF BRIDGE AND TUNNEL OFFICERS EXPOSURE TO CARBON MONOXIDE}

Purpose: This study will address whether the current OSHA standard is adequate to protect the working population from cardiovascular disease.

DSHEFS, Frank B. Stern CAN 505 Dates: 10/88-09/92

\section{ARRHYTHMIA AMONG FREON EXPOSED WORKERS}

Purpose: This project will examine whether fluorocarbon 113 exposure is related to cardiac arrhythmias.

DSHEFS, Grace M. Egeland

CAN 582 Dates: 10/89-09/91

\section{MORTALITY SURVEILLANCE OF OCCUPATION AND INDUSTRY}

Purpose: Through this project occupational health researchers have the data resources necessary to monitor U.S. occupational and industrial mortality differentials and to assist in implementation of the National Prevention Strategies.

DSHEFS, Carol A. Burnett CAN 633 Dates: $10 / 80-C$ 


\section{COMBINED CHEMICAL/RF RADIATION TERATOGENESIS}

Purpose: This project will determine whether long-term, low-level exposure to radiofrequency $(R F)$ radiation acts synergistically in enhancing chemical-induced teratogenesis.

DBBS, David L. Conover

CAN 263 Dates: 10/89-09/92

\section{IN VITRO METHODS FOR DETECTING DEVELOPMENTAL TOXICANTS}

Purpose: This project will further evaluate and confirm the utility of an in vitro (nonmammalian) test system using drosophila melanogaster (fruit flies) to screen chemicals for their potential to cause mammalian developmental toxicity/teratogenesis.

DBBS, Dennis W. Lynch

CAN 286 Dates: 10/90-09/92

\section{METHODS FOR ASSESSING REPRODUCTIVE POTENTIAL IN FEMALES}

Purpose: This project will evaluate the potential of currently available methods to assess reproductive function in females for incorporation into a test battery which can be used to assess the reproductive potential of female workers in occupational settings.

DBBS, James S. Kesner

CAN 287 Dates: 10/87-09/93

\section{METHODS FOR DETERMINING EVIDENCE OF SPERMATOGENIC DAMAGE}

Purpose: This project will evaluate currently available methods to detect germ cell genetic damage and the most useful method(s) will be incorporated into the current DBBS semen profile so that both male reproductive impairment and genetic damage can be assessed using a single semen sample.

DBBS, Steven M. Schrader

CAN 289 Dates: 10/87-09/92

\section{IN VITRO SYSTEMS FOR HUMAN BIOLOGICAL MONITORING}

Purpose: This project will investigate the human cellular responses to occupational carcinogens and developmental toxicants. Cellular effects will be evaluated as potential biomarkers of exposures or heightened individual sensitivity to occupational carcinogens and developmental toxicants.

DBBS, Mark A. Toraason CAN 317 Dates: 10/87-09/93

\section{RF-INDUCED BODY CURRENT AND ABSORBED POWER DETERMINATIONS}

Purpose: This project will assess workplace and operator variables affecting worker exposure to radiofrequency ( $R F$ ) radiation, a suspected human reproductive hazard. NIOSH has documented that many RF sources exceed recommended exposure limits. RF-induced body currents will be used to quantify the influence of these variables on worker exposure.

DBBS, David L. Conover

CAN 363 Dates: 10/87-09/92 


\section{CONTROL OF ANESTHETIC GASES IN DENTAL OPERATORIES}

Purpose: The project will evaluate and/or develop and recommend controls for reducing persistent over-exposures to anesthetic gases in dental operatories. This information will be disseminated through the American Dental Association and other professional organizations.

DPSE, James D. McGlothlin

CAN 405 Dates: 10/86-09/91

\section{GLYCOL ETHERS CRITERIA DOCUMENT}

Purpose: This project will provide a critical evaluation of information on the health risks associated with occupational exposure to ethylene glycol ethers. The evaluation will be used to develop two criteria documents that will provide criteria for a recommended standard for the prevention/control of occupational exposures to ethylene glycol ethers.

DSDTT, Joann A. Wess

CAN 132 Dates: 10/89-09/91

\section{IH EXPOSURE ASSESSMENTS IN SELECTED INDUSTRIES}

Purpose: This project will fill in data gaps on exposure to agents and locate suitable cohorts for epidemiologic investigations.

DSHEFS, Kenneth M. Wallingford

CAN 547 Dates: $10 / 88-C$

\section{REPRODUCTIVE STUDY OF FEMALE VIDEO DISPLAY TERMINAL (VDT) OPERATORS}

Purpose: This epidemiologic study will assess the association between working with video display terminals and the risk of adverse reproductive outcomes.

DSHEFS, Teresa M. Schnorr

CAN 687 Dates: 10/84-03/92 


\section{HUMAN NEUROBEHAVIORAL EFFECTS OF COMBINATION CHEMICAL EXPOSURES}

Purpose: Neurological and behavioral dose-effect characteristics of common industrial solvents administered in combinations (two chemicals/combination) will be evaluated using controlled human exposures. Primary interest will center on the neurotoxic and pharmacokinetic properties of these chemical combinations.

DBBS, Robert B. Dick

CAN 243 Dates: 10/87-09/94

\section{WHO NEUROTOXICITY METHODS VALIDATION}

Purpose: This project is part of an international collaborative effort coordinated by the World Health Organization (WHO) to evaluate the reliability, sensitivity, and specificity of a set of neurobehavioral methods designed to screen, in animals, chemicals that are potential neurotoxic agents in humans.

DBBS, Benjamin K. Nelson

CAN 245 Dates: 10/89-06/92

\section{NEUROBEHAVIORAL ASSESSMENT OF PESTICIDE APPLICATORS}

Purpose: Workers exposed to, or poisoned by, pesticides will be evaluated for neurobehavioral impairment using the WHO-recommended Neurobehavioral Core Test Battery (NCTB), the Neurobehavioral Evaluation System (NES) computerized test battery, and measures specific to detect peripheral neuropathy and acetylcholinesterase (ACHE)/Neuropathy Target Esterace (NTE) activity.

DBBS, John M. Russo

CAN 249 Dates: 10/88-09/92

\section{CONTROL OF METHYLENE CHLORIDE IN FURNITURE STRIPPING}

Purpose: Recommend controls for methylene chloride, a neurotoxin, carcinogen, and reproductive toxin in furniture stripping. This is an industry made up mostly of small businesses with no occupational health expertise.

DPSE, Cheryl L. Fairfield

CAN 418 Dates: 10/87-09/91

\section{CONTROL OF HEALTH HAZARDS IN THE CONSTRUCTION INDUSTRY}

Purpose: This project will document and/or develop, and disseminate appropriate control measures to protect workers from health hazards during maintenance (sand blasting) of steel structures (bridges, water towers, etc.

DPSE, Ronald L. Mickelsen

CAN 435 Dates: 10/89-09/92

\section{REAL-TIME MONITORING FOR PESTICIDES}

Purpose: Instrumentation developed by the Army to monitor for organophosphorus nerve agents will be evaluated. The ACAMS (Automated Continuous Air Monitoring System) and the IMS (Ion Mobility Spectrometer) will be examined.

DPSE, Judd C. Posner

CAN 450 Dates: 10/90-09/91 


\section{MONITORING TECHNIQUES FOR CHEMICAL AGENTS}

Purpose: Improved sensitivity monitoring techniques will be evaluated/developed. This includes evaluating/comparing existing methodologies and optimization of analytical procedures. Particular attention will be paid to sampling high relative humidity atmospheres.

DPSE, Judd C. Posner

CAN 449 Dates: 03/87-09/91

\section{CONTROL OF LEAD EXPOSURES IN INDOOR FIRING RANGES}

Purpose: The project will define the exposure control problems that occur under the present recommendations, and then demonstrate the reduction or elimination of these problems, using known principals of ventilation design. Work will be done in the field and in laboratory model studies, in order to generalize the results.

DPSE, Keith G. Crouch

CAN 844 Dates: 10/88-09/91

\section{INORGANIC LEAD POSITION PAPER}

Purpose: This project will provide a critical evaluation of information of the health risks associated with exposure to lead. The evaluation will be used to develop a position paper that will provide a recommendation to the OD, NIOSH concerning the need to develop a document (e.g., CD, CIB) addressing the hazards of exposure to lead.

DSDTT, Henry U. Nagy

CAN 052 Dates: 10/90-09/92

\section{METHANOL EXPOSURES IN TRANSIT VEHICLES (UMTA)}

Purpose: This project will assess the health and safety aspects of using pure methanol as a fuel in transit buses.

DSHEFS, Greg M. Piacitelli

CAN 502 Dates: 10/88-09/91

\section{NATIONAL REPORTING OF SELECTED OCCUPATIONAL DISEASES}

Purpose: This project will provide for the successful implementation of state-based reporting of occupational lead poisoning.

DSHEFS, M.A. Montopoli and E. Freund CAN 514 Dates: 10/83-C

\section{AN ASSESSMENT OF THE EFFECTIVENESS OF OSHA'S LEAD STANDARD}

Purpose: By identifying industries with current problems controlling lead exposure, surveillance efforts and prevention strategies can be focused to eliminate occupational lead poisoning.

DSHEFS, P.J. Seligman and A.L. Tepper CAN 515 Dates: 10/86-09/93 


\section{NEUROLOGICAL SEQUELAE OF ACUTE PESTICIDE POISONING}

Purpose: This project will seek to determine if there are any long-term neurological effects after organophosphate poisoning.

DSHEFS, Nelson K. Steenland

CAN 530 Dates: 10/89-09/93

\section{STUDY OF METHYL BROMIDE AND SULFURYL FLUORIDE APPLICATORS}

Purpose: This project will assess the effects of methylbromide and sulfuryl fluoride on target organs (nervous system and kidney) and develop biological monitoring techniques for both.

DSHEFS, Anthony J. Suruda

CAN 535 Dates: 10/89-06/92

\section{HEALTH AND HAZARD SURVEILLANCE OF MIGRANT FARM WORKERS}

Purpose: This project will describe the current state of knowledge of the occupational hazards and health of migrant farm workers (MFW). It will also identify existing and potential mechanisms of implementing and conducting health and hazard surveillance of MFW. Mechanisms will be evaluated for designing a model surveillance network.

DSHEFS, L.L. Cameron and R. Brackbill CAN 592 Dates: 10/90-09/92

\section{ASSESSMENT OF LEAD EXPOSURE IN RADIATOR REPAIR SHOPS}

Purpose: This project will assess the level of compliance with existing exposure criteria for lead in radiator repair shops.

DSHEFS, Greg M. Piacitelli

CAN 623 Dates: 10/90-09/92

\section{DIOXIN MORBIDITY AND REPRODUCTIVE STUDY OF U.S. CHEMICAL WORKERS}

Purpose: This epidemiologic study will assess the association between exposure to dioxin and the risk of developing disease, including neurologic disease and dermatologic conditions.

DSHEFS, Marie H. Sweeney

CAN 849 Dates: 10/84-09/92 


\section{HEARING CONSERVATION PROGRAMS FOR UNDERSERVED WORKER GROUPS}

Purpose: This project will develop models for effective hearing conservation in occupations (agriculture/construction) which pose unique problems in implementing efforts to protect workers' hearing. Equipment noise control options, innovative hearing monitoring systems, and selection of hearing protectors will be considered for adoption in the model programs.

DBBS, Derek E. Dunn

CAN 262 Dates: 10/89-09/93

\section{IMPACT NOISE EFFECTS ON HEARING IN LABORATORY ANIMALS}

Purpose: The project will analyze available information, identify critical information gaps, and collect data to define the relationship between auditory damage and exposure to the parameters of impulse and impact noise (e.g., peak pressure, spectrum, duration, rise time, etc.). These data can be used to develop criteria for impact noise exposure.

DBBS, Derek E. Dunn

CAN 264 Dates: 10/89-09/93

\section{NOISE-INDUCED HEARING LOSS: SUPPORT FOR FFHH SURVEY}

Purpose: Project will provide training and support to NIOSH and extramural personnel in the collection of data relating to noise exposure and noise-induced hearing loss among agricultural workers. Project will also involve assisting in follow-back investigations and hearing health promotion activities.

DBBS, Christa L. Themann

CAN 265 Dates: 10/89-09/92

\section{LABORATORY TECHNIQUES TO PREDICT HEARING PROTECTOR ATTENUATION}

Purpose: This project will result in data necessary for the identification of a standardized, laboratory hearing protector evaluation technique that yields noise attenuation values comparable to those measured in the workplace. Such a laboratory procedure will permit the proper selection of hearing protectors for workers in a given noise environment.

DBBS, Carol J. Merry

CAN 267 Dates: 10/90-09/92

\section{ELECTRON MICROSCOPIC METHODS FOR MORPHOLOGICAL INVESTIGATIONS}

Purpose: Electron microscopic (EM) methods will be developed to quantitate cochlear morphological changes resulting from various noise exposures. Additional work will investigate development of quantitative EM morphological methods for other tissue/cells such as sperm, ova, and leukocytes.

DBBS, Stanley F. Platek

CAN 346 Dates: 10/90-09/93

\section{OCCUPATIONAL IMPACT NOISE: EXPOSURE, EFFECT, AND CONTROL}

Purpose: This project will study groups of workers exposed to impact noise or continuous noise. The results will help determine whether separate criteria are needed to adequately protect the hearing of workers exposed to impact noise versus continuous noise.

DBBS, John R. Franks

CAN 359 Dates: 10/88-09/91 


\section{OPTIMIZATION OF SPEECH FOR COMMUNICATIVE/PROTECTIVE DEVICES}

Purpose: This project will establish important parameters for the development of innovative hearing protectors that promote better communication in noise. Communication interference is a primary reason workers refuse to wear hearing protection.

DBBS, John R. Franks

CAN 364 Dates: 10/87-09/91

\section{OCCUPATIONAL NOISE EXPOSURE POSITION PAPER}

Purpose: This project will provide a critical evaluation of recent information on the health risks from occupational exposure to noise. The evaluation will be used to develop a position paper that will provide a recommendation to the OD, NIOSH, concerning the need to revise the Institute's criteria document on noise.

DSDTT, Henry S. Chan

CAN 134 Dates: 10/89-09/91 


\section{DEVELOPMENT OF CONTROL TECHNOLOGY APPLICATIONS OF REAL-TIME MONITORING}

Purpose: This project will explore the use of new real-time instruments to monitor for contaminants in the workplace. The project will also develop procedures for monitoring exposures not previously monitored in real-time. Monitoring for dermal exposures to pesticides will be one area of investigation.

DPSE, Michael G. Gressel CAN 406 Dates: 10/90-09/92

\section{SKIN EXPOSURE TO HAZARDOUS AGENTS ALERT}

Purpose: This project will develop an Alert in conjunction with DSR that identifies the causal factors associated with occupationally related skin disorders. The Alert will make recommendations for preventing such exposures.

DSDTT, Laurence Reed

CAN 115 Dates: 10/89-09/91

\section{CUTTING FLUIDS POSITION PAPER}

Purpose: This project will provide a critical evaluation of information on the health risks associated with exposure to cutting fluids. The evaluation will be used to develop a position paper that will provide a recommendation to the OD, NIOSH, concerning the need to develop a document (e.g., CD, CIB) addressing the hazards of exposure.

DSDTT, Brenda K. Boutin

CAN 140 Dates: 10/89-09/91

\section{ANALYSIS OF HEALTH INTERVIEW SURVEY DATA}

Purpose: This project will continue the surveillance of employment-related morbidity to help achieve the goal of identifying and monitoring employment-related health effects in the U.S. worker population and help establish priorities for NIOSH research.

DSHEFS, Virginia J. Behrens

CAN 508 Dates: 10/83-09/92

\section{IDENTIFICATION OF NEW DERMATOLOGICAL HAZARDS IN AGRICULTURE}

Purpose: We will evaluate the utility of a sentinel dermatologist network for collecting information which can be used to identify risk factors for occupational dermatologic diseases. Agricultural and construction workers will be targeted for the initial evaluations.

DSHEFS, P.J. Seligman and L.L. Cameron CAN 564 Dates: 10/89-09/93

\section{CHARACTERIZATION OF HOLES IN GLOVES}

Purpose: This project will produce and characterize small holes in the range of 50 to 300 microns in protective materials and determine the relationship of penetration rate of chemicals as a function of hole size. Latex gloves have been shown to have a defect (pin hole) rate of 1.7 percent to 9 percent among brands/styles.

DSR, Stephen S. Berardinelli

CAN 886 Dates: 10/88-09/91 


\section{METHODS FOR RATING JOB STRESS/STRAIN}

Purpose: Improved methods for assessing stress factors for purposes of detecting stressful job conditions and promoting more uniform approaches to assessing job stress and strain will be developed.

DBBS, Joseph J. Hurrell

CAN 242 Dates: 10/83-09/91

\section{ELECTRONIC PERFORMANCE MONITORING: STRESS PREVENTION STRATEGIES}

Purpose: Job and organizational factors that contribute to stress in electronic performance monitoring (EPM) will be investigated and work design solutions will be formulated.

DBBS, Lawrence M. Schleifer

CAN 247 Dates: 10/88-09/94

\section{METHODS FOR ASSESSING INFORMATION PROCESSING DEMANDS}

Purpose: Methods will be developed for assessing the contribution of psychological demands in the production of musculoskeletal strain among information workers.

DBBS, Naomi G. Swanson

CAN 248 Dates: 10/90-09/93

\section{STRESS CONTROL STRATEGIES IN COMPUTER-MEDIATED WORK}

Purpose: Laboratory and field studies will be conducted to determine the usefulness of rest breaks and exercise for reducing stress, and to recommend improved rest break designs for implementation in the workplace.

DBBS, Steven L. Sauter

CAN 256 Dates: 10/85-09/92

\section{DEVELOPMENT OF SURVEY ASSESSMENT INSTRUMENT FOR IAQ}

Purpose: An item pool for defining self-report measures of job demands and environmental work conditions will be developed. Such items will be proposed for inclusion in protocols for studying indoor air quality problems where apparent health complaints may be due to interaction among perceived job stressors and air quality factors.

DBBS, Joseph J. Hurrell

CAN 257 Dates: 10/88-06/92

\section{IMMUNOTOXICOLOGY RESEARCH AND SUPPORT}

Purpose: This project will develop and employ immunoassays as molecular and cellular probes for use in pathogenesis studies of cancer and neuroendocrine-based disorders, and in determining the relevance of immune competence to disease resistance. The assays will be applied to NIOSH research and field studies requiring immunology input.

DBBS, Gerry M. Henningsen

CAN 342 Dates: 10/88-C 


\section{PSYCHOLOGICAL DISORDERS}

\section{OCCUPATIONAL PSYCHOLOGICAL DISORDER (OPD) SURVEILLANCE}

Purpose: This project will implement a national surveillance of OPD by defining data needs and recommending ways to improve NIOSH capacity for targeting occupations at risk of psychological disorders and for evaluating efficacy of intervention efforts.

DSHEFS, C.A. Burnett and A.L. Tepper CAN 593 Dates: 10/90-09/92 


\section{NEUROBEHAVIORAL ASSESSMENT OF PESTICIDE APPLICATORS}

Purpose: Workers exposed to, or poisoned by, pesticides will be evaluated for neurobehavioral impairment using the WHO-recommended Neurobehavioral Core Test Battery (NCTB), the Neurobehavioral Evaluation System (NES) computerized test battery, and measures specific to detect peripheral neuropathy and acetylcholinesterase (ACHE)/Neuropathy Target Esterace (NTE) activity.

DBBS, John M. Russo

CAN 249 Dates: 10/88-09/92

\section{HEARING CONSERVATION PROGRAMS FOR UNDERSERVED WORKER GROUPS}

Purpose: This project will develop models for effective hearing conservation in occupations (agriculture/construction) which pose unique problems in implementing efforts to protect workers' hearing. Equipment noise control options, innovative hearing monitoring systems, and selection of hearing protectors will be considered for adoption in the model programs.

DBBS, Derek E. Dunn

CAN 262 Dates: 10/89-09/93

\section{NOISE-INDUCED HEARING LOSS:} SUPPORT FOR FFHH SURVEY

Purpose: Project will provide training and support to NIOSH and extramural personnel in the collection of data relating to noise exposure and noise-induced hearing loss among agricultural workers. Project will also involve assisting in follow-back investigations and hearing health promotion activities.

DBBS, Christa L. Themann

CAN 265 Dates: 10/89-09/92

\section{DEVELOPMENT OF CONTROL TECHNOLOGY APPLICATIONS OF REAL-TIME MONITORING}

Purpose: This project will explore the use of new real-time instruments to monitor for contaminants in the workplace. The project will also develop procedures for monitoring exposures not previously monitored in real-time. Monitoring for dermal exposures to pesticides will be one area of investigation.

DPSE, Michael G. Gressel CAN 406 Dates: 10/90-09/92

\section{APPLICATION OF PROCESS HAZARD ANALYSIS FOR AGRICULTURAL CHEMICALS}

Purpose: This project will identify and recommend preventive measures for ammonia releases in agricultural applications.

DPSE, Amy A. Beasley

CAN 423 Dates: 10/89-09/91

\section{ENDOTOXIN DETECTION IN COTTON DUST}

Purpose: Knowledge related to which endotoxins are the most toxic will lead to standard development based on measurements of etiologic agents. Relative toxicity of the most likely etiologic agent (endotoxin) will be studied and defined so that intervention techniques can be applied at cultivation or processing.

DRDS, Stephen A. Olenchock

CAN 104 Dates: 10/88-09/91 


\section{CENTERS FOR AGRICULTURAL RESEARCH, EDUCATION AND DISEASE AND INJURY}

Purpose: The Centers' program, through cooperative agreements with several facilities, will expand existing programs and establish new model programs in agricultural health and safety.

DRDS, Stephen A. Olenchock CAN 130 Dates: 10/89-02/93

\section{MICROBIAL EXPOSURES IN AGRICULTURE}

Purpose: This project will provide data on the quantitative and qualitative distribution of microorganisms in respirable dust associated with a variety of agricultural processes. Such data are needed to understand the mechanism of acute febrile illness associated with exposure and to develop appropriate intervention strategies.

DRDS, Stephen A. Olenchock

CAN 147 Dates: 10/89-02/93

\section{INFLAMMATORY AGENTS IN AGRICULTURAL DUSTS}

Purpose: This project will evaluate the inflammatory potential of, and the inflammatory reaction to, selected agricultural dusts. This information will provide a basis for determining the types of dusts likely to produce pulmonary inflammation.

DRDS, Daniel M. Lewis

CAN 148 Dates: 10/89-09/92
ROLE OF FUNGAL SPORES IN ORGANIC DUST TOXIC SYNDROME (ODTS)

Purpose: This project will help to provide an understanding of the role of fungal spores in the etiology of ODTS through isolation of pure preparations of fungal spores, and through investigations of the effects of those spores on cellular components of the immune system.

DRDS, William G. Sorenson

CAN 150 Dates: 10/89-09/93

\section{EVALUATION OF ROLE OF INTERFERON SYSTEM IN OCCUPATIONAL ASTHMA ASSOCIATED WITH AGRICULTURAL DUST}

Purpose: This project will determine the effects of in vitro exposure to grain dusts, dust extracts, and microbial agents on the production of Interferon by Alveolar Type II cells and macrophages. Dose-response and time-course studies will be conducted.

DRDS, Nicholas Hahon

CAN 154 Dates: 10/89-09/92

\section{AGRICULTURAL DUST: ELUCIDATION DISEASE MECHANICS WITH ANIMAL MODEL, BIOMARKERS}

Purpose: This project will help physicians to understand the time course of the cellular response, airway reactivity, and airway inflammation following exposure to selected agricultural dusts. Knowledge of these responses will aid in the prevention and treatment of lung diseases resulting from exposure to agricultural dusts.

DRDS, David G. Frazer

CAN 163 Dates: 10/89-09/92 


\section{AGRICULTURAL DUSTS: ANIMAL MODELS OF ASTHMA}

Purpose: The animal model will mirror worker pulmonary response to grain and wood dust inhalation, as well as dust-induced airway hyper-reactivity. Animal responses will be compared to published human responses. The toxicities of the dusts will be assayed biologically with proven and new in vitro airways preparations.

DRDS, Jeffrey S. Fedan

CAN 165 Dates: 10/89-09/93

\section{OCCUPATIONAL RESPIRATORY DISEASE SURVEILLANCE IN AGRICULTURE}

Purpose: This project will support the NIOSH program of Occupational Disease Surveillance by analyzing existing secondary data sources to identify high-risk occupations (by agricultural sector, geographic region, etc.) for further evaluation, research, or public health intervention.

DRDS, Karl J. Musgrave

CAN 186 Dates: 10/89-C

\section{ENDOTOXIN EXPOSURE/ACUTE RESPIRATORY EFFECTS IN AGRICULTURAL WORKERS}

Purpose: This project will analyze data previously collected by NIOSH in order to evaluate the exposure-response relationship between acute respiratory effects and inhalational exposure to airborne endotoxin in agricultural workers.

DRDS, Robert M. Castellan CAN 187 Dates: 10/89-03/92
FARM FAMILY SURVEY: RESPIRATORY DISEASE TECHNICAL SUPPORT

Purpose: This project will provide technical support for occupational respiratory disease activities to the U.S. Farm Family Health and Hazard Survey.

DRDS, Robert M. Castellan

CAN 190 Dates: 10/89-09/95

\section{ASTHMA IN AND OUT OF THE WORKPLACE: CONFERENCE}

Purpose: This project will assist the New York Academy of Sciences with the planning and implementation of a research symposium on asthma in the workplace. This meeting will attract investigators from the international community to the first meeting of its kind to emphasize the growing problem of workplace exposure-induced asthma.

DRDS, Kenneth C. Weber CAN 206 Dates: 10/90-12/92

\section{OCCUPATIONAL ASTHMA IDENTIFICATION METHODS}

Purpose: This project will develop simple, objective, standardized methods, and criteria for identifying cases of occupational asthma. This will encourage case reporting by physicians and surveillance efforts by state health departments.

DRDS, Edward L. Petsonk

CAN 213 Dates: 10/89-09/93 


\section{AGRICULTURAL DUSTS: FIELD-BASED EVALUATION-EXPOSURE AND ACUTE RESPIRATORY ILLNESS}

Purpose: This project will provide information on exposure and disease relationships to be used for prevention strategies.

DRDS, Gregory J. Kullman CAN 215 Dates: 10/89-C

\section{RURAL HOSPITAL NURSES: RESPIRATORY DISEASE TECHNICAL SUPPORT}

Purpose: This project provides technical support on occupational respiratory diseases to the NIOSH Rural Hospital Nurses Program.

DRDS, Elizabeth B. Knutti

CAN 216 Dates: 10/89-C

\section{PILOT ENVIRONMENTAL SURVEILLANCE OF ENDOTOXIN AT SELECTED COTTON GINS}

Purpose: This project will demonstrate the feasibility of determining the distribution of endotoxins in the U.S. cotton crop.

DRDS, Shib S. Bajpayee

CAN 227 Dates: 10/89-09/92

\section{AGRICULTURAL HEALTH AND SAFETY DISSEMINATION}

Purpose: This project enables NIOSH material to be distributed to appropriate secondary disseminators in the agricultural industry.

DSDTT, Charlene B. Maloney

CAN 073 Dates: 10/89-C

\section{ENVIRONMENTAL AND HEALTH ASSESSMENT OF EXPOSURE TO ALACHLOR-ENHANCEMENT}

Purpose: This study will evaluate exposure to alachlor among agricultural applicators using environmental and biological exposure measurements. If feasible, the study will also include markers of genotoxicity.

DSHEFS, Wayne T. Sanderson

CAN 529 Dates: 10/89-09/92

\section{STATE FARM FAMILY HEALTH AND HAZARD SURVEY (FFHHS)}

Purpose: Identify existing gaps in our information base about hazard and health effects, and initiate steps leading to prevention of occupational disease among farm workers.

DSHEFS, John P. Sestito

CAN 549 Dates: 10/89-09/95


SURVEY INSTRUMENT DESIGN: HEALTH HISTORY EXAMINATION

Purpose: Examination modules are used in the Farm Family Health and Hazard Survey (FHHS) data collection by the state agencies.

DSHEFS, Lorraine L. Cameron CAN 559 Dates: 10/89-09/92

\section{FARM HEALTH HAZARD AWARENESS}

Purpose: This project will use appropriate and established information sources in the communities in which the FFHHS project is focused to enhance the visibility and acceptability of the project.

DSHEFS, Eugene Freund

CAN 563 Dates: 10/89-09/92

\section{IDENTIFICATION OF NEW DERMATOLOGICAL HAZARDS IN AGRICULTURE}

Purpose: We will evaluate the utility of a sentinel dermatologist network for collecting information which can be used to identify risk factors for occupational dermatologic diseases. Agricultural and construction workers will be targeted for the initial evaluations.

DSHEFS, P.J. Seligman and L.L. Cameron CAN 564 Dates: 10/89-09/93

\section{SURVEYOR TRAINING}

Purpose: This project will identify and provide the training and data needed by cooperative agreement states to assess the chemical, physical, biological, and safety hazards in the agricultural sector.

DSHEFS, David H. Pedersen

CAN 566 Dates: 10/89-09/92

\section{RURAL HOSPITAL DISEASE/INJURY SURVEILLANCE AND FOLLOW-BACK}

Purpose: This project will both gather surveillance data and provide technical assistance to the rural nurses project.

DSHEFS, L.L. Cameron and E. Freund CAN 568 Dates: 10/89-C

\section{CANCER SCREENING IN FARMERS}

Purpose: This project will develop a series of cancer control demonstration projects. It will also provide for a series of studies to identify barriers to effective cancer control and to evaluate markers of premalignant changes.

DSHEFS, Paul A. Schulte CAN 577 Dates: 10/89-09/92 


\section{SURVEY INSTRUMENT DESIGN: HAZARD QUESTIONNAIRE}

Purpose: Questions are purposely designed to provide information on occupational exposures in the agricultural sector.

DSHEFS, D.H. Pedersen and J.A. Seta CAN 579 Dates: 10/89-09/92

\section{OCCUPATIONAL AND SAFETY SURVEILLANCE THROUGH HEALTH DEPARTMENTS AND NURSES IN AGRICULTURAL COMMUNITIES}

Purpose: Provide community-based surveillance and intervention by assigning nurses in rural communities.

DSHEFS, Eugene Freund

CAN 585 Dates: 10/90-09/95

\section{SURVEILLANCE DATA MICROCOMPUTER SYSTEM}

Purpose: The project will provide a mechanism to respond quickly and efficiently to requests for occupational exposure data on specified agents or tradename products. Development of the system will permit in-depth analysis and investigation of occupational exposure data without reliance on costly mainframe data processing.

DSHEFS, R.O. Young and W.K. Sieber CAN 586 Dates: 10/90-09/93

\section{HEALTH AND HAZARD SURVEILLANCE OF MIGRANT FARM WORKERS}

Purpose: This project will describe the current state of knowledge of the occupational hazards and health of migrant farm workers (MFW). It will also identify existing and potential mechanisms of implementing and conducting health and hazard surveillance of MFW. Mechanisms will be evaluated for designing a model surveillance network.

DSHEFS, L.L. Cameron and R. Brackbill CAN 592 Dates: 10/90-09/92

\section{AGRICULTURE-RELATED EMERGING PROBLEMS}

Purpose: Collect information to determine if epidemiologic studies in the agriculture industry are feasible.

DSHEFS, Marilyn M. Fingerhut

CAN 625 Dates: 10/90-C

\section{MUSCULOSKELETAL INJURIES IN AGRICULTURE}

Purpose: This project will recommend procedures to reduce the biomechanical stresses to the musculoskeletal system for high-risk agricultural jobs.

DSR, Thomas G. Bobick

CAN 806 Dates: 10/90-09/93 


\section{GRAIN HANDLING INJURY AND FATALITY PREVENTION}

Purpose: This project will develop a work practices guide to provide scientifically sound recommendations on safe work practices to reduce the hazards of working with grain and grain handling systems on the farm and in other industrial environments.

DSR, Roger C. Jensen

CAN 808 Dates: 10/89-09/93

\section{ROLLOVER PROTECTION FOR AGRICULTURAL TRACTORS}

Purpose: This project will reduce traumatic injuries and fatalities associated with agricultural tractors by evaluating the advantages and disadvantages of different rollover protection systems, making recommendations for effective intervention strategies, and supporting their implementation.

DSR, John R. Etherton

CAN 810 Dates: 10/89-09/92

\section{OCCUPATIONAL TRAUMATIC INJURY SURVEILLANCE OF FARMERS}

Purpose: This project will promote a uniform agricultural traumatic injury surveillance system through extension safety specialists in various states, evaluate data acquired specifically from the agricultural industry, and perform analyses in support of interventions to reduce fatalities and traumatic injuries.

DSR, John R. Myers

CAN 827 Dates: 10/87-C

\section{U.S. FARM FAMILY HEALTH AND HAZARD SURVEY-INJURY SURVEILLANCE}

Purpose: This project will develop the model questionnaire to determine the severity of work-related injuries to agricultural operators.

DSR, Deborah D. Landen

CAN 877 Dates: 10/89-09/92

\section{ANALYSIS OF OCCUPATIONAL INJURIES IN THE HEALTH INTERVIEW SURVEY}

Purpose: Injuries to farmers will be examined. A second study, which will provide more detailed analysis of injuries among all occupation groups, will be done with data from 1988 occupational supplement, in collaboration with BLS and NCHS.

DSR, Deborah D. Landen

CAN 882 Dates: 10/90-09/92

\section{AGRICULTURAL HEALTH PROMOTION SYSTEM}

Purpose: This project will provide direct access to agricultural workers and their families by utilizing the existing USDA cooperative extension programs within land grant universities. This access will permit the dissemination of safety and health information through the largest agricultural outreach service in the United States.

DSR, David L. Hard

CAN 883 Dates: $10 / 89-C$ 


\section{INJURY MORTALITY IN ALASKA'S FISHING INDUSTRY}

Purpose: This project will coordinate death certificate cause-of-death data and coast guard reports on circumstances of death for all work-related fatalities during 1979-1989 in the Alaskan fishing industry.

DSR, Patricia G. Schnitzer

CAN 888 Dates: 10/90-09/91

\section{OCCUPATIONAL INJURY PREVENTION IN ALASKA}

Purpose: This project will develop a state-based field approach to the study and prevention of the leading types of work-related trauma. Prevention strategies will be identified, evaluated, and demonstrated in the Alaskan workplace.

DSR, Thomas R. Bender

CAN 893 Dates: 10/90-C

\section{AGRICULTURAL SAFETY AND HEALTH}

Purpose: Provide for the development of the educational resources to prepare various disciplines with knowledge to reduce fatalities, diseases, and injuries in the agricultural sector.

DTMD, John T. Talty

CAN 772 Dates: 10/89-C
OCCUPATIONAL HEALTH AND SAFETY SURVEILLANCE THROUGH NURSES IN AGRICULTURAL COMMUNITIES

Purpose: This project will provide on-going responsive surveillance of agriculturalrelated disease and injury by placing occupational health nurses in agricultural communities.

OD, Paul Seligman

CAN 878 Dates: 10/90-09/93 


\section{BIOMOLECULAR MARKERS OF CHRONIC TRAUMA}

Purpose: This project will identify biomolecular markers which will be used to detect the development of occupationally related joint injury at an early, pre-clinical stage. Those workers most vulnerable to this condition can potentially be identified before irreversible damage occurs and moved to a less physically demanding job.

DBBS, James P. Mastin

CAN 344 Dates: 10/88-09/92

\section{EVALUATION OF MESOTHELIOMA PRODUCTION BY ASBESTOS SUBSTITUTES}

Purpose: This project will evaluate the toxicity/carcinogenicity of two modified chrysolite asbestos products which have been proposed as safe substitutes for asbestos through intrapleural implantation in rats. The toxicity/carcinogenicity of these substitute materials will be evaluated and compared to untreated asbestos materials.

DBBS, Stanley F. Platek

CAN 376 Dates: 10/84-09/92

\section{ASBESTOS REMOVAL CONTROL TECHNOLOGY ASSESSMENT}

Purpose: This work evaluates glove bags, a control to prevent asbestos release into the work environment during removal of pipe lagging. Limitations of this control and ways to overcome them will be identified and disseminated to personnel doing asbestos abatement work.

DPSE, Phillip A. Froehlich CAN 408 Dates: 10/84-09/91

\section{IDENTIFICATION OF INTERVENTION POINTS IN WOOD DUST EXPOSURE}

Purpose: The study results will be used by DPSE/MCRB to prioritize equipment for control development and to evaluate specific high-exposure tasks. Work practices to lower risk may be identified.

DPSE, Thomas C. Cooper

CAN 414 Dates: 10/90-09/91

\section{CONTROL OF WOOD DUST FROM WOODWORKING PROCESSES}

Purpose: Results of this project will be used to increase the efficiency of emission controls for woodworking processes including hand sanding and sawing. Technology will be applicable to a number of processes although the control criteria will be developed with a focus on reduction of wood dust emissions.

DPSE, Jennifer L. Topmiller CAN 430 Dates: 10/90-09/93

\section{A NATIONAL CONSTRUCTION INDUSTRY CONTROL TECHNOLOGY DATABASE}

Purpose: This project will evaluate the feasibility of a national database, potentially including physical, biological, and chemical agents, as well as chronic trauma.

DPSE, James A. Gideon

CAN 434 Dates: 10/89-C 


\section{CONTROL OF HEALTH HAZARDS IN THE CONSTRUCTION INDUSTRY}

Purpose: This project will document and/or develop, and disseminate appropriate control measures to protect workers from health hazards during maintenance (sand blasting) of steel structures (bridges, water towers, etc.

DPSE, Ronald L. Mickelsen

CAN 435 Dates: 10/89-09/92

\section{DEVELOPMENT OF BIOASSAYS: IDENTIFY HEALTH RISKS OF ASBESTOS SUBSTITUTES}

Purpose: This project will develop in vitro and in vivo methodologies to evaluate the potential toxicity of asbestos and asbestos substitutes. Particles having different dimensions but identical chemistry will be tested to determine the importance of morphology on toxicity.

DRDS, Vincent Castranova

CAN 160 Dates: 10/89-09/92

\section{SILICOSIS RISK IN THE CONSTRUCTION INDUSTRY}

Purpose: This project will provide data to estimate the prevalence and the potential risk of silicosis in selected segments of the construction industry.

DRDS, Robert M. Castellan

CAN 188 Dates: 10/89-03/94
HEALTH RISK OF EXPOSURE TO ASBESTOS SUBSTITUTES IN INSULATION WORK

Purpose: This project will provide data to estimate the prevalence of dust-induced disease in a selected group of insulation workers.

DRDS, Robert M. Castellan

CAN 189 Dates: 10/89-09/92

\section{STUDIES OF AIRWAY CLOSURE AND EMPHYSEMA}

Purpose: This project is designed to provide information concerning the magnitude and consequences of surface forces that may act in the lung, and their role in the progression of lung disease. This knowledge may aid in the prevention and treatment of lung diseases resulting from tissue destruction due to abnormal surface forces.

DRDS, David G. Frazer

CAN 203 Dates: 10/90-09/93

\section{CHARACTERIZATION OF WELDING FUMES}

Purpose: This project will determine if welding fumes should be characterized by simple total fume measurements (traditional), or by mass or elemental distribution measurements coupled with minute volume measurements. It will determine if the particle size distribution and specific surface areas of different types of welding fumes are significantly different.

DRDS, Paul Hewett

CAN 234 Dates: 10/90-09/91 


\section{INORGANIC LEAD POSITION PAPER}

Purpose: This project will provide a critical evaluation of information of the health risks associated with exposure to lead. The evaluation will be used to develop a position paper that will provide a recommendation to the OD, NIOSH concerning the need to develop a document (e.g., CD, CIB) addressing the hazards of exposure to lead.

DSDTT, Henry U. Nagy

CAN 052 Dates: 10/90-09/92

\section{CONSTRUCTION HEALTH AND SAFETY DISSEMINATION}

Purpose: This project will enable NIOSH materials to be distributed to appropriate secondary disseminators in the construction industry.

DSDTT, Charlene B. Maloney

CAN 075 Dates: 10/89-C

\section{TECHNICAL INQUIRIES, CONSTRUCTION}

Purpose: This project will improve the delivery of construction safety and health information to researchers, employers, and employees by publicizing the availability of the information through the NIOSH 800-number and disseminating the information as requested.

DSDTT, Rodger L. Tatken

CAN 076 Dates: $10 / 89-\mathrm{C}$

\section{LIBRARY-CONSTRUCTION REFERENCES}

Purpose: This project will improve the delivery of occupational safety and health information to NIOSH researchers and the occupational safety and health community.

DSDTT, Lawrence Q. Foster

CAN 079 Dates: 10/89-C

\section{ASPHALT POSITION PAPER}

Purpose: This project will provide a critical evaluation of information on the health risks associated with exposure to asphalt. The evaluation will be used to develop a position paper that will provide a recommendation to the OD, NIOSH, concerning the need to develop a document (e.g., CD, CIB) addressing the hazards of exposure to asphalt.

DSDTT, Crystal L. Ellison

CAN 144 Dates: 10/89-09/91

\section{CONFINED SPACES POSITION PAPER}

Purpose: This project will provide a critical evaluation of recent information on the health risks of working in confined spaces. The evaluation will be used to develop a position paper that will provide a recommendation to the OD, NIOSH, concerning the need to revise the Institute's criteria document on confined spaces.

DSDTT, Clayton B. Doak

CAN 146 Dates: 10/89-09/91 


\section{LABORER'S UNION HEALTH PROGRAM}

Purpose: This project will develop specific programs for health promotion and disease prevention for laborers. NIOSH and other centers in CDC will serve as resources to assist the Laborer's National Health and Safety Fund in developing and implementing these programs.

DSHEFS, Paul A. Schulte

CAN 558 Dates: 10/88-09/91

\section{EVALUATION OF RADON/RADON PROGENY EXPOSURES TO RADON MITIGATORS}

Purpose: This project will determine the factors involved in exposure to radon during mitigation activities.

DSHEFS, Thomas F. Bloom

CAN 573 Dates: 10/89-09/92

\section{CONSTRUCTION TRADES - MORTALITY STUDIES}

Purpose: Proportionate mortality rates

(PMR) analyses will be used to identify high mortality risks as leads to

in-depth epidemiologic studies of exposure disease relationships.

DSHEFS, C. Robinson and F.B. Stern

CAN 578 Dates: 10/89-09/92

\section{NOES IMPROVEMENT THROUGH TREND ANALYSIS}

Pupose: Trend analysis will help to resolve differences between and within NOHS and NOES. In addition, important research information may be uncovered giving direction to future surveillance activities.

DSHEFS, L. Murthy and J.F. Mastromauro CAN 588 Dates: 10/90-09/92

\section{CONSTRUCTION TRADES SURVEILLANCE}

Purpose: Will identify excess risks for death in construction workers that can be targeted for intervention strategies and those that need further research. Project will assist a national union with the development of an in-house mortality surveillance program per the request from the Occupational Health Foundation, Building and Construction Trades Department.

DSHEFS, F.B. Stern and C. Robinson

CAN 594 Dates: 10/90-09/93

\section{EVALUATION OF EXPOS. AND ADVERSE HEALTH OUTCOMES IN THE CONSTRUCTION INDUSTRY}

Purpose: This project will assess the feasibility of conducting large-scale industrywide studies of exposure and adverse health outcomes in construction industry populations.

DSHEFS, Kenneth M. Wallingford CAN 624 Dates: 10/90-09/92 


\section{COMPARATIVE OCCUPATIONAL MORTALITY ANALYSIS}

Purpose: This project will compare results from occupational mortality surveillance studies to (1) assess the extent to which associations are observed consistently in different populations and different time periods; and (2) generate hypotheses for further research.

DSHEFS, N. Lalich and J. Slag

CAN 640 Dates: 10/89-09/92

\section{OCCUPATIONAL FATALITY INJURY SURVEILLANCE}

Purpose: This project will identify the number and rate of occupational fatalities occurring in the nation through establishment of a National Traumatic Occupational Fatality Database.

DSR, E. Lynn Jenkins

CAN 805 Dates: 10/84-C

\section{REDUCING THE RISK OF FALLS THROUGH ROOF OPENINGS AND SKYLIGHTS}

Purpose: This project will reduce the incidence of workers falling through skylights, and also through openings in elevated work surfaces by developing improved work practices.

DSR, Thomas G. Bobick

CAN 813 Dates: 10/89-09/91

\section{REDUCING FALLS FROM LARGE OFF-ROAD CONSTRUCTION VEHICLES}

Purpose: This project will reduce the incidence of workers falling during ingress and egress of large off-road construction vehicles by developing improved access system design.

DSR, Thomas G. Bobick

CAN 814 Dates: 10/89-09/91

\section{FAILURE ANALYSIS OF SUSPENDED SCAFFOLD HOISTING DEVICE}

Purpose: This project will analyze how suspended scaffold hoist devices fail, recommend methods of preventing failure, and evaluate controls in a laboratory setting.

DSR, Carl A. Angoli

CAN 816 Dates: 10/89-09/91

\section{QUANTIFICATION OF RISK FACTORS FOR FALLS FROM BUILDINGS UNDER CONSTRUCTION}

Purpose: This project will coordinate data from surveillance databases to estimate fatal injury rates due to falls and causes of injury in the construction industry. An accident reporting system in the construction industry will be developed and prevention strategies evaluated.

DSR, Gwendolyn Cattledge

CAN 825 Dates: 10/87-09/94 


\section{SURVEILLANCE AND FIELD INVESTIGATIONS BRANCH MANAGEMENT}

Purpose: This project will coordinate, evaluate, and facilitate the merging of musculoskeletal and traumatic injury research and surveillance programs into a coordinated research initiative which will address the recommendations of the National Strategies for Prevention of the Leading Work-Related Diseases and Injuries.

DSR, Timothy J. Pizatella

CAN 847 Dates: $10 / 85-C$

\section{ANALYSIS AND FIELD EVALUATIONS BRANCH MANAGEMENT}

Purpose: This project will coordinate, evaluate, and facilitate the merging of musculoskeletal and traumatic injury analytic research programs into a coordinated research initiative which will address the recommendations of the National Strategies for Prevention of the Leading Work-Related Diseases and Injuries. DSR, Harlan E. Amandus

CAN 866 Dates: 10/90-C

STATE-BASED FATALITY SURVEILLANCE USING THE FACE MODEL

Purpose: This project will enable individual states to perform occupational epidemiologic research through fatality accident investigations. This pilot study will evaluate the fatality notification system, data collection procedures, and costs involved in developing and conducting fatality investigation programs within state agencies.

DSR, John M. Dower

CAN 870 Dates: 10/88-09/91

\section{DSR SURVEILLANCE REPORT SERIES}

Purpose: This project will develop a form and format, using desktop publishing technology, to simplify, streamline, and speed up the process of dissemination of surveillance data and analyses.

DSR, Joel Z. Rabkin

CAN 876 Dates: 10/90-09/92

\section{NATIONAL FATAL OCCUPATIONAL INJURY SURVEILLANCE AND INVESTIGATION SYSTEM}

Purpose: This project will develop a timely automated fatal occupational injury reporting system capable of report generation and trend analysis at a national level, and facilitate the expansion of the FACE project to investigate all fatal occupational injuries in the United States at the state level using the FACE model.

DSR, E. Lynn Jenkins

CAN 879 Dates: 10/90-C

\section{STATE MODEL CONSTRUCTION SAFETY AND HEALTH PROGRAM}

Purpose: This project will develop a model industrial safety and health program for the construction industry in a state. The purpose is to develop injury reporting systems and intervention modules to reduce industry-specific occupational injuries.

DSR, Ronald L. Stanevich

CAN 884 Dates: 10/89-09/93 


\section{CONSTRUCTION-RELATED PROJECTS}

\section{CONSTRUCTION SAFETY AND HEALTH TRAINING}

Purpose: Collaboration will be conducted with key professional and trade groups in the construction industry to develop training materials for construction managers, foremen, apprentices, and vocational students. These academic construction technology programs will produce a cadre of "competent persons" for implementing the OSHA Standard 29 CFR 1926/1910.

DTMD, Walter E. Ruch

CAN 762 Dates: 10/89-C

\section{INDOOR AIR QUALITY INITIATIVE}

Purpose: Informational materials, lectures, courses and other training materials will be developed, tested, and used in NIOSH/ERC continuing education programs.

DTMD, Pantelis G. Rentos

CAN 769 Dates: 10/88-09/94

\section{HEALTH AND SAFETY PROGRAMS FOR CONSTRUCTION WORK}

Purpose: The project will support health and safety programs for construction work that involve evaluation of work-related injuries and diseases, data management and analysis, and intervention activities.

OD, Roy M. Fleming
CAN 876
Dates: $10 / 90-C$ 


\section{TECHNICAL ASSISTANCE AND \\ PROGRAM SUPPORT \\ (PSYCHOLOGY/ERGONOMICS)}

Purpose: Assures program planning, budget management, and staff development to conduct research, methods development, control studies, consultations and evaluations as prescribed in the national prevention strategies in work-related musculoskeletal injuries, neurotoxic and psychological disorders.

DBBS, Robert J. Biersner

CAN 284 Dates: $10 / 80-\mathrm{C}$

\section{TECHNICAL ASSISTANCE AND PROGRAM SUPPORT (TOXICOLOGY)}

Purpose: Effect plans and manage resources for toxicology research and methods development which implement the national prevention strategies and NIOSH initiatives; furnish support to NTP and other public health programs requiring toxicology expertise.

DBBS, Russell E. Savage

CAN 348 Dates: 10/86-C

\section{TECHNICAL ASSISTANCE AND PROGRAM SUPPORT (PHYSICAL AGENTS)}

Purpose: The project will provide management and guidance for the implementation of the national prevention strategies as well as consultation involving investigative research, instrument/methods development, and personal protective equipment.

DBBS, Derek E. Dunn

CAN 374 Dates: 10/83-C

\section{TECHNICAL ASSISTANCE AND PROGRAM SUPPORT (BIOLOGY/CHEMISTRY)}

Purpose: This project will provide technical assistance and support for investigative research, methods development, and biological and immunological assay activities related to implementation of the national prevention strategies and plan/manage branch programs and resources directed to such needs.

DBBS, Lloyd E. Stettler

CAN 390 Dates: $10 / 80-C$

\section{QUALITY ASSURANCE OF ANALYTICAL MEASUREMENTS}

Purpose: This project will expand the internal quality assurance program to insure the quality of analytical data generated internally and by MRSB contract laboratories.

DPSE, Peter M. Eller

CAN 420 Dates: $10 / 85-\mathrm{C}$

\section{CONTROL TECHNOLOGY SUPPORT FOR INFECTIOUS DISEASE INVESTIGATIONS}

Purpose: Engineering assistance will be provided to DSHEFS and other CDC divisions for the control of HIV in both occupational and health care facilities. Real-time sampling assistance will be provided to the DPSE/MCRB HIV project.

DPSE, Kenneth F. Martinez CAN 427 Dates: 10/90-C 


\section{HIV ENGINEERING CONTROL AND MONITORING TECHNICAL ASSISTANCE}

Purpose: The project will provide engineering control and monitoring support to DSHEFS and other CDC divisions for the control of HIV in both occupational and health care facilities.

DPSE, Robert $T$. Hughes

CAN 440 Dates: $10 / 90-C$

\section{ANALYTICAL SUPPORT FOR INFECTIOUS DISEASES}

Purpose: Provides timely analytical services to the infectious diseases program by assuring rapid turnaround of requests for sample analyses. It is projected that $\mathbf{3 0 0}$ field samples will be analyzed by both inhouse staff and task order contracts.

DPSE, John L. Holtz

CAN 485 Dates: 10/90-C

\section{RESPIRATORY DISEASE HEALTH HAZARD EVALUATION AND TECHNICAL ASSISTANCE}

Purpose: This project responds to health concerns of miners in coal, metal and non-metal mines and to workers in general industry with respiratory related complaints. This project will address the division objective to increase the number of completed HHE/TAs by effectively responding to requests for health hazard evaluations.

DRDS, John L. Hankinson
CAN 153
Dates: $10 / 87-\mathrm{C}$

\section{TELEPHONE INFORMATION SERVICE}

Purpose: This project will provide to the public free access to NIOSH information resources and to the HETA program.

DSDTT, Raymond L. Ruhe CAN 149 Dates: 10/89-C

\section{STATE FARM FAMILY HEALTH AND HAZARD SURVEY (FFHHS)}

Purpose: Identify existing gaps in our information base about hazard and health effects, and initiate steps leading to prevention of occupational disease among farm workers.

DSHEFS, John P. Sestito

CAN 549 Dates: 10/89-09/95

\section{GUIDELINES FOR GENERIC EXPOSURE ASSESSMENT}

Purpose: The project will assist OSHA in its attempt to develop a standardized approach to exposure assessment and monitoring by providing a document which addresses the general principles of workplace exposure determination, and provides guidelines for designing and implementing exposure assessment programs.

DSHEFS, Robert F. Herrick

CAN 642 Dates: 10/90-10/91 


\section{HEALTH HAZARD EVALUATIONS AND TECHNICAL ASSISTANCE}

Purpose: Investigations result in recommendations relating to the National Prevention Strategies.

DSHEFS, David S. Sundin

CAN 688 Dates: $10 / 80-C$

\section{HEALTH HAZARD ASSESSMENT AT SUPERFUND SITES}

Purpose: Characterization of toxic airborne and skin exposures among persons employed at hazardous waste sites will aid ATSDR/EPA in resolving the related public health issues.

DSHEFS, Richard W. Gorman

CAN 897 Dates: $10 / 84-C$

\section{SAFETY COMPONENTS OF SMALL BUSINESS INITIATIVE}

Purpose: This project will enable DSR to collaborate with other NIOSH divisions in identifying hazards found in small businesses and in developing intervention strategies to minimize risk of traumatic injuries.

DSR, Dwayne L. Smith

CAN 804 Dates: 10/88-C 


\section{DBBS ADMINISTRATION}

Purpose: Expedition, intervention, or reallocation of expenditures by four branches is provided. Personnel utilization is evaluated and considered when assigning special tasks and allocating positions.

Responses to requests for technical assistance are assigned to available personnel and expedited through a tracking system.

DBBS, Janet C. Haartz

CAN 303 Dates: 10/76-C

\section{ADMINISTRATIVE SUPPORT FOR DPSE RESEARCH}

Purpose: This project will, in addition to providing strategy implementation, develop criteria for monitoring and assessing control technology through research and development. Provides for the Institute's chemical analysis needs and operates a quality control reference program for analytical laboratories.

DPSE, Philip J. Bierbaum

CAN 402 Dates: $10 / 85-C$

\section{WORKSHOP ON ELECTROMAGNETIC RADIATION}

Purpose: This project provides the administrative vehicle to conduct the workshop.

DPSE, Philip J. Bierbaum

CAN 419 Dates: 10/90-09/91

\section{OFFICE OF THE DIRECTOR-DIVISION MANAGEMENT}

Purpose: Provide management and guidance for the implementation of the National Prevention Strategies involving investigative research, environmental, and medical surveillance.

DRDS, Gregory R. Wagner CAN 103 Dates: 10/86-C

\section{PROGRAM MANAGEMENT}

Purpose: This project will provide management and guidance for the implementation of the National Prevention Strategies. This project is primarily directed toward increasing the number and quality of documents and other NIOSH policy statements produced annually through management of resources and disseminating information.

DSDTT, Richard W. Niemeier CAN 082 Dates: 10/70-C

\section{TECHNOLOGY TRANSFER}

Purpose: This project will address the goal by extending access to NIOSH developed databases worldwide by monitoring interagency agreements and memoranda of understanding for NIOSH information services.

DSDTT, Vivian K. Morgan

CAN 084 Dates: 10/83-C 


\section{CONSULTATION AND BRANCH ADMINISTRATION: DOCUMENT DEVELOPMENT BRANCH}

Purpose: This project will provide administrative, consultative, statistical, and technical assistance for implementation of the National Prevention Strategies.

DSDTT, Ralph D. Zumwalde CAN 094 Dates: 10/84-C

\section{PRINTING MANAGEMENT}

Purpose: This project will serve as liaison with GPO, GSA, commercial printers, and other federal agencies for the procurement of NIOSH printed materials, typesetting, graphic requirements, and other related services. Works directly with NIOSH officials at all levels in a consulting capacity at all stages in the development of publications.

DSDTT, Shirley M. Carr CAN 170 Dates: $10 / 90-C$

\section{TECHNICAL MANAGEMENT-DSHEFS (OD)}

Purpose: This project will provide technical and managerial guidance for the implementation of the National Prevention Strategies. In addition to surveillance, industry-wide studies, and hazard evaluations, methods will be developed to intervene in certain situations so as to reduce workplace hazards.

DSHEFS, Lawrence J. Fine CAN 522 Dates: 10/80-C

\section{TECHNICAL MANAGEMENT}

Purpose: This project maintains staff of highly skilled ADP professionals and statisticians and actively recruits for vacancies at established and respected institutions, provides training opportunities to current staff to enable them to maintain and improve skills, and contracts for services not available.

DSHEFS, Lawrence R. Catlett CAN 680 Dates: 10/87-C

\section{DIVISION ADMINISTRATION AND COLLABORATIVE NETWORKS}

Purpose: This project will provide management and guidance for the implementation of the National Prevention Strategies involving work force development, health promotion and support to academic programs.

DTMD, Thomas C. Purcell

CAN 763 Dates: 10/88-C

\section{GRANTS ADMINISTRATION (GRADS)}

Purpose: This project will specifically Address Section 21 of the OSH Act which calls for an adequate supply of qualified personnel to carry out the purposes of the Act. It supports academic programs by building the OSH professional work force for implementation of the NIOSH strategies.

DTMD, John T. Talty

CAN 764 Dates: 10/88-C 


\section{SURVEILLANCE AND FIELD INVESTIGATIONS BRANCH MANAGEMENT}

Purpose: This project will coordinate, evaluate, and facilitate the merging of musculoskeletal and traumatic injury research and surveillance programs into a coordinated research initiative which will address the recommendations of the National Strategies for Prevention of the Leading Work-Related Diseases and Injuries.

DSR, Timothy J. Pizatella

CAN 847 Dates: 10/85-C

\section{ANALYSIS AND FIELD EVALUATIONS BRANCH MANAGEMENT}

Purpose: This project will coordinate, evaluate, and facilitate the merging of musculoskeletal and traumatic injury analytic research programs into a coordinated research initiative which will address the recommendations of the National Strategies for Prevention of the Leading Work-Related Diseases and Injuries.

DSR, Harlan E. Amandus

CAN 866 Dates: 10/90-C

\section{NATIONAL FATAL OCCUPATIONAL INJURY SURVEILLANCE AND INVESTIGATION SYSTEM}

Purpose: This project will develop a timely automated fatal occupational injury reporting system capable of report generation and trend analysis at a national level, and facilitate the expansion of the FACE project to investigate all fatal occupational injuries in the United States at the state level using the FACE model.

DSR, E. Lynn Jenkins

CAN 879 Dates: 10/90-C

\section{ANALYSIS OF OCCUPATIONAL INJURIES IN THE HEALTH INTERVIEW SURVEY}

Purpose: Injuries to farmers will be examined. A second study, which will provide more detailed analysis of injuries among all occupation groups, will be done with data from 1988 occupational supplement, in collaboration with BLS and NCHS.

DSR, Deborah D. Landen

CAN 882 Dates: 10/90-09/92 


\section{COMPLIANCE WITH HIV PREVENTION MEASURES AMONG HIGH-RISK WORKERS}

Purpose: Identification and assessment of educational and motivational techniques that enhance compliance with HIV prevention practices will result in the development of training programs optimized to reduce worker exposure to HIV infection.

DBBS, Lawrence R. Murphy

CAN 251 Dates: 10/90-09/95

\section{STATISTICAL SUPPORT TO DBBS}

Purpose: Support personnel, equipment, and training are provided to increase the quality and quantity of support given to division project officers in design, implementation, and analyses of planned projects.

DBBS, Stephen D. Simon

CAN 305 Dates: 10/85-C

\section{BIOLOGICAL MONITORING RESEARCH AND SUPPORT}

Purpose: This project will provide biological monitoring support, including the development and application of new methods to implement research strategies in DSHEFS and DBBS. Support activities will be conducted in-house and by BPA labs. Biological monitoring methods will be evaluated in the field in collaboration with DSHEFS staff.

DBBS, Alexander W. Teass

CAN 378 Dates: $10 / 80-C$

\section{STATISTICAL SUPPORT FOR DPSE RESEARCH}

Purpose: Experiments will be designed using statistics, and data will be statistically analyzed to support DPSE research projects.

DPSE, Thomas J. Fischbach

CAN 407 Dates: 10/85-C

\section{HIGH-RISK PROCEDURES DURING SURGERY USING REAL-TIME MONITORING}

Purpose: The project will use real-time monitoring and videotaping techniques to demonstrate the production of aerosols during surgical procedures. These techniques can then be used to train surgical personnel about which procedures produce aerosols and to study measures that can be used to reduce exposure.

DPSE, Jerome P. Smith

CAN 428 Dates: 10/90-10/93

\section{DEVELOP HIV EMISSION CONTROLS FOR MEDICAL PROCEDURES}

Purpose: This project will focus on the development of controls for airborne aerosols for medical procedures which may result in health care personnel contracting AIDS or other infectious diseases. The results will be used by health care and engineering professionals to identify, correct, or install control technology where potential exposures occur.

DPSE, Vincent D. Mortimer

CAN 432 Dates: 10/90-09/94 


\section{CONTROL TECHNOLOGY GUIDELINES FOR HIV TREATMENT FACILITIES}

Purpose: This project will develop, evaluate, and document effective ventilation and other controls to prevent the spread of airborne infectious disease in hospitals and health care facilities. The guidelines will be used by health care and engineering professionals to identify and correct problems and to incorporate effective control systems.

DPSE, Vincent D. Mortimer CAN 433 Dates: 10/90-09/94

\section{AGRICULTURAL HEALTH AND SAFETY DISSEMINATION}

Purpose: This project enables NIOSH material to be distributed to appropriate secondary disseminators in the agricultural industry.

DSDTT, Charlene B. Maloney

CAN 073 Dates: 10/89-C

\section{CONSTRUCTION HEALTH AND SAFETY DISSEMINATION}

Purpose: This project will enable NIOSH materials to be distributed to appropriate secondary disseminators in the construction industry.

DSDTT, Charlene B. Maloney

CAN 075 Dates: 10/89-C

\section{TECHNICAL INQUIRIES, CONSTRUCTION}

Purpose: This project will improve the delivery of construction safety and health information to researchers, employers, and employees by publicizing the availability of the information through the NIOSH 800 -number and disseminating the information as requested.

DSDTT, Rodger L. Tatken CAN 076 Dates: 10/89-C

\section{LIBRARY-CONSTRUCTION REFERENCES}

Purpose: This project will improve the delivery of occupational safety and health information to NIOSH researchers and the occupational safety and health community.

DSDTT, Lawrence Q. Foster CAN 079 Dates: 10/89-C

\section{LIBRARY SERVICES}

Purpose: This project will maintain the collection and provide services of the Cincinnati Facilities Libraries.

DSDTT, Lawrence Q. Foster CAN 083 Dates: 10/83-C 


\section{RESPONSES TO REGULATORY ACTIVITIES}

Purpose: This project will provide for coordination of activities by NIOSH, DOL/ OSHA/MSHA standards development staff in making recommendation for workplace standards through the DOL/OSHA/MSHA rule-making process. The most current information developed by or available to NIOSH is used to develop public testimony and make recommendations to

DOL/OSHA/MSHA.

DSDTT, Laurence Reed

CAN 087 Dates: $10 / 83-\mathrm{C}$

\section{SENIOR REVIEW ACTIVITIES}

Purpose: This project will provide a multi-disciplinary team of senior scientists who will evaluate scientific and policy issues to ensure the accuracy and scientific quality of documents and the appropriate consideration of policy implications. This review will provide for the implementation of all of the National Prevention Strategies.

DSDTT, John J. Whalen

CAN 092 Dates: 10/87-C

\section{NIOSH INFORMATION SYSTEMS}

Purpose: This project will provide for availability of technical information through current, computerized databases to NIOSH personnel and the OSH community. Principal systems include the Document Information Directory System (DIDS), and the NIOSH Mailing List (NMLS).

DSDTT, Rolland R. Rogers

CAN 095 Dates: 10/70-C

\section{REGISTRY OF TOXIC EFFECTS OF CHEMICAL SUBSTANCES (RTECS)}

Purpose: This project will deliver toxicological data to serve the information needs of the occupational safety and health community and produce innovative changes to assist users.

DSDTT, Doris V. Sweet

CAN 096 Dates: 10/70-C

\section{NIOSHTIC}

Purpose: This project will assist the research and technical assistance activities of NIOSH and the occupational safety and health community as a whole. This system currently contains over 164,000 citations derived from the world's occupational safety and health literature.

DSDTT, William D. Bennett CAN 097 Dates: 10/70-C

\section{PUBLICATION AND DISSEMINATION OF NIOSH PUBLICATIONS}

Purpose: This project will address the goal by providing for dissemination of occupational safety and health information in support of NIOSH research and in response to public inquiries. In addition, NIOSH-developed technologies will be presented through the exhibit program.

DSDTT, Charlene B. Maloney

CAN 098 Dates: 10/83-C 


\section{INFORMATION RETRIEVAL AND ANALYSIS}

Purpose: This project will provide technical information services to Institute personnel in support of research, public hearings, and to the public requesting information on $\mathrm{OSH}$ issues. Also provides for the development of chemical and hazard-specific information packages.

DSDTT, Rodger L. Tatken

CAN 099 Dates: 10/70-C

\section{OCCUPATHONAL DISEASES BOOK UPDATE}

Purpose: This project will result in the revision and update of the NIOSH publication "Occupational Diseases: A Guide to their Recognition."

DSDTT, Ralph D. Zumwalde

CAN 100 Dates: 10/90-09/93

\section{CRITERIA FOR ESTABLISHING JOINT MANAGEMENT/WORKER COMMITTEES (CD)}

Purpose: This project will provide a critical evaluation of the effectiveness of management/worker committees in reducing health risks. The evaluation will be used to develop a criteria document that can be used for establishing and defining the scope of management/worker committees in all workplaces.

DSDTT, Faye L. Rice

CAN 117 Dates: 10/90-09/93
INTERNATIONAL PROGRAMME FOR CHEMICAL SAFETY (IPCS) CARDS

Purpose: This project will develop 25 chemical safety cards each year for the next three years as a joint effort with the International Programme on Chemical Safety (IPCS), World Health Organization (WHO).

DSDTT, Howard R. Ludwig CAN 118 Dates: 10/89-C

\section{NIOSH POCKET GUIDE TO CHEMICAL HAZARDS}

Purpose: This project will update the existing information in the pocket guide and list an additional 200 chemicals with NIOSH RELS and/or OSHA PELS.

DSDTT, Howard R. Ludwig CAN 120 Dates: 10/89-C

\section{IMMEDIATELY DANGEROUS TO LIFE OR HEALTH (IDLH) CONCENTRATIONS}

Purpose: This project will formulate criteria for selecting IDLHs for chemicals that currently have none assigned.

DSDTT, Vlasta B. Molak

CAN 125 Dates: 10/89-09/91 


\section{HAZARD REVIEW PROGRAM}

Purpose: This project will assist DSDTT in selecting future topics for document development and provide other divisions with a source of information for assessing research needs.

DSDTT, Vlasta B. Molak

CAN 145 Dates: 10/90-C

\section{SURVEY INSTRUMENT DESIGN:} HEALTH HISTORY EXAMINATION

Purpose: Examination modules are used in the Farm Family Health and Hazard Survey (FHHS) data collection by the state agencies.

DSHEFS, Lorraine L. Cameron

CAN 559 Dates: 10/89-09/92

\section{FARM HEALTH HAZARD AWARENESS}

Purpose: This project will use appropriate and established information sources in the communities in which the FFHHS project is focused to enhance the visibility and acceptability of the project.

DSHEFS, Eugene Freund

CAN 563 Dates: 10/89-09/92

\section{CONSTRUCTION TRADES - MORTALITY} STUDIES

Purpose: Proportionate mortality rates (PMR) analyses will be used to identify high mortality risks as leads to in-depth epidemiologic studies of exposure disease relationships.

DSHEFS, C. Robinson and F.B. Stern

CAN 578 Dates: 10/89-09/92

\section{CORRECTION OF NOES REPORTING}

Purpose: The project will provide researchers with complete information on potential occupational exposure to individual hazards.

DSHEFS, J. Mastromauro and W.K. Sieber CAN 589 Dates: 10/90-09/91

\section{HISTORIC PHOTOGRAPHS OF INDUSTRIAL WORKERS}

Purpose: Through photographs, this study will investigate the history of occupational disease in the United States.

DSHEFS, Barbara L. Jenkins

CAN 595 Dates: 10/90-09/93 


\section{SAFETY DIVISION MANAGEMENT}

Purpose: This project will provide management and guidance for the implementation of the National Prevention Strategies involving investigative research, information dissemination/document development, respirators, surveillance, and other epidemiological studies.

DSR, Thomas R. Bender

CAN 802 Dates: 06/77-C 

NIOSH PROJECTS BY DIVISION 
as 
DIVISION OF BIOMEDICAL AND BEHAVIORAL SCIENCE (DBBS)

$\underline{\text { CAN }}$

PAGE

OCCUPATIONAL LUNG DISEASES

1. Evaluation of Mesothelioma

Production by Asbestos Substitutes

376

54

\section{MUSCULOSKELETAL INJURIES}

2. Ergonomic Risks from Tool Usage and

Design

3. Biodynamics of Frequent Asymmetric

Lifting

4. Age as an Ergonomic Risk Factor

5. Shoulder/Neck Muscle Tension for

Repetitive Work

6. Biomolecular Markers of Chronic

Trauma

\section{OCCUPATIONAL CANCERS}

7. Methods for Assessing Worker Exposure to Electromagnetic Fields

8. Experimental Model for Human Bladder Carcinogenesis

9. Temporal Factors Influencing

Carcinogenicity of Industrial

Chemicals

10. Biological Monitoring for Aryl

Amines

11. Immunological Markers of Herbicide

Exposure

12. Validation Studies in Occupational

Immunotoxicology

13. Inhalation Toxicology and Research

Support 
DIVISION OF BIOMEDICAL AND BEHAVIORAL SCIENCE (DBBS)

$\underline{\text { CAN }}$

PAGE

14. Animal Husbandry Services

385

81

15. Diagnostic and Research Pathology

386

81

16. Particulate and Tissue Analysis Research and Service

\section{OCCUPATIONAL CARDIOVASCULAR DISEASES}

17. Inhibition of Intercellular Communication by Workplace Chemicals

\section{DISORDERS OF REPRODUCTION}

18. Combined Chemical/RF Radiation Teratogenesis

19. In Vitro Methods for Detecting Developmental Toxicants

20. Methods for Assessing Reproductive Potential in Females

21. Methods for Determining Evidence of Spermatogenic Damage

22. In Vitro Systems for Human Biological Monitoring

23. RF-Induced Body Current and Absorbed Power Determinations

\section{NEUROTOXIC DISORDERS}

24. Human Neurobehavioral Effects of Combination Chemical Exposures

25. WHO Neurotoxicity Methods

Validation

26. Neurobehavioral Assessment of 


\section{NOISE-INDUCED HEARING LOSS}

27. Hearing Conservation Programs for Underserved Worker Groups

28. Impact Noise Effects on Hearing in

29. Noise-Induced Hearing Loss: Support for

30. Laboratory Techniques to Predict Hearing

31. Electron Microscopic Methods for Morphological Investigations

32. Occupational Impact Noise: Exposure, Effect, and Control

33. Optimization of Speech for Communicative/Protective Devices

\section{PSYCHOLOGICAL DISORDERS}

34. Methods for Rating Job Stress/

Strain

35. Electronic Performance Monitoring: Stress Prevention Strategies

36. Methods for Assessing Information

Processing Demands

37. Stress Control Strategies in Computer-Mediated Work

38. Development of Survey Assessment Instrument for IAQ

39. Immunotoxicology Research and Support 
DIVISION OF BIOMEDICAL AND BEHAVIORAL SCIENCE (DBBS)

CAN

PAGE

AGRICULTURE-RELATED PROJECTS

40. Neurobehavioral Assessment of

Pesticide Applicators

249

109

41. Hearing Conservation Programs for

Underserved Worker Groups

262

109

42. Noise-Induced Hearing Loss: Support for

Farm Family Health Hazard Survey

265

109

CONSTRUCTION-RELATED PROJECTS

43. Biomolecular Markers of Chronic

Trauma

344

117

44. Evaluation of Mesothelioma

Production by Asbestos Substitutes

376

117

\section{ASSISTANCE REQUESTS}

45. Technical Assistance and Program

Support (Psychology/Ergonomics)

46. Technical Assistance and Program

Support (Toxicology)

47. Technical Assistance and Program

Support (Physical Agents)

48. Technical Assistance and Program Support (Biology/Chemistry)

\section{ADMINISTRATION}

49. DBBS Administration

303

127 
DIVISION OF BIOMEDICAL AND BEHAVIORAL SCIENCE (DBBS)

CAN

PAGE

OTHER

50. Compliance with HIV Prevention Measures among High-Risk Workers

51. Statistical Support to DBBS

52. Biological Monitoring Research and Support 


\section{DIVISION OF PHYSICAL SCIENCES AND ENGINEERING (DPSE)}

$\underline{\text { CAN }}$

PAGE

OCCUPATIONAL LUNG DISEASES

1. Asbestos Removal Control Technology

Assessment

408

54

2. Implement Asbestos Controls during Brake

Shoe Replacement

409

54

3. Control of Exposures during Auto

Body Repair

410

54

4. Analytical Methods for Inorganic

Substances

413

54

5. Identification of Intervention

Points in Wood Dust Exposure

414

54

6. Technology Transfer for DPSE Projects

416

55

7. Application of Process Hazard

Analysis for Agricultural Chemicals

423

55

8. Health Hazard Evaluation Analytical

Chemistry Support

425

55

9. Mining and Respiratory Disease Research

Analytical Support

10. Pilot Study: Evaluation of Process

Containment for Bioaerosols

55

11. A National Construction Industry

Control Technology Database

434

55

12. A Method for Sampling and Analysis

of Indoor Air for Organic Compounds

436

56

13. Analytical Methods for Organic Compounds

437

56

14. Analytical Method for Total Isocyanate in Air 


\section{DIVISION OF PHYSICAL SCIENCES AND ENGINEERING (DPSE)}

$\underline{\text { CAN }}$

$\underline{\text { PAGE }}$

15. Methods for Evaluating Indoor

Air Ventilation Systems

442

56

16. Evaluation of Toxic Gas Monitors

for Indoor and Workplace Air

443

56

17. Revision of the NIOSH Manual of

Analytical Methods

18. Analytical Methods for Asbestos Fibers

19. Particle Sampler Performance Testing

455

57

20. Quality Assurance (External)

458

57

21. Maintenance and Calibration

459

57

22. Gas and Vapor Measurement Techniques

496

57

\section{MUSCULOSKELETAL INJURIES}

23. Development of an Intervention Model for Musculoskeletal Injuries

24. Ergonomic Interventions for the Beverage Delivery Industry

\section{OCCUPATIONAL CANCERS}

25. Applied Control Technology Studies

26. Control Technology for NIOSH

Surveillance Activities

27. Control Technology for Small Business

28. Control of Formaldehyde Exposures in

Embalming Procedures

29. Control of Wood Dust from

Woodworking Processes 
DIVISION OF PHYSICAL SCIENCES AND ENGINEERING (DPSE)

CAN

PAGE

30. A Sampling and Analytical Method for Airborne Diesel-Exhaust Particles

31. Portable Mass Spectrometer or FTIR Evaluation

32. Engineering Control Assistance

33. Development of Analytical Methods for Agricultural Chemicals

34. Applied Monitoring Studies

35. Comprehensive Analytical Chemistry Services

36. Analytical Support to DBBS Research and IWSB/DSHEFS

37. Analytical Chemistry Support to DPSE Research

38. Control of Particulate and Gaseous Agents by Air Curtain Technology

\section{OCCUPATIONAL CARDIOVASCULAR DISEASES}

39. Expansion of Direct Reading

Instrumentation Capabilities

\section{DISORDERS OF REPRODUCTION}

40. Control of Anesthetic Gases in Dental Operatories 
DIVISION OF PHYSICAL SCIENCES AND ENGINEERING (DPSE)

CAN

PAGE

\section{NEUROTOXIC DISORDERS}

41. Control of Methylene Chloride in Furniture Stripping

42. Control of Health Hazards in the Construction Industry

43. Real-Time Monitoring for Pesticides

44. Monitoring Techniques for Chemical Agents

45. Control of Lead Exposures in Indoor Firing Ranges

\section{DERMATOLOGICAL CONDITIONS}

46. Development of Control Technology Application of Real-Time Monitoring

\section{AGRICULTURE-RELATED PROJECTS}

47. Development of Control Technology

Applications of Real-Time Monitoring

48. Application of Process Hazard

Analysis for Agricultural Chemicals

\section{CONSTRUCTION-RELATED PROJECTS}

49. Asbestos Removal Control Technology Assessment

50. Identification of Intervention

Points in Wood Dust Exposure

51. Control of Wood Dust from

Woodworking Processes

52. A National Construction Industry 


\section{DIVISION OF PHYSICAL SCIENCES AND ENGINEERING (DPSE)}

CAN

$\underline{\text { PAGE }}$

53. Control of Health Hazards in the

Construction Industry

435

118

\section{ASSISTANCE REQUESTS}

54. Quality Assurance of Analytical

Measurements

420

124

55. Control Technology Support for

Infectious Disease Investigations

427

124

56. HIV Engineering Control and Monitoring

Technical Assistance

440

125

57. Analytical Support for Infectious

Diseases

485

125

\section{ADMINISTRATION}

58. Administrative Support for DPSE Research

402

127

59. Workshop on Electromagnetic Radiation

419

127

\section{OTHER}

60. Statistical Support for DPSE Research

61. High-Risk Procedures during Surgery using Real-Time Monitoring

62. Develop HIV Emission Controls for Medical Procedures

63. Control Technology Guidelines for HIV Treatment Facilities 


\section{DIVISION OF RESPIRATORY DISEASE STUDIES (DRDS)}

CAN

$\underline{\text { PAGE }}$

\section{OCCUPATIONAL LUNG DISEASES}

1. Pulmonary Response to Cotton Dust 102

2. Endotoxin Detection in Cotton Dust

104

3. Pathology Analysis of the NCWAS and EM Support

4. Induction of DNA-Adduct in the Lungs by Industrial Chemicals

5. Effect of Silica Exposure on the Lung:

Biochemical/Path Studies

6. Assessment of the Carcinogenic

Potential of Selected Dusts

7. Animal and Exposure Facility

Support for DRDS

8. Validation Studies of In Situ Assay

Systems in Occupational Setting

9. Centers for Agricultural Research, Education and Disease and Injury

10. NHANES III Support

11. Microbial Exposures in Agriculture

12. Inflammatory Agents in Agricultural Dusts

13. Role of Fungal Spores in Organic Dust Toxic Syndrome (ODTS)

14. Emerging Technology for Respiratory

Disease Evaluations

15. Evaluation of Role of Interferon System in Occupational Asthma Associated with Agricultural Dust

16. Emerging Problems in Environmental 


\section{DIVISION OF RESPIRATORY DISEASE STUDIES (DRDS)}

CAN

PAGE

17. Development of Bioassays: Identify

Health Risks of Asbestos Substitutes

160

60

18. Surveillance of Lung Disease Agents

in Small Businesses

162

60

19. Agricultural Dust: Elucidation

Disease Mechanics with Animal Model,

Biomarkers

163

60

20. National Occupational Health Survey

of Mining

21. Agricultural Dusts: Animal Models

of Asthma

165

22. Effective Silica Indices for Respirable

Mineral Dust

167

61

23. Environmental Hazard Surveillance

173

24. Technical and Statistical Support

176

25. Silicosis and Cancer in Metal Miners

177

26. Radiological/Pathological Correlation in CWP

27. Silicosis in Surface Miners Examined in Surveillance Program

28. Medical Field Team Technical Support

29. National Study of CWP and Related Research

30. Identification of Longwall Miners for Assessment/Prevention of CWP

31. Occupational Respiratory Disease

Surveillance in Agriculture

32. Endotoxin Exposure/Acute Respiratory Effects in Agricultural Workers 


\section{DIVISION OF RESPIRATORY DISEASE STUDIES (DRDS)}

CAN

PAGE

33. Silicosis Risk in the Construction

Industry

188

63

34. Health Risk of Exposure to Asbestos

Substitutes in Insulation Work

189

63

35. Farm Family Survey: Respiratory Disease

Technical Support

190

63

36. Development of Respiratory Disease

Surveillance Systems

192

63

37. Emerging Problems in Occupational

Respiratory Disease

193

63

38. Medical Technical Support

202

64

39. Studies of Airway Closure and Emphysema

203

64

40. Effects of Silica on Pulmonary Enzymes

in the Pathogenesis of Lung Cancer

204

64

41. Byssinosis Prevention

205

64

42. Asthma In and Out of the Workplace:

Conference

206

64

43. Airways Disease in Miners

212

64

44. Occupational Asthma Identification

Methods

213

65

45. Analysis of Data from an Egyptian

Silica Study: USAID 214

65

46. Agricultural Dusts: Field-Based

Evaluation-Exposure and

Acute Respiratory Illness

215

65

47. Rural Hospital Nurses: Respiratory

Disease Technical Support

216

65

48. Evaluation/Rehabilitation of

Occupational Respiratory

Disease and Injury 


\section{DIVISION OF RESPIRATORY DISEASE STUDIES (DRDS)}

CAN

PAGE

49. Hazard Surveillance in the

Construction Industry

218

65

50. Industrial Hygiene Technical

Support

223

66

51. Bias in Particulate Exposure

Sampling Devices

224

66

52. Fiber Toxicity: Surface Properties and Analysis

225

66

53. Environmental Surveillance of Small

Coal Mines

54. Pilot Environmental Surveillance of

Endotoxin at Selected Cotton Gins

55. Evaluation Support to NIOSH

Coal Workers' Surveillance Program

228

66

56. Computer Support

232

67

57. Autopsy Program: Program Operation

233

67

58. Characterization of Welding Fumes

234

67

59. Coal Miner Medical Surveillance:

Receiving Center Operation

60. Diesel Particulate Measurements

61. Respirable Genotoxic Particulate

Exposure Measurement Monitoring

237

67

62. Where's the Endotoxin?

238

68

\section{OCCUPATIONAL CANCERS}

63. Toxicity Studies of Mild Gasification Products 


\section{AGRICULTURE-RELATED PROJECTS}

64. Endotoxin Detection in Cotton Dust

104

109

65. Centers for Agricultural Research, Education and Disease and Injury

66. Microbial Exposures in Agriculture

67. Inflammatory Agents in Agricultural Dusts

68. Role of Fungal Spores in Organic Dust

Toxic Syndrome (ODTS)

69. Evaluation of Role of Interferon System in Occupational Asthma Associated with Agricultural Dust

70. Agricultural Dust: Elucidation

Disease Mechanics with Animal Model, Biomarkers

71. Agricultural Dusts: Animal Models of Asthma

72. Occupational Respiratory Disease Surveillance in Agriculture

73. Endotoxin Exposure/Acute Respiratory Effects in Agricultural Workers

74. Farm Family Survey: Respiratory Disease Technical Support

75. Asthma In and Out of the Workplace:

Conference

76. Occupational Asthma Identification Methods

77. Agricultural Dusts: Field-Based

Evaluation-Exposure and

Acute Respiratory Illness 
78. Rural Hospital Nurses: Respiratory

Disease Technical Support

79. Pilot Environmental Surveillance of Endotoxin at Selected Cotton Gins

\section{CONSTRUCTION-RELATED PROJECTS}

80. Development of Bioassays: Identify

Health Risks of Asbestos Substitutes

81. Silicosis Risk in the Construction Industry

82. Health Risk of Exposure to Asbestos Substitutes in Insulation Work

83. Studies of Airway Closure and Emphysema

84. Characterization of Welding Fumes

\section{ASSISTANCE REQUESTS}

85. Respiratory Disease Health Hazard Evaluation and Technical Assistance

\section{ADMINISTRATION}

86. Office of the Director--

Division Management 
DIVISION OF SURVEILLANCE, HAZARD EVALUATIONS, AND FIELD STUDIES (DSHEFS)

CAN

$\underline{\text { PAGE }}$

OCCUPATIONAL LUNG DISEASES

1. An Epidemiologic Study of IAQ 527

2. Cohort Mortality Study of Antimony Smelter Workers

3. Mortality Study of Workers Exposed to Toluene Diisocyanate

4. Laborer's Union Health Program

5. Uranium Miners-Low Dose Investigation

6. Beryllium Retrospective Cohort Investigation

7. Surveillance Data Microcomputer System

8. Data Acquisition Management and Evaluation (DAME)

9. Mortality Study of Butadiene Production Workers

\section{MUSCULOSKELETAL INJURIES}

10. Carpal Tunnel Study 507

11. Sentinel Health Event Follow-Back

12. P.C. Version of Life Table Analysis System

13. Evaluation of Upper Extremity

Musculoskeletal Disorders

14. National Estimate of Work-Related Cumulative Trauma Disorders

16. Rural Hospital Disease/Injury Surveillance and Follow-Back 
17. Occupational and Safety Surveillance through Health Departments and Nurses in Agricultural Communities

18. Selected Surveillance Survey Data

Dissemination

19. Development of Industry-Wide Musculoskeletal Studies

\section{OCCUPATIONAL CANCERS}

20. Industrywide Study of Workers Exposed to 4,4'-Methylene Dianiline

21. Estimation of Exposures and Releases from Unit Operations

22. Registry of Dioxin Workers and Mortality Study

23. Environmental and Health Assessment of Exposure to Alachlor-Enhancement

24. Epidemiologic Methods Development

25. Mortality Study of Workers Exposed to Halowax

26. Epidemiological Study of Bladder Cancer Among Workers Exposed to $\mathrm{O}$-Toluidine and O-Aniline

27. Update of Completed Cohort Mortality Studies

28. Medical, Biometric, and IH Study of Emerging Problems

29. Exposure Assessment of Workers

Exposed to Acrylonitrile 
$\underline{\text { CAN }}$

31. Worker Notification

32. Multiple Cause of Death

33. Feasibility Assessments for New Topics

34. Ethylene Oxide Mortality Study

35. Genotoxic Effects of Formaldehyde

Exposure of Mortuary Science Students

36. Evaluation of Radon/Radon Progeny

Exposures to Radon Mitigators

37. Computerization of IHS/IWSB Files

38. Lung Cancer Mortality Among Black

Workers

39. Cancer Screening in Farmers

40. Biological Markers of Occupational Bladder Cancer

41. NOES Improvement through Trend Analysis

42. Construction Trades Surveillance

43. Coal Hydrogenation Mortality Study

44. Pentachlorophenol Production Workers Mortality Study

45. Support of EPA's Environmental

Epidemiologic Program

46. Dry Cleaning Mortality Update and Cancer Morbidity

47. Evaluation of Exposure and Adverse Health Outcomes in the Construction Industry
607

89

622

89

PAGE

86

87

87

87

87

87

87

88

88

88

88

88

88

89

624 
$\underline{\text { CAN }} \quad \underline{\text { PAGE }}$

48. Agriculture-Related Emerging Problems

625

89

49. Job/Exposure Matrix

637

89

50. Occupational Mortality Surveillance

Validation

639

90

51. Comparative Occupational Mortality Analysis

640

90

52. Sponsorship of 9th International

Symposium of Epidemiology in

Occupational Health

643

90

53. Access to NOHS Database--Profile

Development

662

90

54. Drake Registry and Screening Project

894

90

SEVERE OCCUPATIONAL TRAUMATIC INJURIES

55. Survey Instrument Design: Hazard

Questionnaire

579

92

\section{OCCUPATIONAL CARDIOVASCULAR DISEASES}

56. Mortality and IH Study of Bridge and

Tunnel Officers Exposure to Carbon

Monoxide

505

98

57. Arrhythmia Among Freon Exposed Workers

582

98

58. Mortality Surveillance of Occupation and

Industry

633

98

\section{DISORDERS OF REPRODUCTION}

59. IH Exposure Assessments in Selected Industries

60. Reproductive Study of Female Video

Display Terminal (VDT) Operators

687

100 


\title{
DIVISION OF SURVEILLANCE, HAZARD EVALUATIONS, AND FIELD
} STUDIES (DSHEFS)

\author{
CAN $\quad \underline{\text { PAGE }}$
}

\section{NEUROTOXIC DISORDERS}

61. Methanol Exposures in Transit Vehicles

(UMTA)

502

102

62. National Reporting of Selected

Occupational Diseases

63. An Assessment of the Effectiveness of OSHA's Lead Standard

64. Neurological Sequelae of Acute Pesticide Poisoning

65. Study of Methyl Bromide and Sulfuryl

Fluoride Applicators

66. Health and Hazard Surveillance of Migrant Farm Workers

67. Assessment of Lead Exposure in Radiator Repair Shops

68. Dioxin Morbidity and Reproductive Study of U.S. Chemical Workers

\section{DERMATOLOGICAL CONDITIONS}

69. Analysis of Health Interview Survey Data

70. Identification of New Dermatological

Hazards in Agriculture

\section{PSYCHOLOGICAL DISORDERS}

71. Occupational Psychological Disorders (OPD) Surveillance 


\section{DIVISION OF SURVEILLANCE, HAZARD EVALUATIONS, AND FIELD STUDIES (DSHEFS)}

CAN $\quad \underline{\text { PAGE }}$

\section{AGRICULTURE-RELATED PROJECTS}

72. Environmental and Health Assessment of Exposure to Alachlor-Enhancement

73. State Farm Family Health and Hazard Survey (FFHHS)

74. Survey Instrument Design:

Health History Examination

75. Farm Health Hazard Awareness

76. Identification of New Dermatological

Hazards in Agriculture

77. Surveyor Training

78. Rural Hospital Disease/Injury

Surveillance and Follow-Back

79. Cancer Screening in Farmers

80. Survey Instrument Design: Hazard Questionnaire

81. Occupational and Safety Surveillance through Health Departments and Nurses in Agricultural Communities

82. Surveillance Data Microcomputer System

83. Health and Hazard Surveillance of Migrant Farm Workers 


\section{STUDIES (DSHEFS)}

CAN $\quad \underline{\text { PAGE }}$

\section{CONSTRUCTION-RELATED PROJECTS}

85. Laborer's Union Health Program $\quad 558 \quad 120$

86. Evaluation of Radon/Radon Progeny

Exposures to Radon Mitigators 573

120

87. Construction Trades - Mortality Studies 578

120

88. NOES Improvement through Trend Analysis 588

120

89. Construction Trades Surveillance

594

120

90. Evaluation of Exposure and Adverse

Health Outcomes in the Construction

Industry

624

120

91. Comparative Occupational Mortality Analysis

640

121

\section{ASSISTANCE REQUESTS}

92. State Farm Family Health and Hazard

Survey (FFHHS) 549

125

93. Guidelines for Generic Exposure Assessment

642

125

94. Health Hazard Evaluations and Technical Assistance

95. Health Hazard Assessment at Superfund Sites

\section{ADMINISTRATION}

96. Technical Management - DSHEFS, (OD)

97. Technical Management 
DIVISION OF SURVEILLANCE, HAZARD EVALUATIONS, AND FIELD STUDIES (DSHEFS)

$\underline{\text { CAN PAGE }}$

OTHER

98. Survey Instrument Design:

Health History Examination

559

134

99. Farm Health Hazard Awareness

563

134

100. Construction Trades - Mortality Studies

578

134

101. Correction of NOES Reporting

589

134

102. Historic Photographs of Industrial Workers 


\section{DIVISION OF SAFETY RESEARCH (DSR)}

$\underline{\text { CAN }}$

PAGE

OCCUPATIONAL LUNG DISEASES

$\begin{array}{lll}\text { 1. Protective Technology Branch Management } & 785 & 71\end{array}$

$\begin{array}{lll}\text { 2. Simulated Workplace Protection Factors } & 786 & 71\end{array}$

3. Liquid Particulate Challenge to Replace DOP $\quad 812 \quad 71$

4. Chemical Weapons Conventional

$\begin{array}{lll}\text { Verification Technical Assistance } & 818 & 71\end{array}$

5. Organic Vapor Challenge to Replace

Carbon Tetrachloride $\quad 828$

72

6. "Use Test" for SCBA Performance

Evaluation $\quad 829$

72

$\begin{array}{lll}\text { 7. Workplace Protection Factor (WPF) Study } & 832 & 72\end{array}$

$\begin{array}{lll}\text { 8. } & \text { Projected Respirator WPF Values } & 837\end{array}$

$\begin{array}{lll}\text { 9. } & \text { Promulgation of } 42 \text { CFR } 84 & 839\end{array}$

10. Evaluation, Certification, and

Coordination Actvities $\quad 852$

72

11. Air Purifying Respirator Testing $\quad 853 \quad 73$

$\begin{array}{lll}\text { 12. } & \text { Atmosphere Supplied Respirator Testing } & 854\end{array}$

13. Coal Mine Dust Personal Sampler Unit $\quad 855 \quad 73$

14. Quality Assurance Documentation Control $\quad 857 \quad 73$

15. Quantification of Industrial Respirator Use $\quad 858 \quad 73$

16. Development of Alveolar and Thoracic

Personal Dust Sampler

17. Laboratory Modification Needed for Implementation of New Regulations 


\section{DIVISION OF SAFETY RESEARCH (DSR)}

$\underline{\text { CAN }}$

$\underline{\text { PAGE }}$

MUSCULOSKELETAL INJURIES

18. Musculoskeletal Injuries in Agriculture 806

19. NIOSH Atlas of Low Back Tests/Measures:

Clinical Trials

815

79

20. Ergonomic Technical Assistance/Research

Identification

822

79

\section{OCCUPATIONAL CANCERS}

21. Prevention of Biological Exposure in Health Care Workers

22. Percutaneous Absorption to Evaluate the Standard CPC Permeation Method

\section{SEVERE OCCUPATIONAL TRAUMATIC INJURIES}

23. Occupational Fatality Injury

Surveillance

805

93

24. Fatal Accident Circumstances and Epidemiology/Technical Assistance

25. Grain Handling Injury and Fatality

Prevention

26. Development of a Workplace Homicide

Prevention Strategy

27. Rollover Protection for Agricultural

Tractors

28. Reducing the Risk of Falls Through Roof Openings and Skylights

29. Reducing Falls from Large Off-Road

Construction Vehicles

30. Failure Analysis of Suspended Scaffold Hoisting Device 
DIVISION OF SAFETY RESEARCH (DSR)

CAN $\quad \underline{\text { PAGE }}$

31. Quantification of Risk Factors for Falls from Buildings Under Construction

32. Occupational Traumatic Injury

Surveillance of Farmers

33. Development of New Methods for Occupational Injury Surveillance

34. State-Based Fatality Surveillance using the FACE Model

35. Development of Surveillance Methods for Occupational Motor Vehicle Injuries

36. DSR Surveillance Report Series

37. U.S. Farm Family Health and Hazard Survey--Injury Surveillance

38. Study of Lineman-Related Fatalities and Injuries

39. Agricultural Health Promotion System

40. State Model Construction Safety and Health Program

41. Surveillance of Site Specific Construction Safety and Health Program

42. Industry Specific Injury Reporting System

43. Injury Mortality in Alaska's Fishing Industry

44. Evaluation of Nursing Home Back Injury Program

45. National Agenda for Injury Control 
DIVISION OF SAFETY RESEARCH (DSR)

$\underline{\text { CAN }}$

$\underline{\text { PAGE }}$

\section{DERMATOLOGICAL CONDITIONS}

47. Characterization of Holes in Gloves 886

106

\section{AGRICULTURE-RELATED PROJECTS}

48. Musculoskeletal Injuries in Agriculture

806

114

49. Grain Handling Injury and Fatality

Prevention

808

115

50. Rollover Protection for Agricultural

Tractors

810

115

51. Occupational Traumatic Injury

Surveillance of Farmers

827

115

52. U.S. Farm Family Health and

Hazard Survey--Injury Surveillance

877

53. Analysis of Occupational Injuries in the Health Interview Survey

54. Agricultural Health Promotion System

55. Injury Mortality in Alaska's Fishing Industry

56. Occupational Injury Prevention in Alaska

893

\section{CONSTRUCTION-RELATED PROJECTS}

57. Occupational Fatality Injury

Surveillance

58. Reducing the Risk of Falls Through Roof

Openings and Skylights

59. Reducing Falls from Large Off-Road

Construction Vehicles

60. Failure Analysis of Suspended Scaffold Hoisting Device 


\section{DIVISION OF SAFETY RESEARCH (DSR)}

61. Quantification of Risk Factors for Falls from Buildings Under Construction

62. Surveillance and Field Investigations

Branch Management

63. Analysis and Field Evaluations Branch Management

64. State-Based Fatality Surveillance using the FACE Model

65. DSR Surveillance Report Series

66. National Fatal Occupational Injury Surveillance and Investigation System

67. State Model Construction Safety and Health Program

\section{ASSISTANCE REQUESTS}

68. Safety Components of Small Business Initiative

\section{ADMINISTRATION}

69. Surveillance and Field Investigations

Branch Management

70. Analysis and Field Evaluations Branch Management

71. National Fatal Occupational Injury Surveillance and Investigation System

72. Analysis of Occupational Injuries in the Health Interview Survey

\section{OTHER}




\section{DIVISION OF STANDARDS DEVELOPMENT AND TECHNOLOGY}

TRANSFER (DSDTT)

OCCUPATIONAL LUNG DISEASES

1. Coal Dust Position Paper 053

2. General Principles of Occupational

Medical Screening (CD) 055

68

3. Man-Made Mineral Fibers Position Paper

088

68

4. Acrylamide--Current Intelligence Bulletin (CIB)

5. General Principles of Exposure

Assessment

6. Update of NIOSH and OSHA Occupational Safety and Health Guidelines

7. Health and Safety Hazards Among

Cosmetologists Alert

8. Exposure to Air Contaminants During Laser Surgery Alert

9. Interim-Recommended Exposure Limits (I-RELS) Guidelines

10. Surface Coal Miners Criteria Document

\section{MUSCULOSKELETAL INJURIES}

11. Cumulative Trauma Disorders Position Paper

\section{OCCUPATIONAL CANCERS}

12. Tobacco Smoke in the Occupational Environment (CIB) 


\section{DIVISION OF STANDARDS DEVELOPMENT AND TECHNOLOGY}

TRANSFER (DSDTT)

$\underline{\text { CAN }}$

PAGE

14. Acetaldehyde/Propanedial-Current

Intelligence Bulletin (CIB)

127

84

15. Rubber Products Manufacturing Position

Paper

84

16. Asphalt Position Paper

144

84

\section{SEVERE OCCUPATIONAL TRAUMATIC INJURIES}

17. Economic and Management Factors in the Control of Work Exposures

18. Occupationally Related Homicides Alert

112

92

19. Locking and Tagging of Energy Sources Alert

20. Falls from Scaffolds/Elevated

21. Confined Spaces Position Paper

\section{DISORDERS OF REPRODUCTION}

22. Glycol Ethers Criteria Document

132

100

NEUROTOXIC DISORDERS

23. Inorganic Lead Position Paper

052

102

NOISE-INDUCED HEARING LOSS

24. Occupational Noise Exposure Position Paper 


\section{DIVISION OF STANDARDS DEVELOPMENT AND TECHNOLOGY}

TRANSFER (DSDTT)

CAN $\quad \underline{\text { PAGE }}$

\section{DERMATOLOGICAL CONDITIONS}

25. Skin Exposure to Hazardous Agents Alert 115

106

26. Cutting Fluids Position Paper

140

106

\section{AGRICULTURE-RELATED PROJECTS}

27. Agricultural Health and Safety

Dissemination

073

112

\section{CONSTRUCTION-RELATED PROJECTS}

28. Inorganic Lead Position Paper

052

119

29. Construction Health and Safety

Dissemination

075

119

30. Technical Inquiries--Construction

076

119

31. Library-Construction References

079

119

32. Asphalt Position Paper

144

119

33. Confined Spaces Position Paper

146

119

\section{ASSISTANCE REQUESTS}

34. 800 Telephone Information Service

\section{ADMINISTRATION}

35. Program Management 082

36. Technology Transfer

084

127

37. Consultation and Branch Administration:

Document Development Branch

38. Printing Management 


\section{DIVISION OF STANDARDS DEVELOPMENT AND TECHNOLOGY TRANSFER (DSDTT)}

OTHER

39. Agricultural Health and Safety Dissemination

40. Construction Health and Safety Dissemination

41. Technical Inquiries--Construction

42. Library-Construction References

43. Library Services

44. Responses to Regulatory Activities

45. Senior Review Activities

46. NIOSH Information Systems

47. Registry of Toxic Effects of Chemical Substances (RTECS)

48. NIOSHTIC

49. Publication and Dissemination of NIOSH Publications

50. Information Retrieval and Analysis

51. Occupational Diseases Book Update

52. Criteria for Establishing Joint Management/Worker Committees (CD)

53. International Programme for Chemical Safety (IPCS) Cards

54. NIOSH Pocket Guide to Chemical Hazards

55. Immediately Dangerous to Life or Health (IDLH) Concentrations
PAGE

131

131

131

131

131

132

132

132

132

132

132

133

133

133

133

133

133

134 


\section{DIVISION OF TRAINING AND MANPOWER DEVELOPMENT (DTMD)}

$\underline{\text { CAN }}$

PAGE

OCCUPATIONAL LUNG DISEASES

1. Safety and Health for Occupational

Professionals (SHOP)

766

74

2. Indoor Air Quality Initiative

769

74

3. Agricultural Safety and Health

772

74

4. Small Business Initiative

774

74

5. Audio Visual/Graphics Support Services

777

74

6. Project EPOCH

790

75

MUSCULOSKELETAL INJURIES

7. Project SHAPE

775

79

OCCUPATIONAL CANCERS

8. Courses/Modules Development

765

91

9. Hazardous Substances Training

779

91

SEVERE OCCUPATIONAL TRAUMATIC INJURIES

10. Construction Safety and Health Training

762

97

11. Project Minerva

776

97

AGRICULTURE-RELATED PROJECTS

12. Agricultural Safety and Health

772

116

CONSTRUCTION-RELATED PROJECTS

13. Construction Safety and Health Training

762

123

14. Indoor Air Quality Initiative

769

123 
DIVISION OF TRAINING AND MANPOWER DEVELOPMENT (DTMD)

CAN $\underline{\text { PAGE }}$

\section{ADMINISTRATION}

15. Division Administration and Collaborative Networks

16. Grants Administration

764

128 
OFFICE OF THE DIRECTOR (OD)

CAN $\quad$ PAGE

\section{AGRICULTURE-RELATED PROJECTS}

1. Occupational Health and Safety Surveillance

Through Nurses in Agriculture Communities

878

116

CONSTRUCTION-RELATED PROJECTS

2. Health and Safety Programs for Construction Work 876

123 




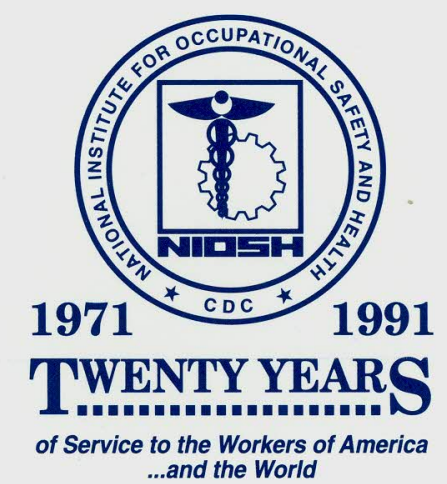

